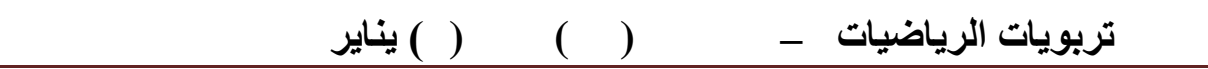

فاعلية استخدام استراتيجية الصفوف المقلوبة لتنمية التحصيل ومهارات لل

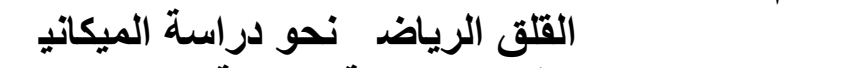

لاى طلاب المرحلّة الثانوية

\author{
إعداد \\ أ.م.د. إيمان سمير حمدى احمد إد المدري

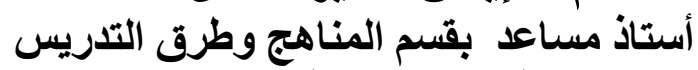 \\ بكلية البنات جامعة عين شمس التر
}


ملخص البهث:

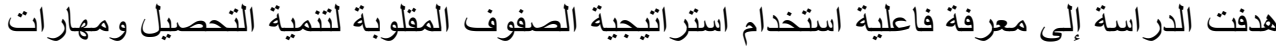

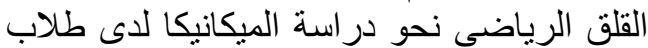

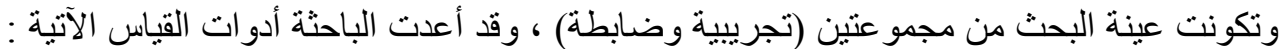

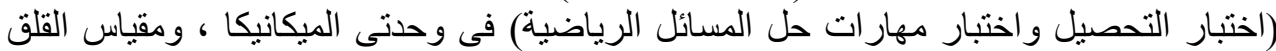
إحصائية بين متوسطى المجمو عة التجريبيا

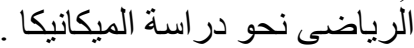

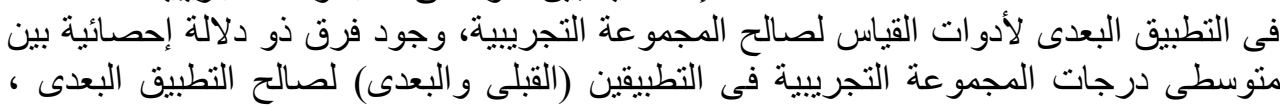

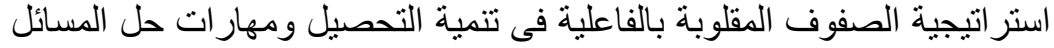

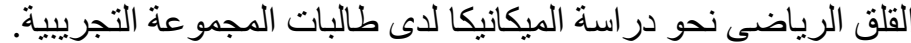

الكلمات الافتتاحية: استراتيجية الصفوف المقلوبة ، لرئية مهارات حل المسائل الرياضية،

Using the Flipped classroom Strategy for developing achievement , problems solving skills and Reducing math anxiety towards the study of mechanics for the stage of secondary students.

\section{A bstract:}

The study aimed to find out the effectiveness of using of the Flipped classroom Strategy for developing achievement, problems solving skills and Reducing math anxiety towards the study of mechanics for the second year of secondary students, the random sample have formed of two groups (experimental and control group), and the tools of research have include : (achievement test ,Mathematical problems solving skills test, and math. anxiety towards study of mechanics scale).

The study has been reached :There is statistically significant difference between the mean scores of the experimental group and the control group in the post application of the measurement tools in the favour of the experimental group, There is statistically significant difference between the mean scores of the experimental group in the pre and post application of measurement tools in the favour of the post application, and The Flipped classroom Strategy have been effective in developing achievement, problems solving skills and reducing math anxiety towards the study of mechanics for the experimental group .

Keywords :Flipped classroom Strategy, Mathematical problems solving skills, math anxiety. 


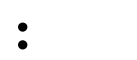

علم الرياضيات هو علم كمي أو علم القياس والأعداد، بل تعتبر الرياضيات

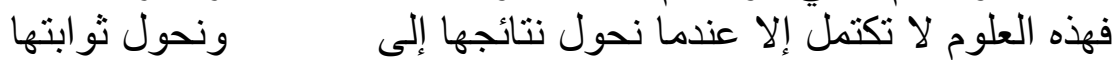

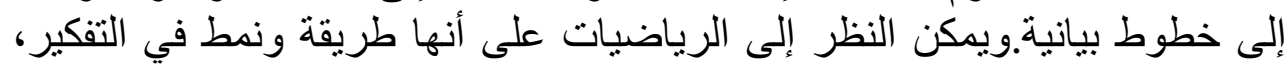

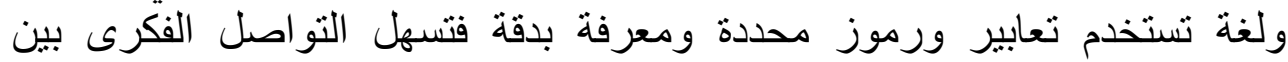

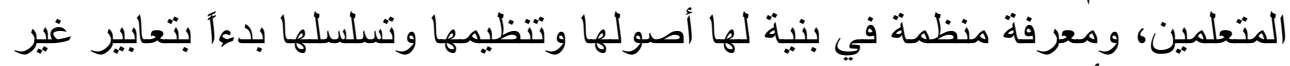
فة إلى أن تتكامل وتصل إلى نظريات وتعميمات ونتائج، و وعلم يهتم بدراسة استة

(Patterns)

بجمال في تناسقهـا، وترتيب وتسلسل الأفكار الواردة فيها. وتعد الميكانيكا فرع هام

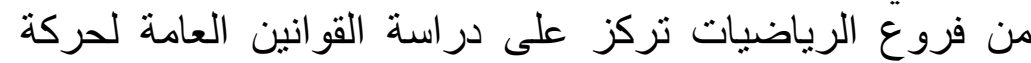
المادية تحت تأثثر القوى عليها وهى تركى تنقسم إلى قسمين: الاستاتيكا Statics

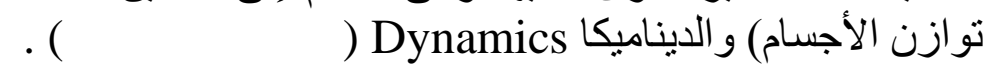

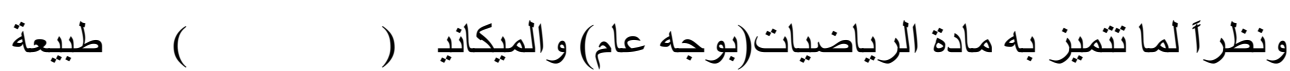

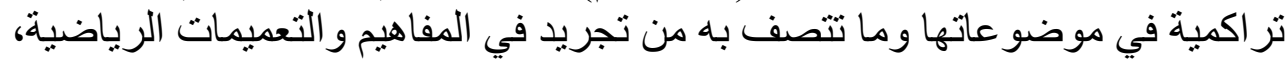

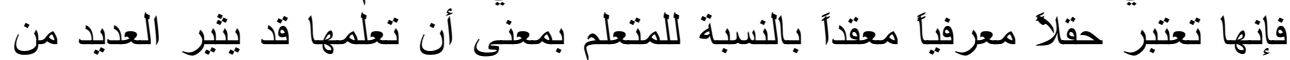

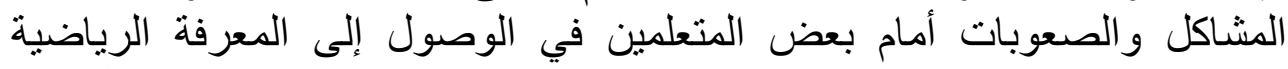

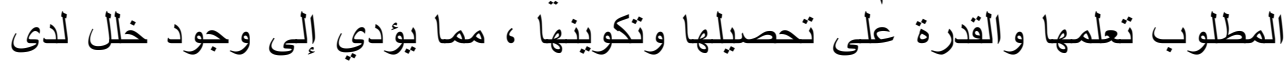
الطالب يمكن كثفه إذا تم تكليفه بالقيام بحل بعض ولكر المسائل والأنشطة الرياضية

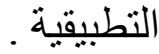

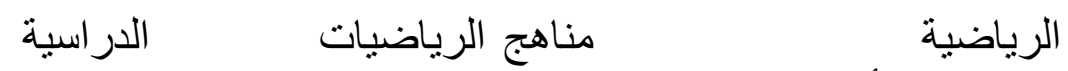

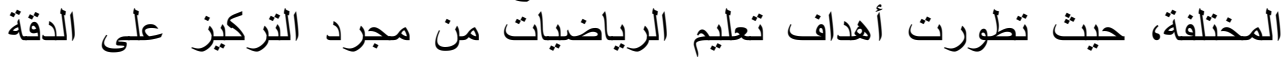

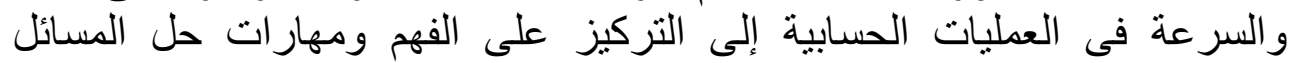

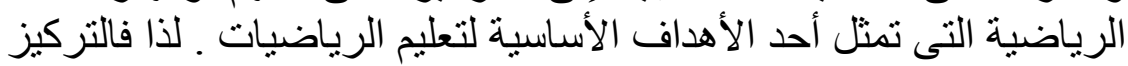

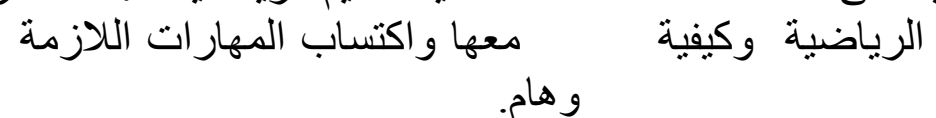

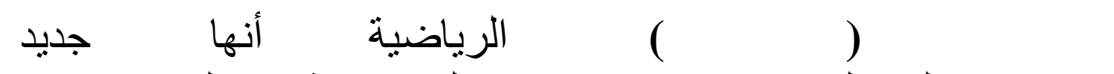

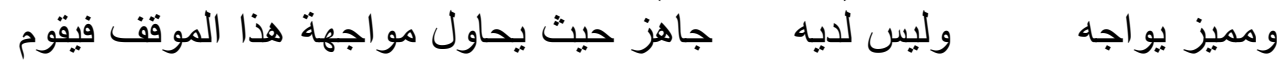
بعمليات ذهنية تمكنه 


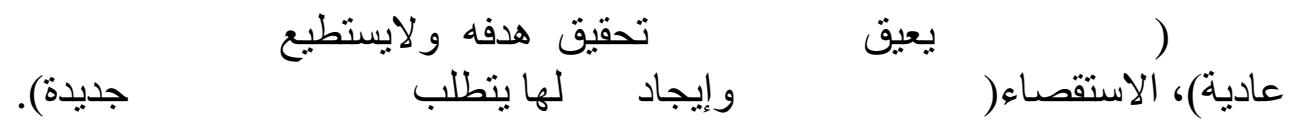

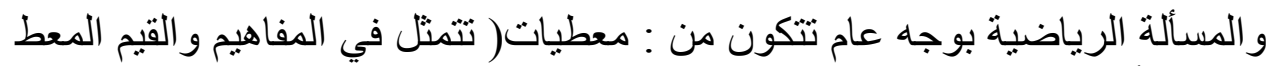

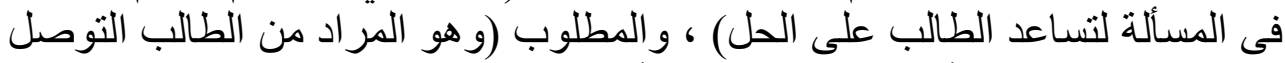

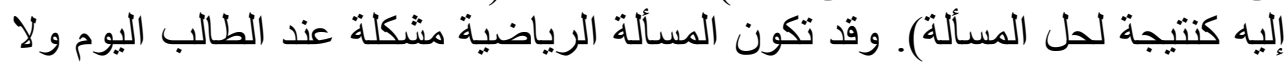
رياضية ، كذلك هنالك مسائل

و وهذا يعتمد تكون عنده بعد فترة لأنه اكتسب الكبان

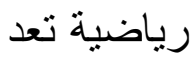
على ما لديه من معلومات وخبر ات رياض رياضية .

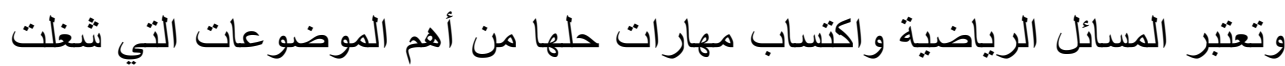

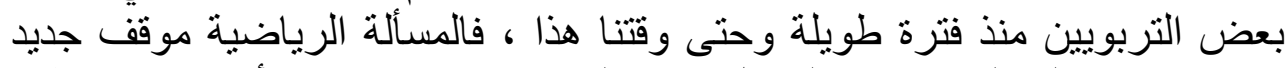

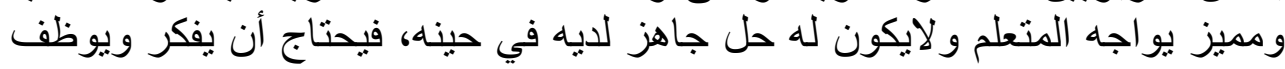
دراسته

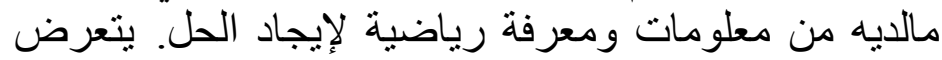

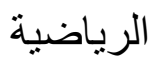
الرياضيات (بوجه عام) و الميكانيكا (بصفة خاصة لإنة للكثير

$$
\text { يوجه الري }
$$$$
\text { تفكير }
$$$$
\text { التوجيه الصحيح لكيفية حلها فإنه سيصاب }
$$

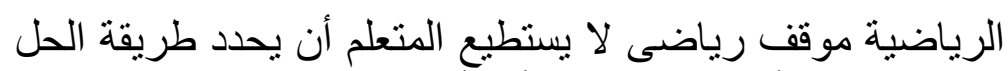

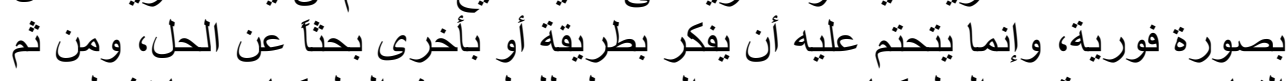

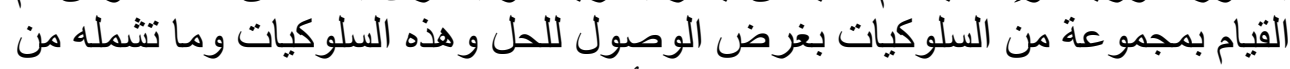

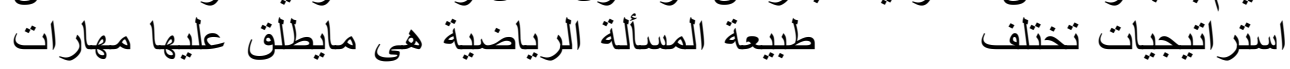

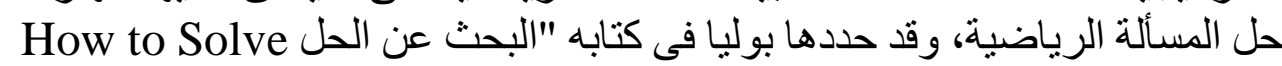

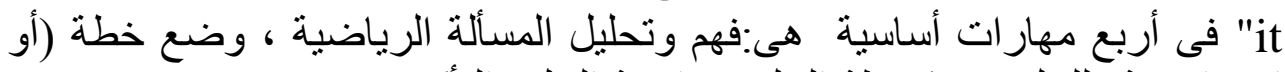

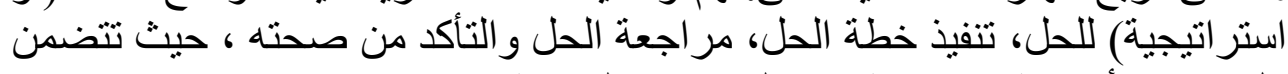

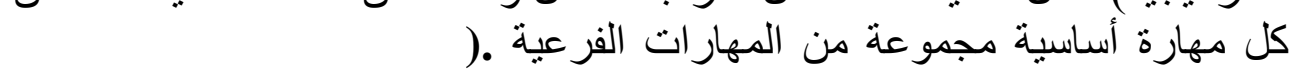

$$
\text { و المقاهيم }
$$




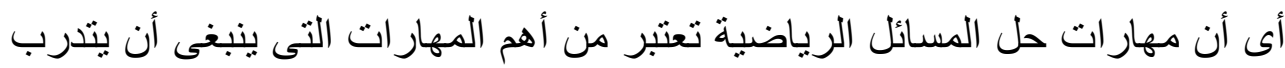

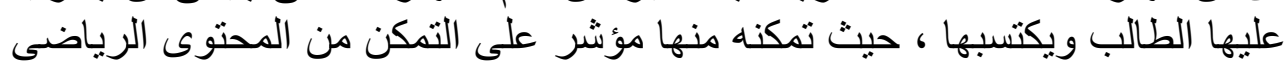

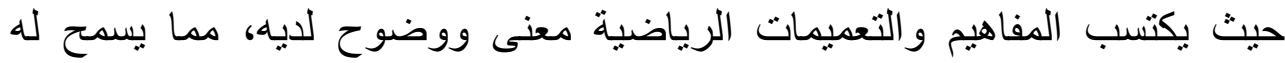

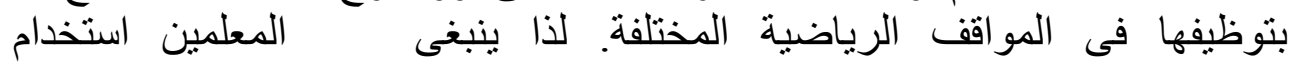

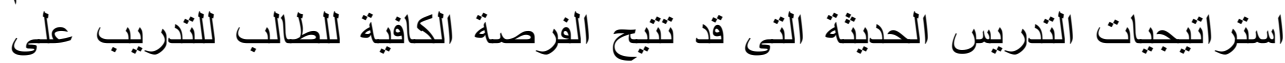

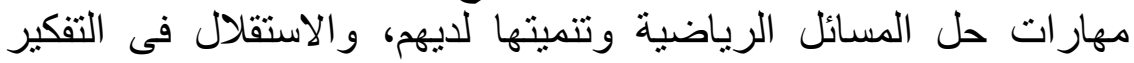

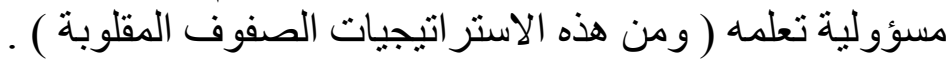

دافعيتهم

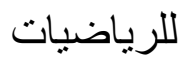

ظاهرة

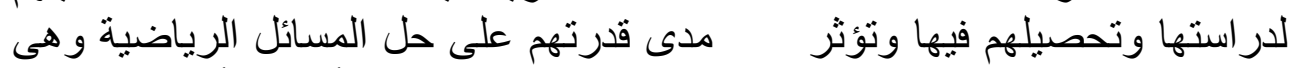

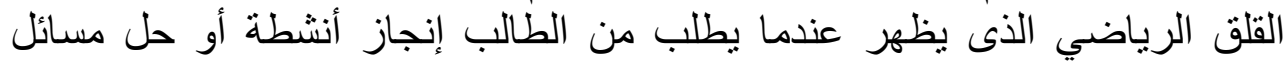

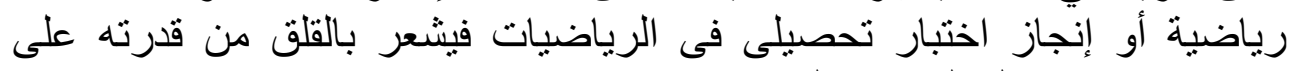
مما يسبب له الضيق و التوتر.

(2003,138) Brian\& David

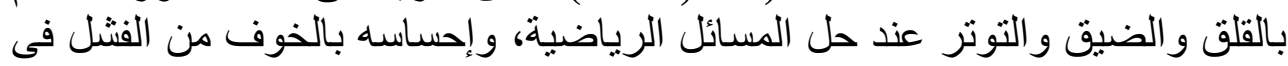

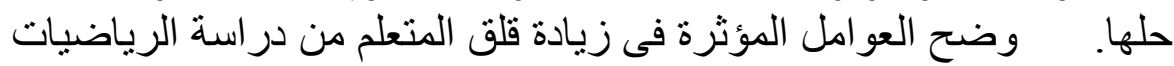

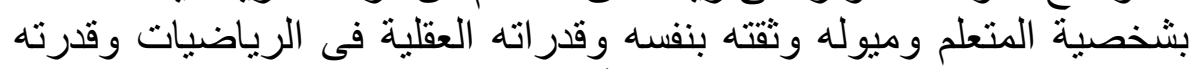

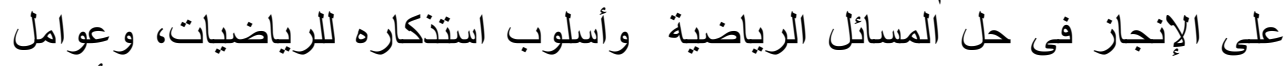

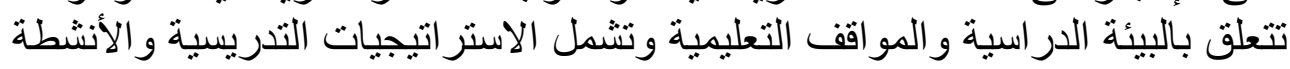
و الوسائل التبعليمية وأساليب التقويم التى يستخدمها المعلم.

و القلق الرياضى يوجد لاى معظم المتعلمين فى جميع المراحل ولكن بمستويات وهو أهدافه و أوضاعه العامة و الخاصة،،فيناك الك

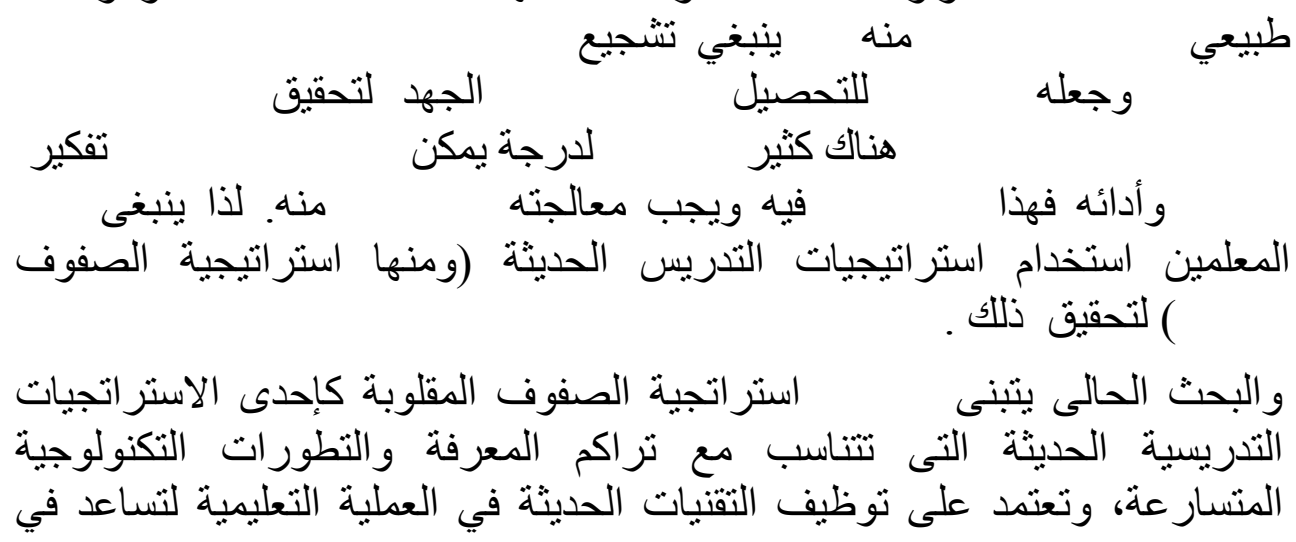

\section{Me}




$$
\text { إعداد أجيال من المتعلمين أكثر قدرة على المشاركة والبحث }
$$

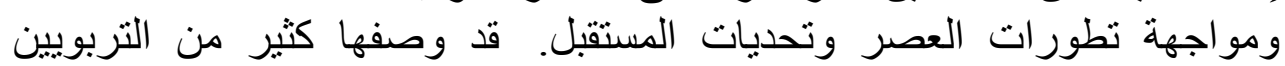

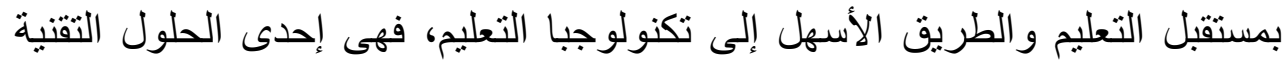

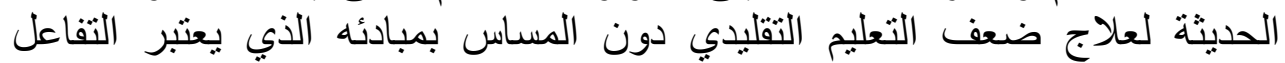

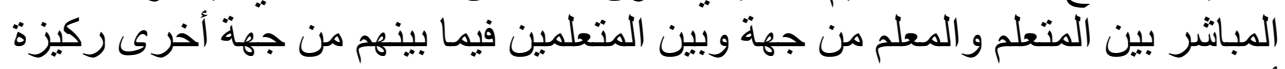

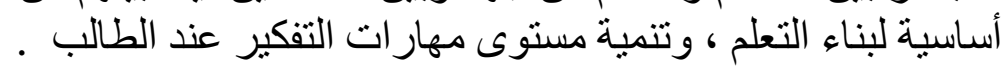

(2012,8)T orkelson

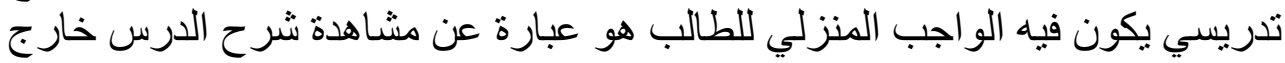

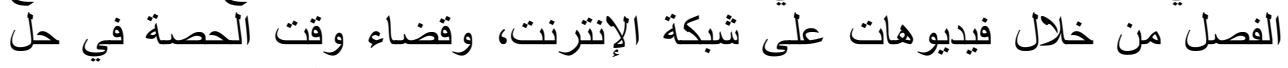

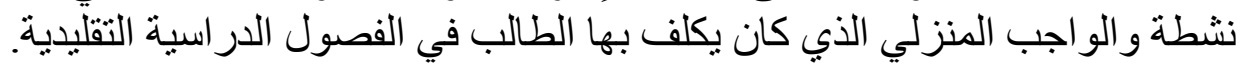

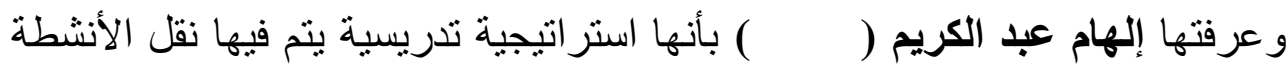

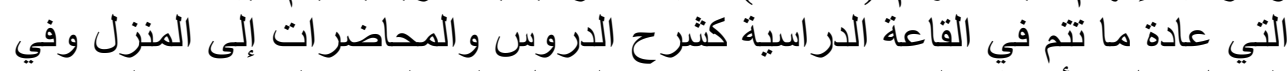

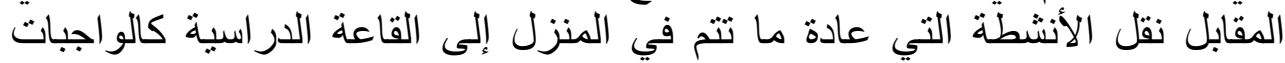

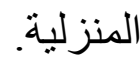
والثكل التالى يوضح مفهوم استراتيجية الصفوف المقلوبة

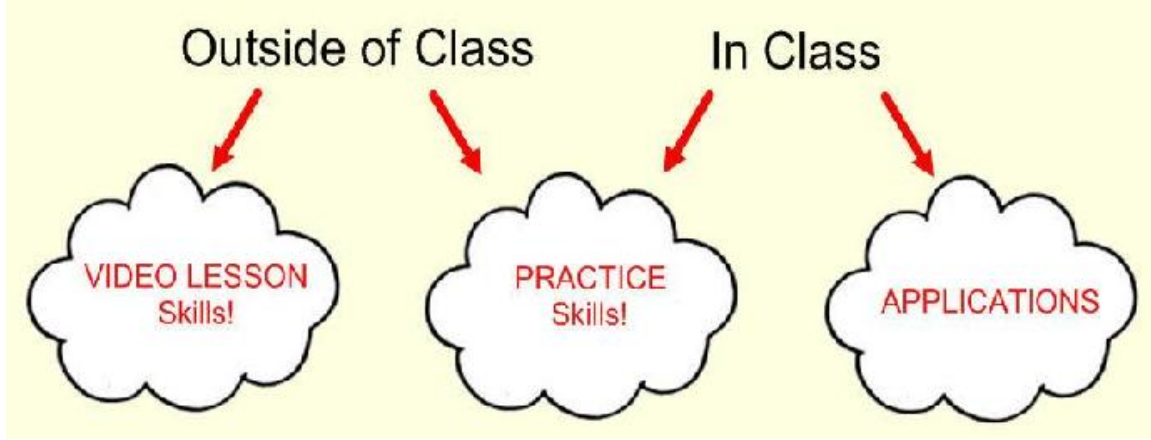

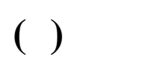

\section{دواعب البهث:}

نبعت مشكلة البحث من الجوانب الآتية:

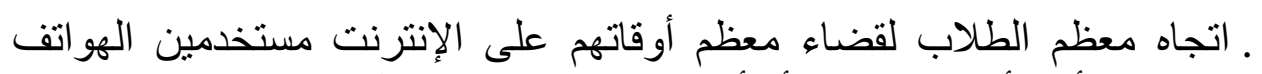
المحمولة أو الأجهزة اللوحية أو أجزة الكمبيوتر المحمول. 


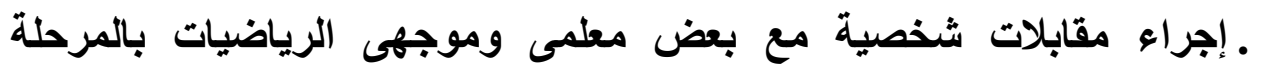

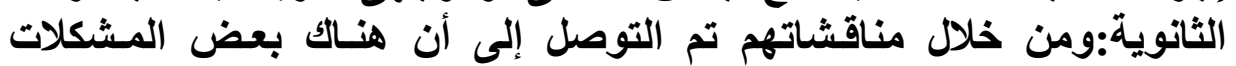

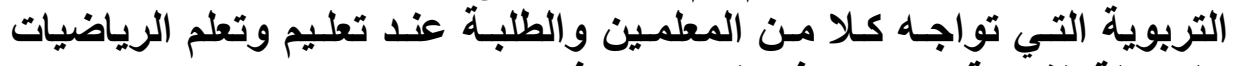
بالمرحلة الثانوية (وخاصة فئ الميكات الميكانيكا) فمنها:

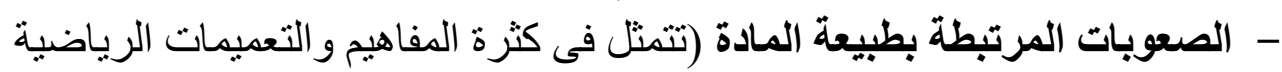

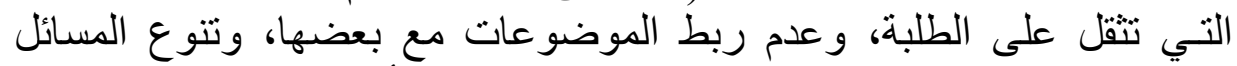

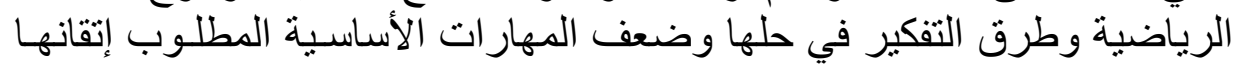

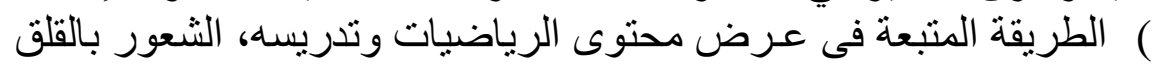

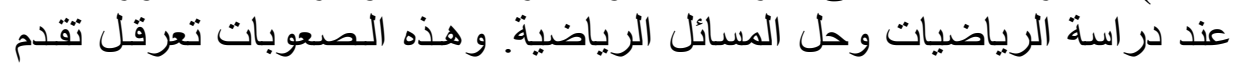

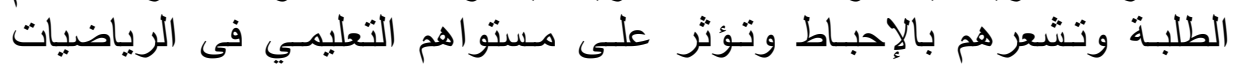

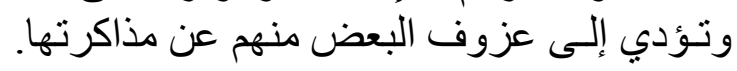

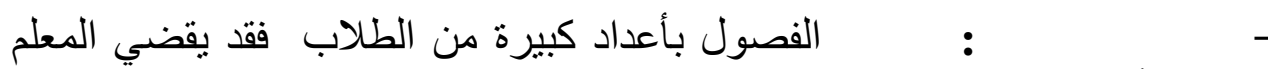

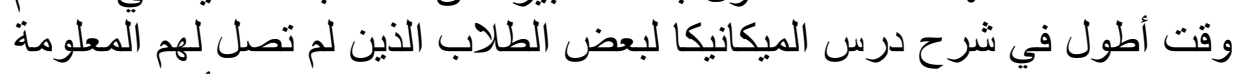

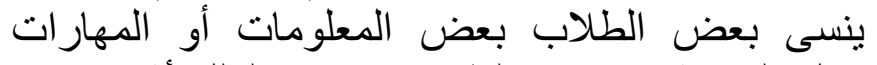

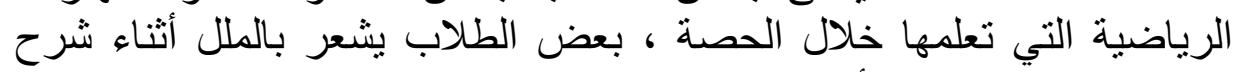

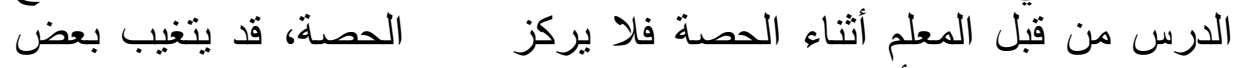

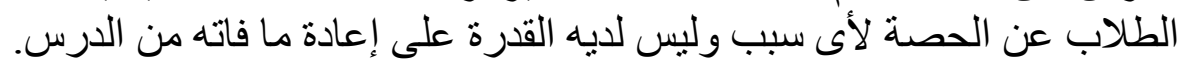

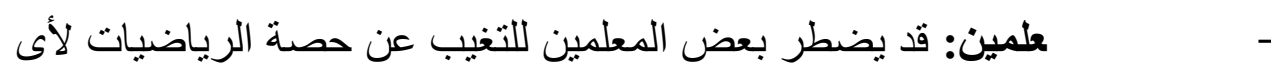

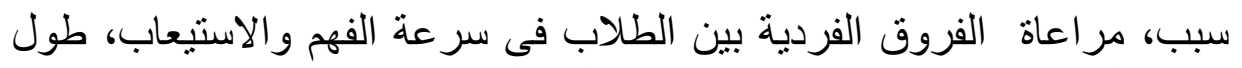

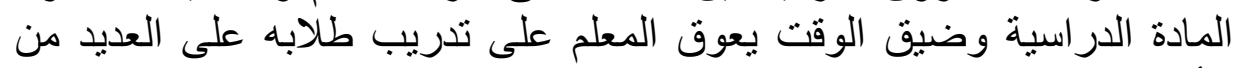

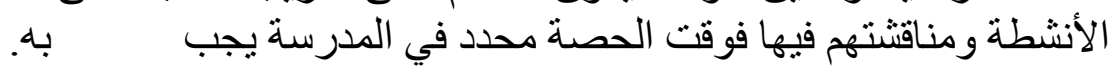

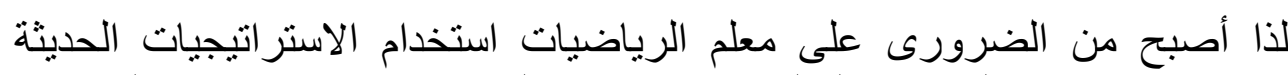

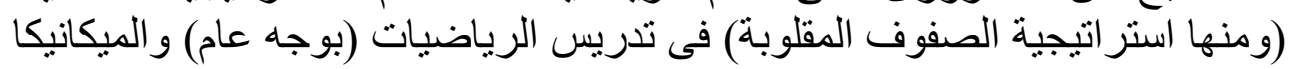

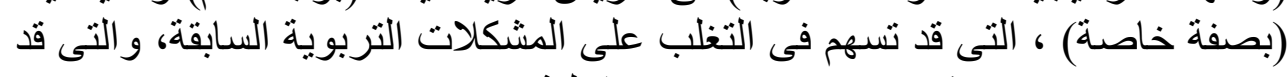
به بفاعلية

رئيسية الحقيقي و المسؤولية الذاتية إليه، والتى قد تسهم فى تنمية التحصيل ومهار اتلى حل المسائل الرياضية و و

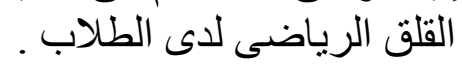

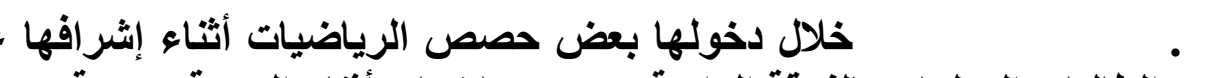
الطالبات المعلمات بالفرقة الرابعة تربوي رياضيات حصن أثناء التربية العملية: 
- وجود مشكلات تواجه بعض الطلاب بالمرحلة الثانوية عند دراسة الرياضيات

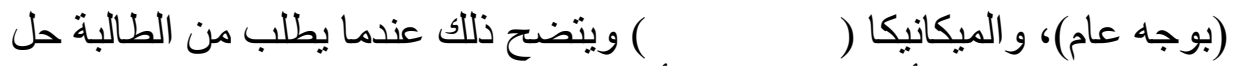

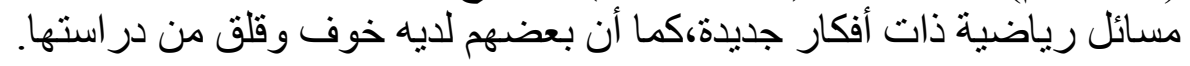

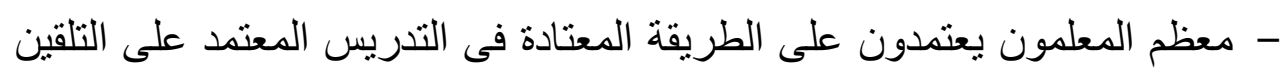

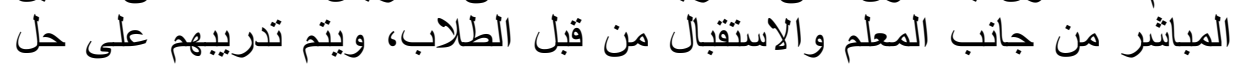

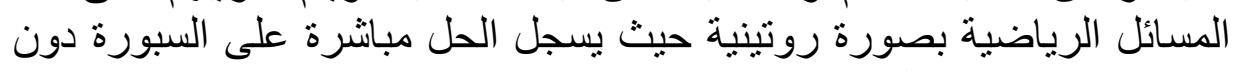

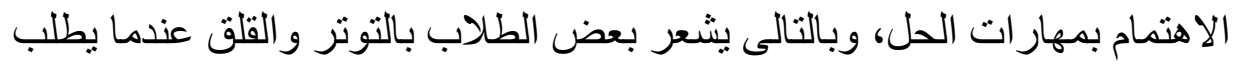

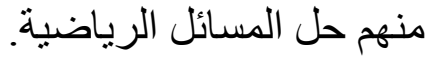
ـ تطبيق اختبار تحصيلى واختبار مهارات حل المسائل الرياضية (بصورة مبائية)

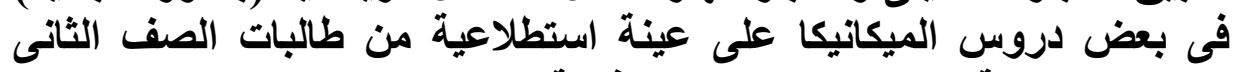

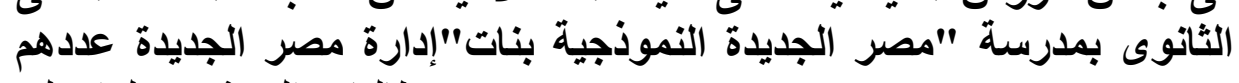

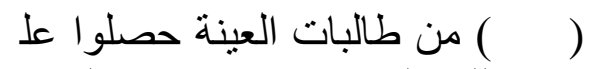

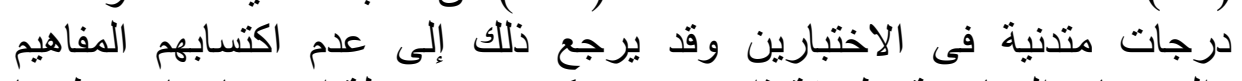

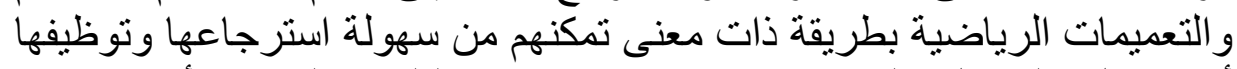

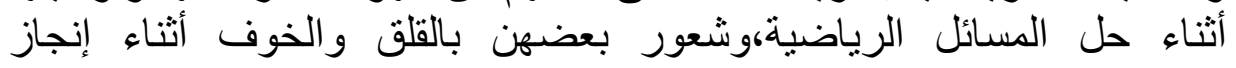
الإلإنبارين. الداع على الدراستة والبحوث الساقة التى تناولت متغيرات البحث، وتم

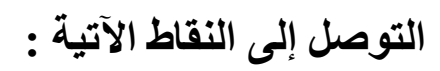

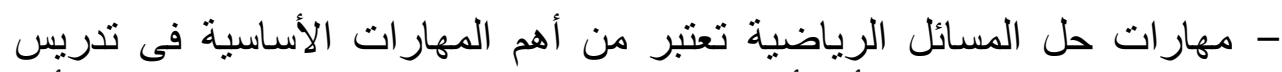

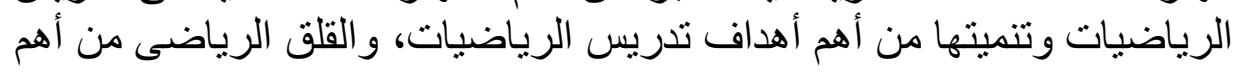

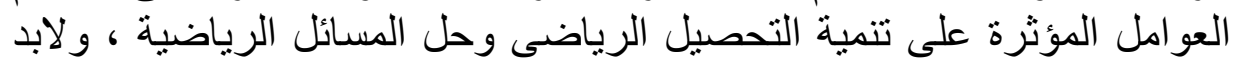

\section{تنميتها}

- العلاقة عكسية بين القلق الرياضى وبين كل من التحصيل والقدرة على حلى القل القل

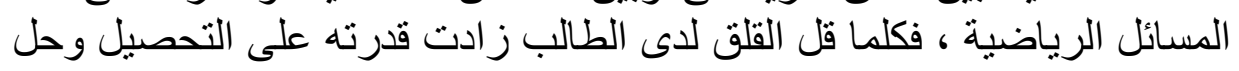

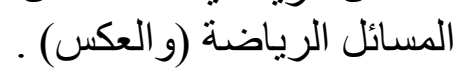

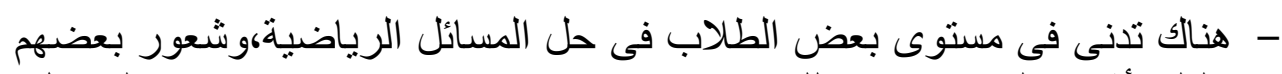

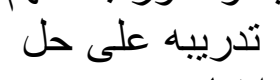

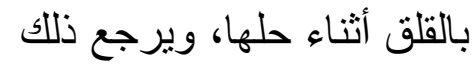

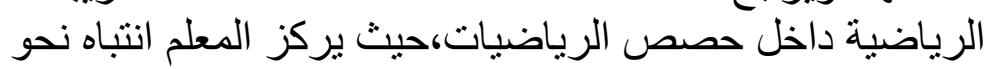

$$
\text { الصحيحة وليس العمليات و المهار الريات المتضمنة }
$$


- الدراسات و البحوث العربية ( على حد علم الباحثة) التى استخدمت استر اتيجية

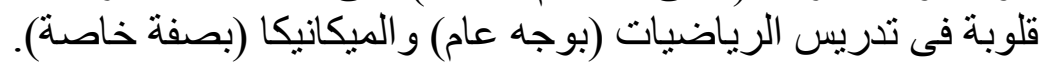

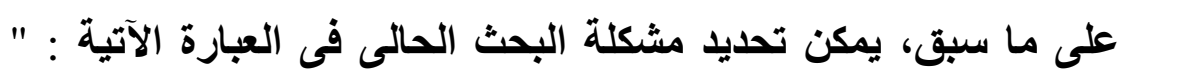

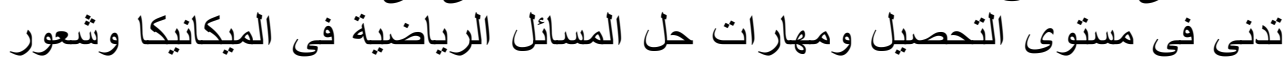

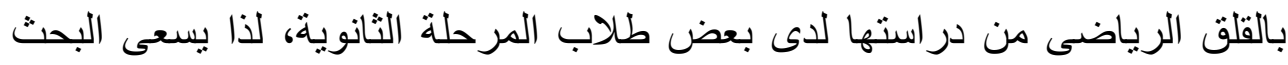

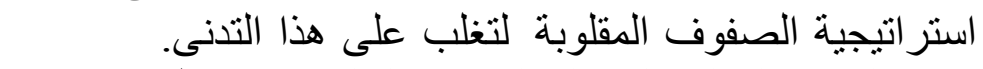

لهذه المشكلة ينبثق عن البحث الحالى السؤال الرئيس التالى: لئلى ما فاعلية أستخدام

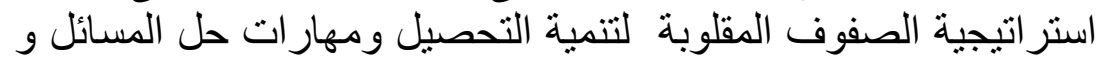
الرياضى نحو دراسة الميكانيكا لاى طلاب المرحلة الثلان الثانوية ؟

ويتفرع عن هذا السؤال الرئيس الأسئلة الفرعية التالية:

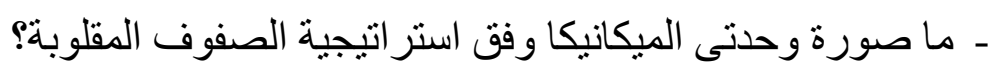

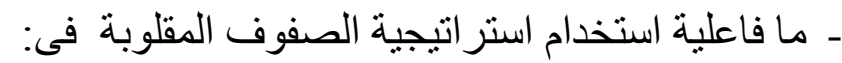

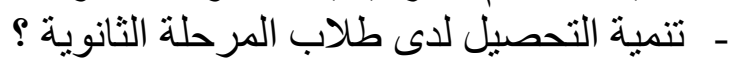

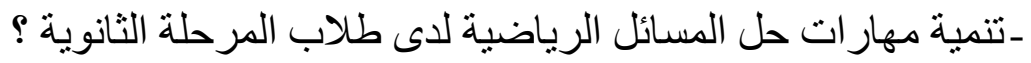

القلق الرياضى نحو در اسة الميكانيكا لدى طلاب المرحلة المرانة الثانوية ؟

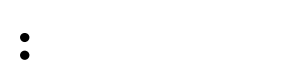

ـ لايوجد فرق ذو دلالة إلهائة إحصائية بين متوسطى درجات طلاب المجموعتين

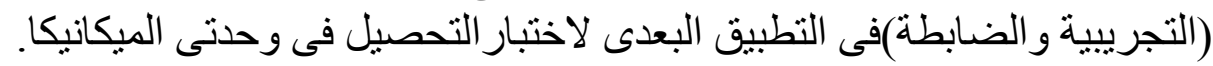

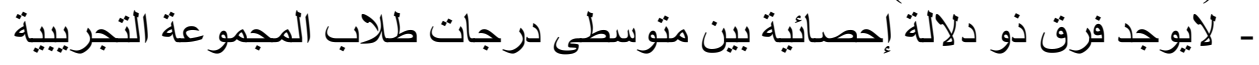

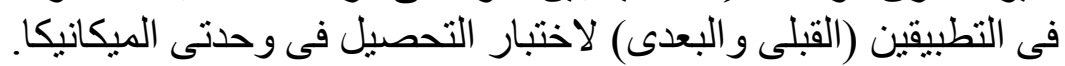

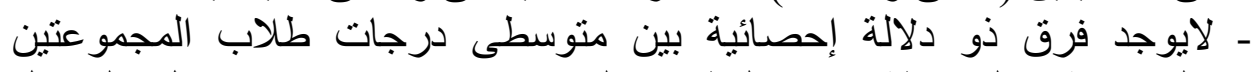

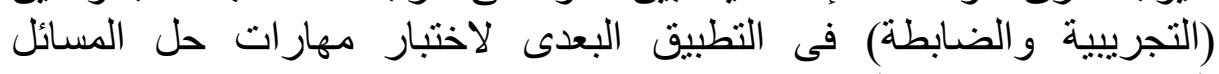
الرياضية فى وحدتى الميكانيكا.

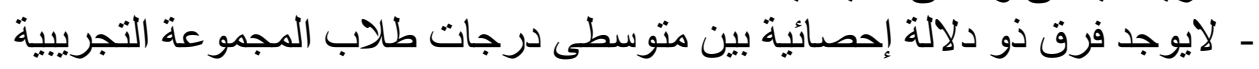

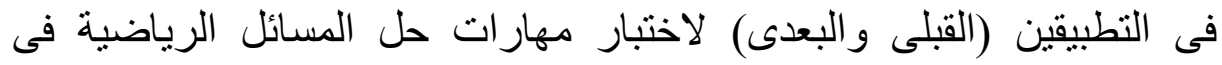
وحدنى الميكانيكا. - لايوجد فرق ذو دلالة إحصائية بين منوسطى درجات طلاب المجمو عتين

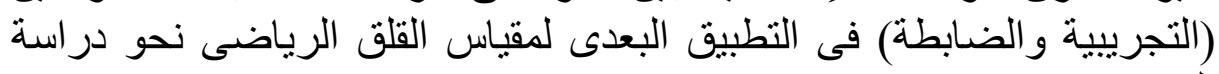


ـ لايوجد فرق ذو دلالة إحصائية بين متوسطى درجات طلاب المجمو عة التجريبية

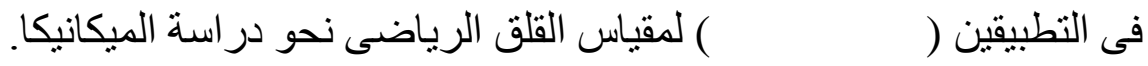

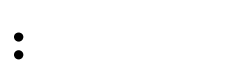

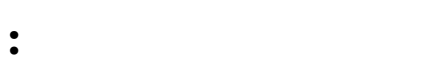

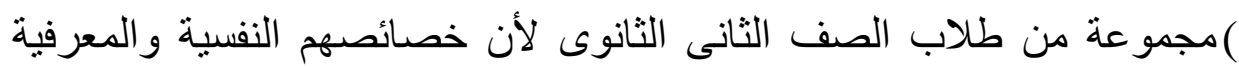

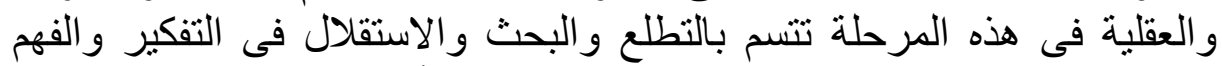

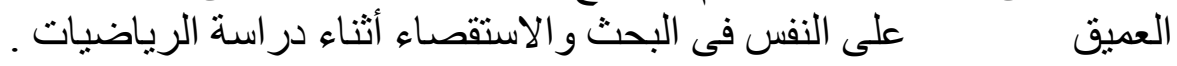

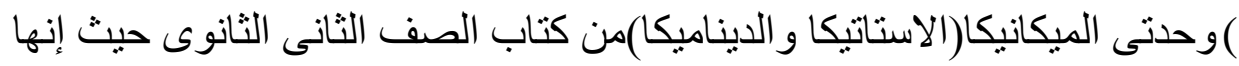

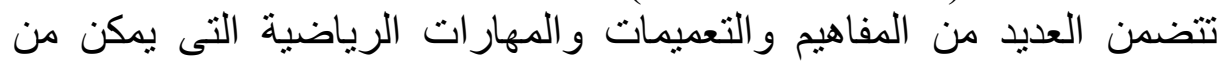

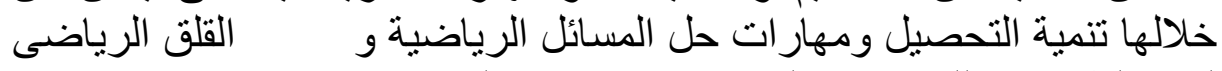

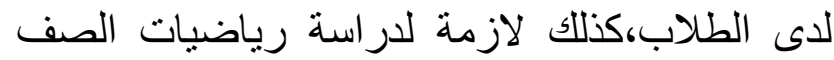

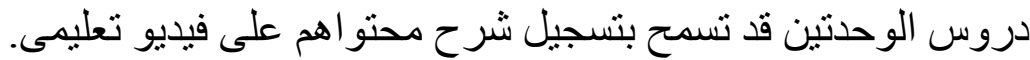
)قياس التحصيل عند مستويات: التذكر ، و الاستيعاب (يتمثل فى الفهم و التطبيق نيقي

\section{مصطلحات السهث:

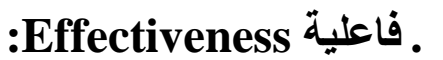

تعرف إجرائيا بأنها مقدار النمو الحادث فى التحصيل ومهار ات حل المسائل الرياضية

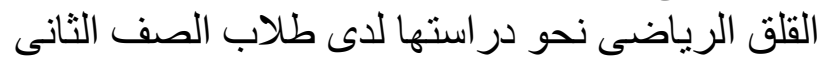
استر اتيجية الصفوف المقلوبة فى تدريس الوحدنين.

فى وحدتى الميكانيكا

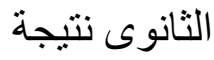

\section{r. الصفوف المقلوبة:}

عرفها

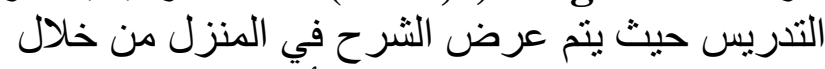

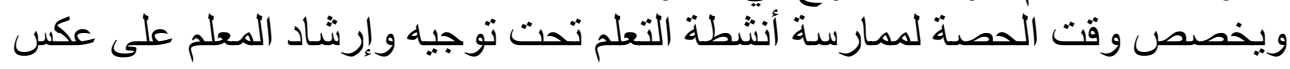

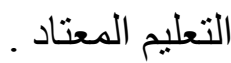

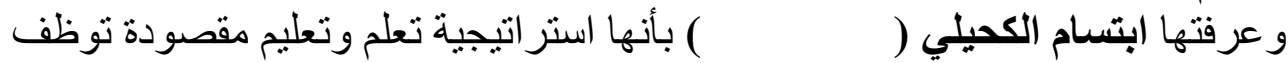

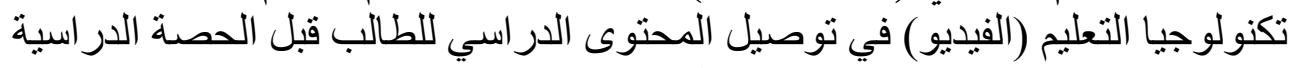

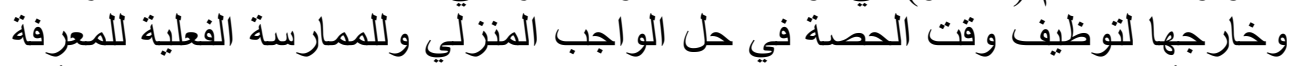

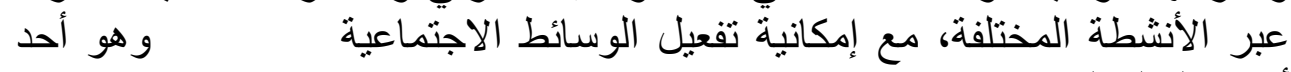

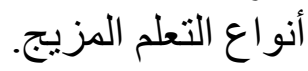




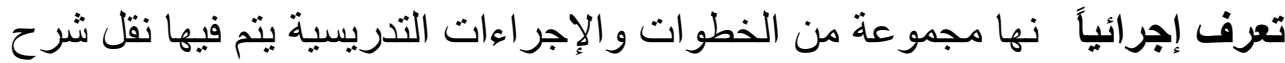

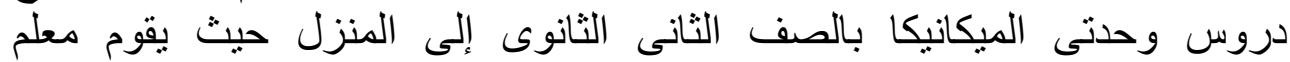

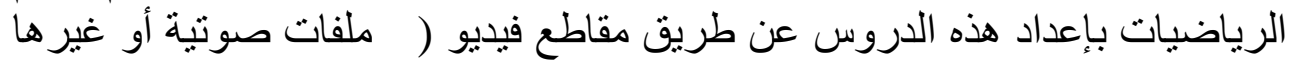

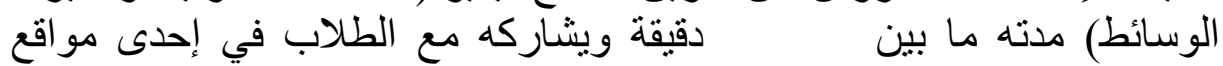

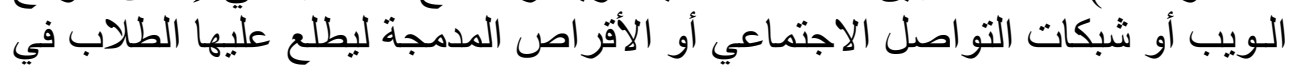

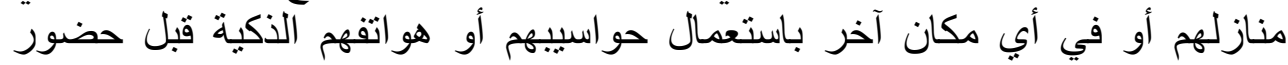

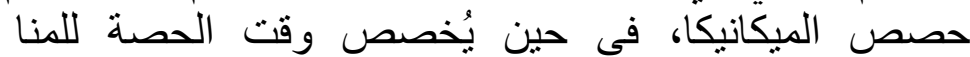
استفسار ات الطلاب وحل المسائل والأنشطة الرياضية كتطبيق على دروس وحدنى

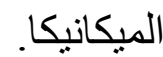
r. مهارات حل المسائل الرياضية: عرفها Klara

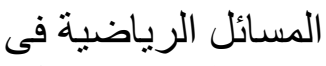

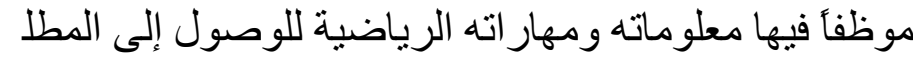
وحنى الميكانيكا ( من خلال المهار ات الآتية : قر اءة المسألة وفههها، التخطيط للحل، التحلى

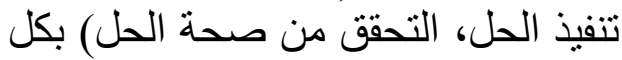
يحصل عليها

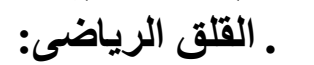

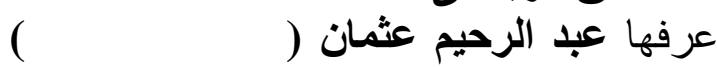

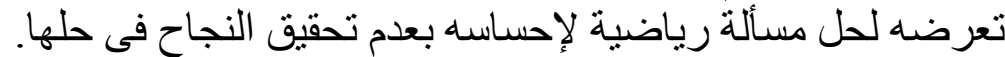

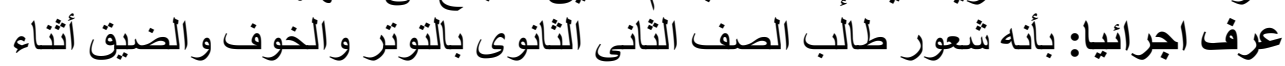

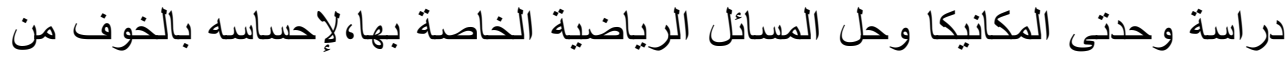

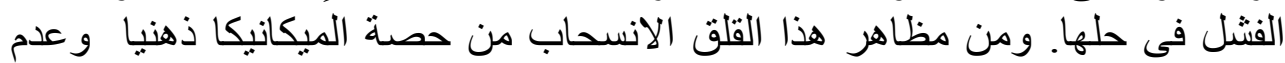

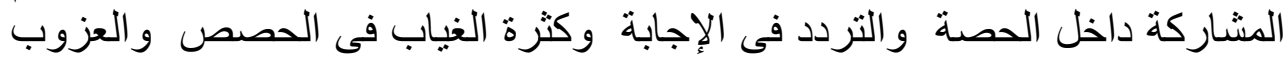
عن قر اءة المسائل الرياضية وحلها. منهج البحث:

تم إتباع المنهج شبه التجريبى باستخدام التصميم التجريبى ذو المجمو عتين المتكافتنتين

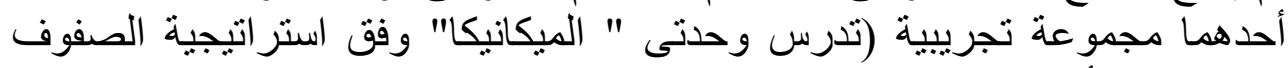
المقلوبة) و الأخرى مجموعة ضمابطة (تدرس نفس الوحدتين بالطريقة المعتادة) . أهمية البحث: والاثري قد يسهم البحث الحالى فئ : 
- تقديم للقائمين على تخطيط المناهج وتطويرها رؤية جديدة فى تنظيم محتوى المئي

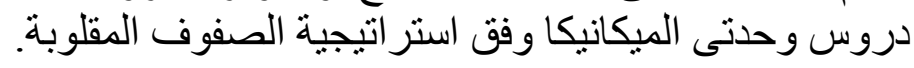

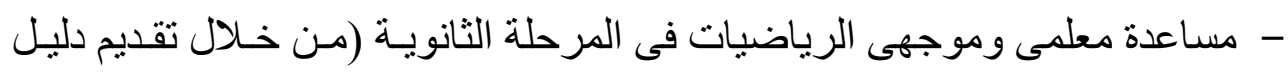

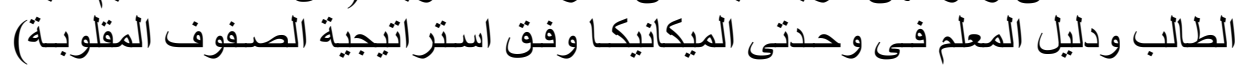

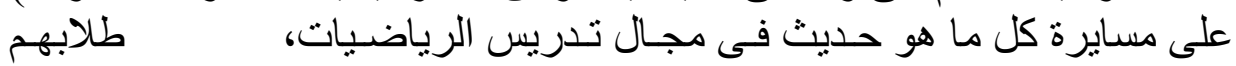

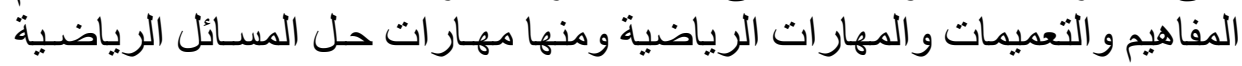

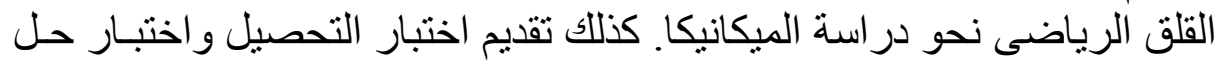

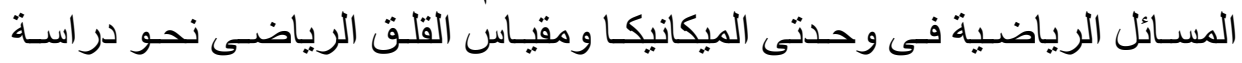

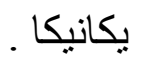

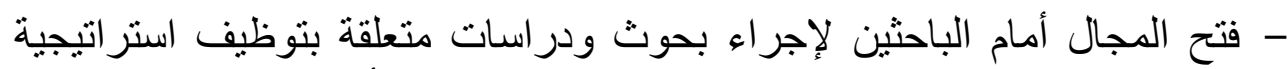

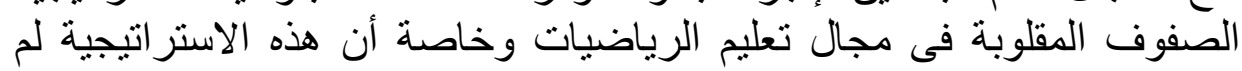
تستخدم كثير ا فى هذا المجال.

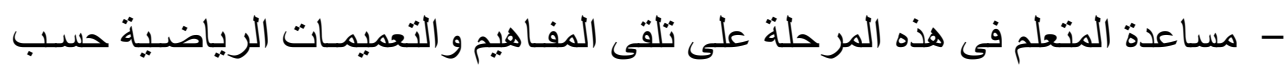

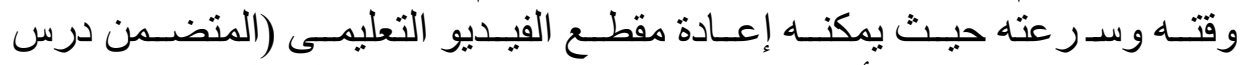

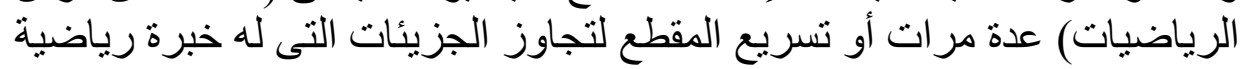

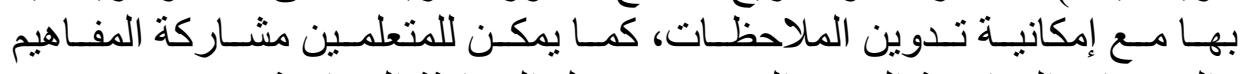

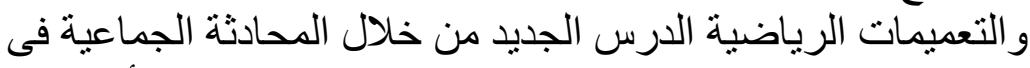

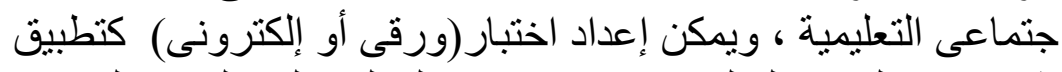

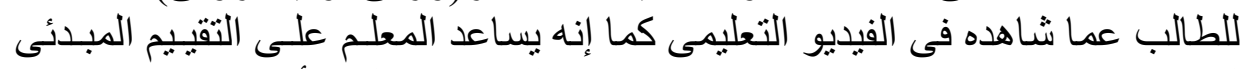

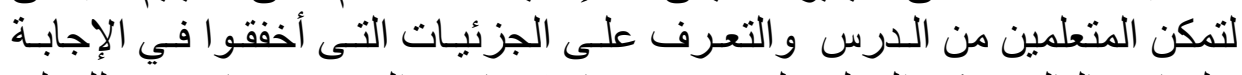

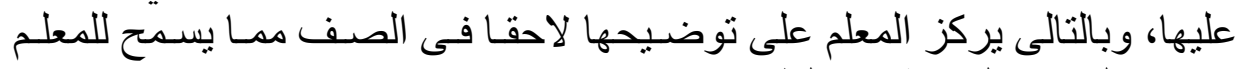
مر اعاة الفروق الفردية بين الطلاب.

\section{إجراءات البحث: \\ قد اتبعت الباحثة الخطوات البحث: الآتية:

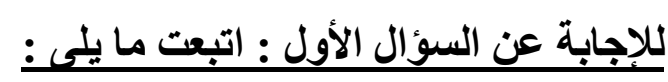

الآتية: استراتيجية الصفوف المقلوبة ، مهارات حل المسائل الرياضية ، القلق

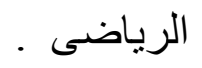


ـ تحليل محتوى وحدنى" الميكانيكا " لتحديد الدفاهيم و التعميمات و المهارات

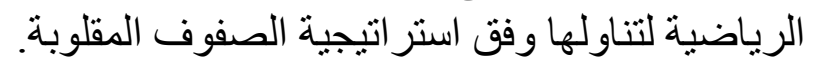

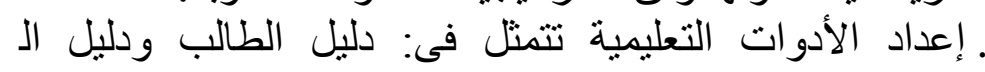

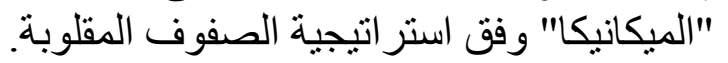

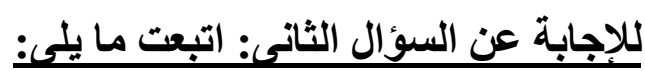

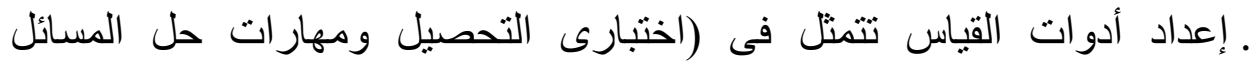

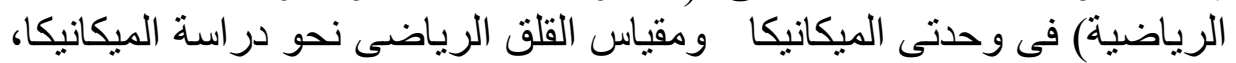

$$
\text { صدقة فيما وثثباتهما. }
$$

ـ اختبار مجمو عة البحث من طلاب الصف الثانى الثانوى وتقسيمها إلى مجمو عتين

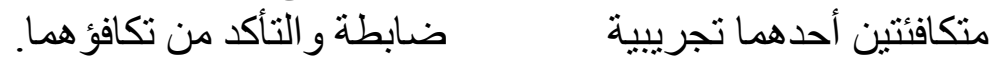

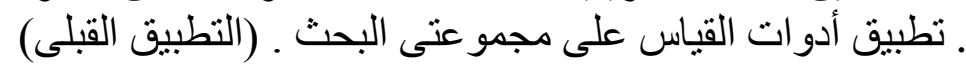

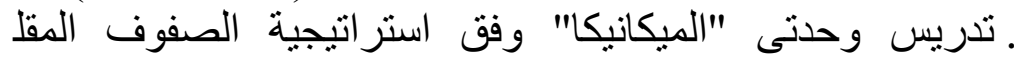

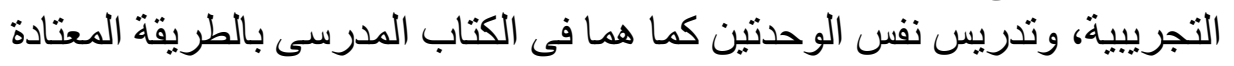

ـ تطبيق أدوات القياس على مجموعتى البحث ـ (التطبيق البعدى)

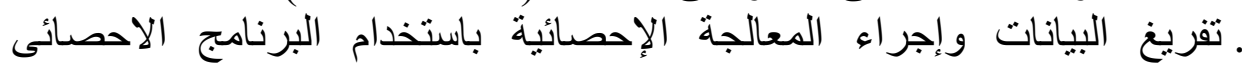

الدراسة الميدانية وتحليلها وتفسيرها ، وتقديم التوصيات

.SPSS

\section{الإلار الظرى والدراسات الساقة \\ أولاً: استراتيجية الصفوف المقلوبة ( المعكوسة ) :}

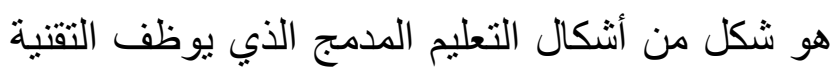

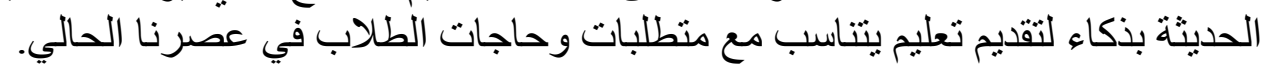

囚 ما هية الصفوف ( الفصول ) المقلوبة:

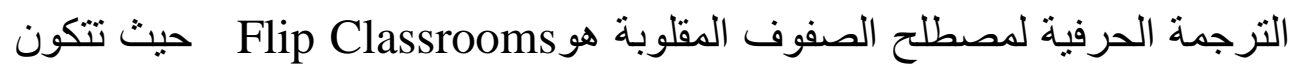
(FLIP)

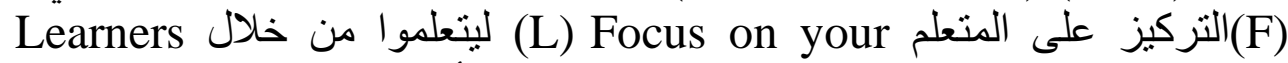

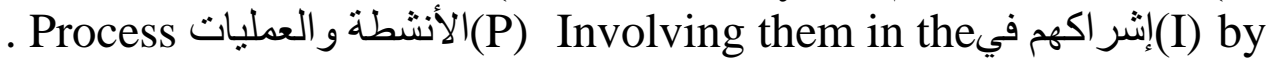

(H oneycutt\& G arrett ,2014) 


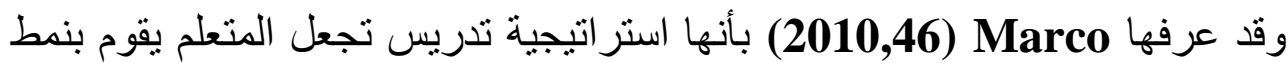

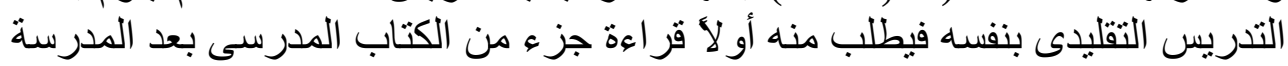

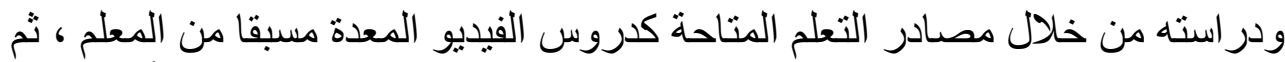

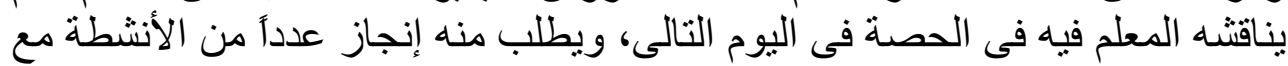

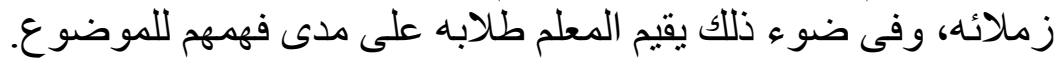

\section{(2013 ,2) Bishop\& Verleger، (2012,16-17)B Bergmann\& Sam}

بأنها استر اتيجية تعليمية تدعم مفهوم التعليم المتمركز حول الطالب لا المعلم،

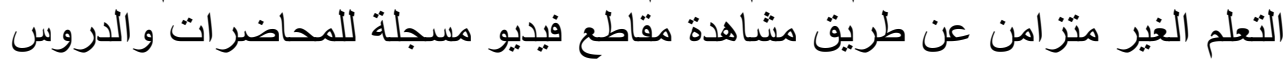

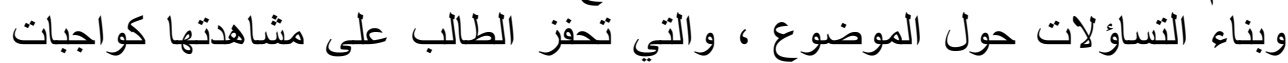

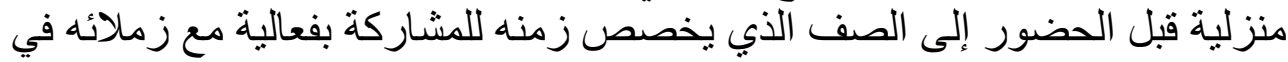

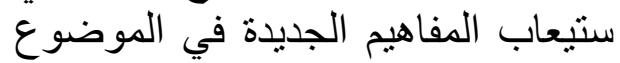

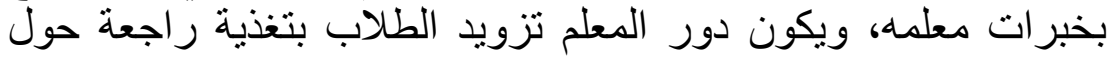
الموضوع ومساعدتهم على الفهم والاستيعاب و التطبيق الفعلي لامجرد تلفين رالقين المعلومات بشكل تقليدي.

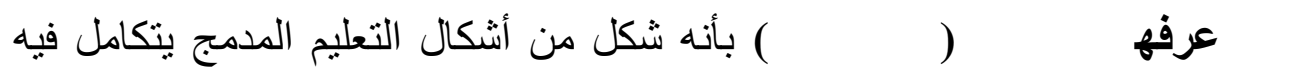

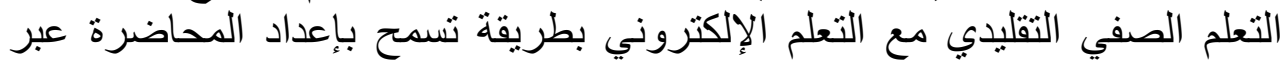

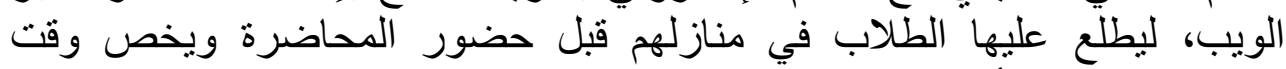

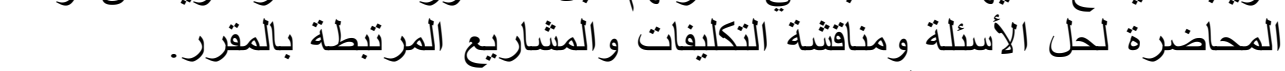

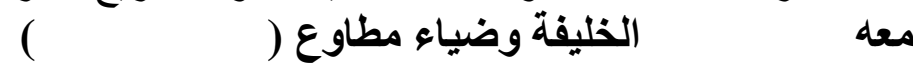

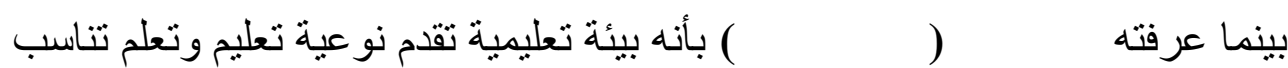

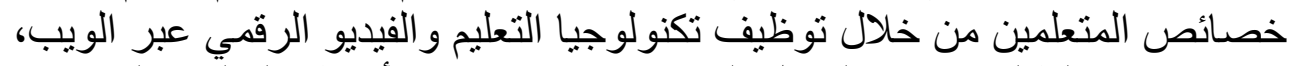
حيث يشاهده الطالب خارج الفصل الدراسي ويقوم بتتفيذ الأنشطة الفعلية و التنديبات النيات

بعد السنقراء التعريفات السابقة تم التوصل إلى أن استراتيجية الصفوف المقلوبة: - تلتقق جميع تعريفاتها على مفهوم واحد وهو قلب بين بيئة التعلم الصفية وبيئة التعلم

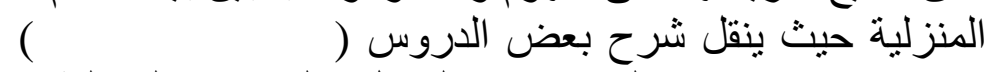

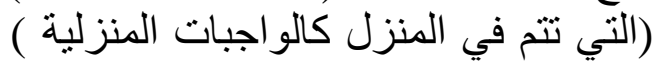
يضمن الاستغلال الأمثل لُوقت المعلم أثناء الحصة. 


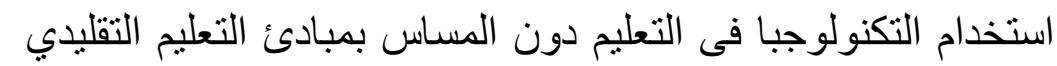

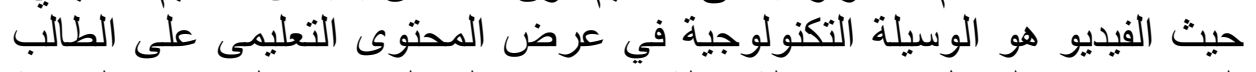

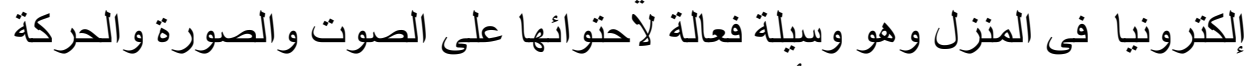
وتوفر عنصر التشويق بشكل أساسي.

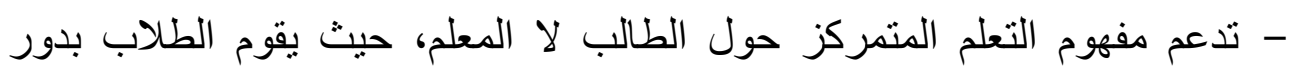

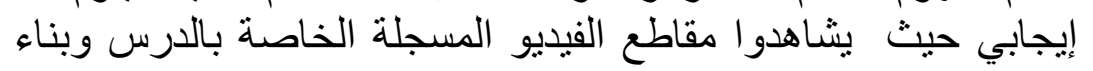

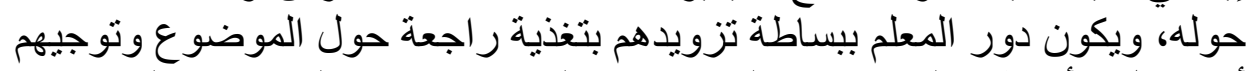

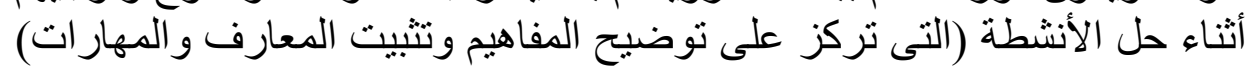

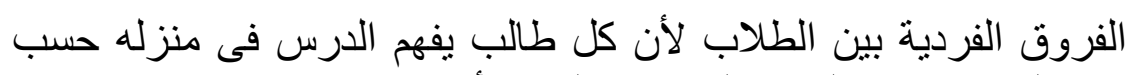

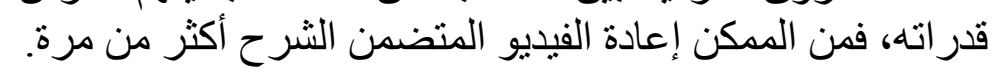

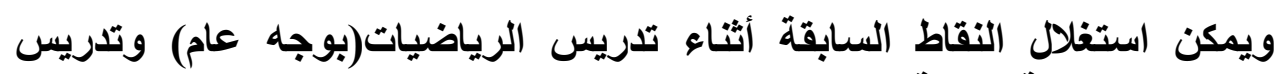
الميكانيكا (بصفة خاصة).

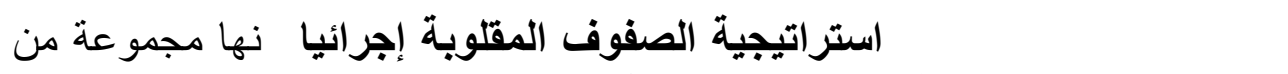

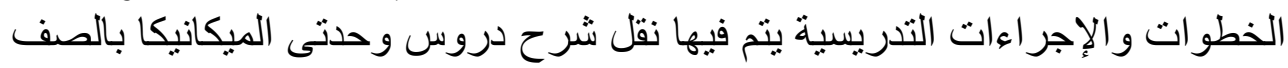

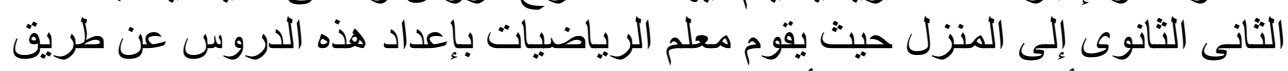

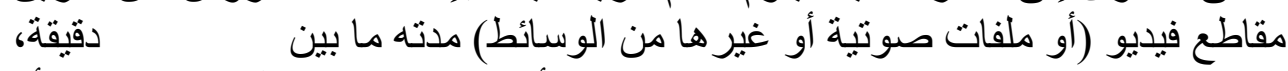

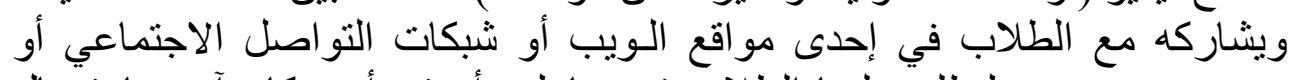

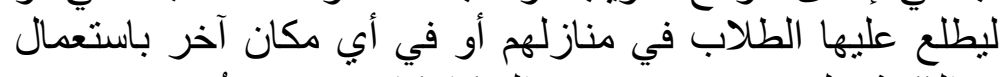

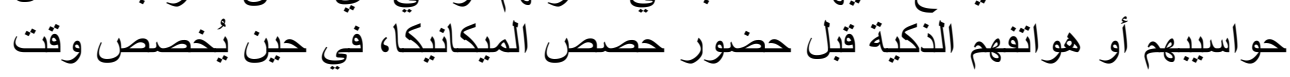

الرياضية كتطبيق على دروس وحدتى الميكانيكا. والثكل التالى يوضح الفرق بين النظام التقليدي والصفوف المقلوبية في التئية التدريس: 


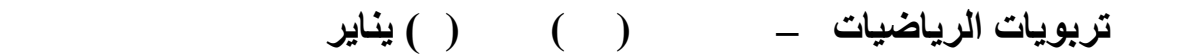

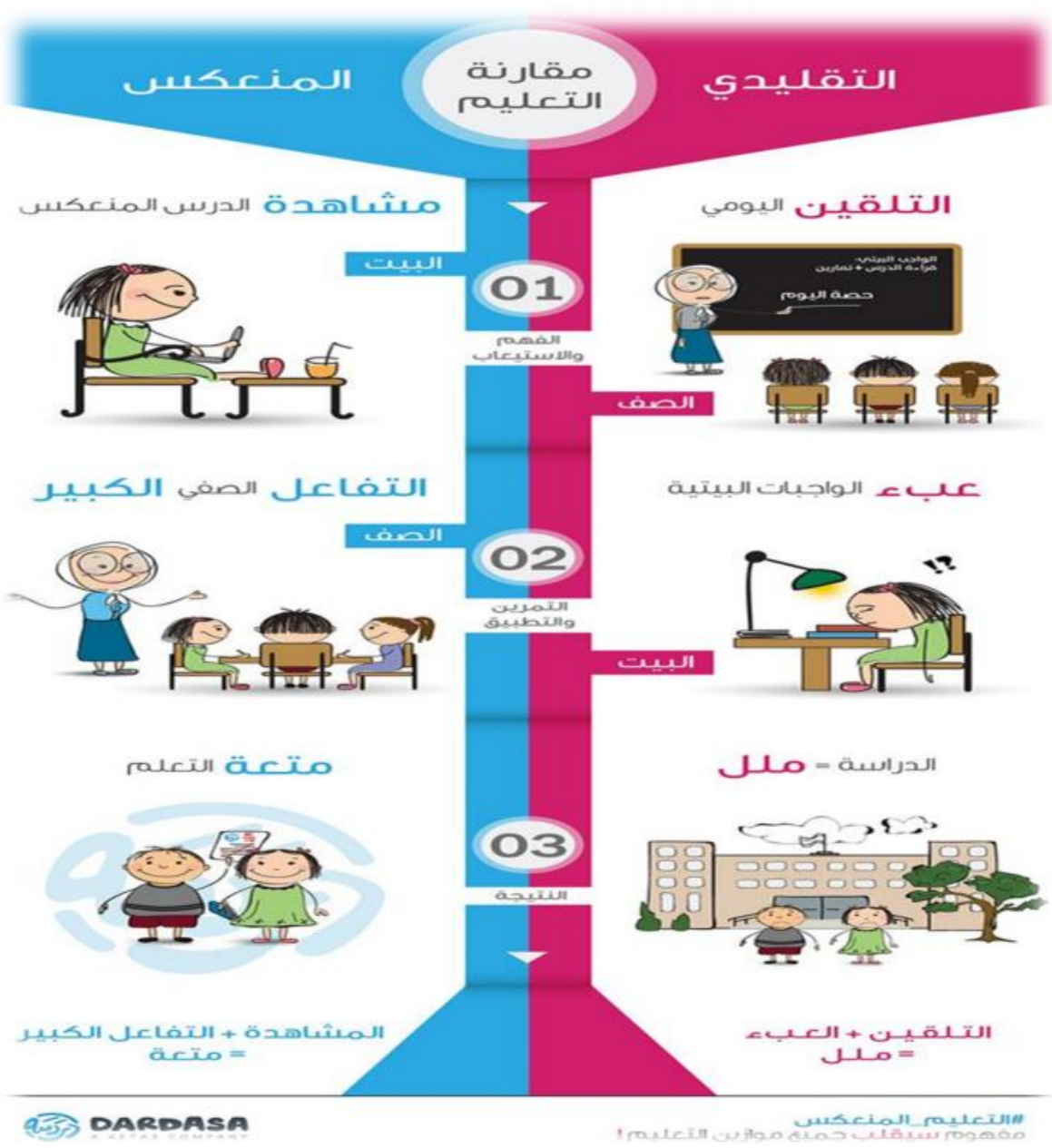

شك (r)

ويمكن تلخيص الدعائم الأساسية التي تقوم عليها استراتيجية الصفوف المقلوبة

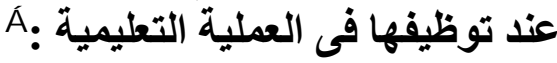

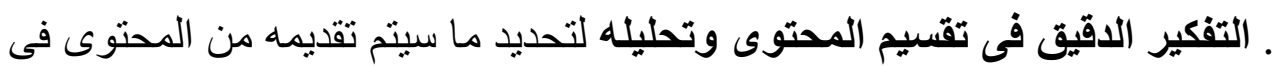
الفيديو التعليمى، ويعتمد هذا على قرار المعلم بناء على طبيعة المادة و الطلبة.

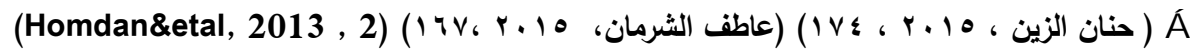
(Bergmann \& Sams, 2012, 67) 
· تغير في فهم التعلم من مفهوم أن المعلم هو محور العملية التعلمية ومصدر

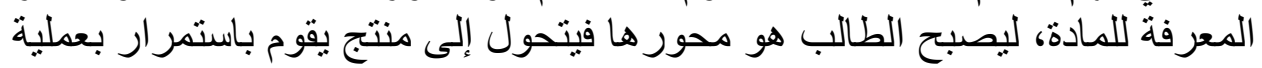
تشكيل المعرفة بشكل فعال و إيجابي ويكون المعلم هو المرشد والئ المساعد له له

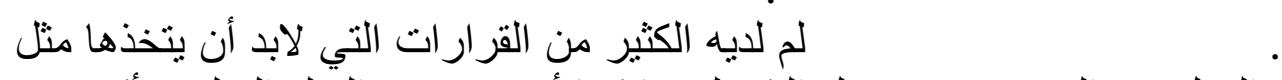

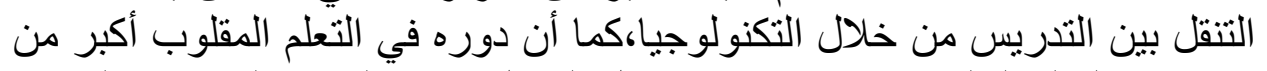

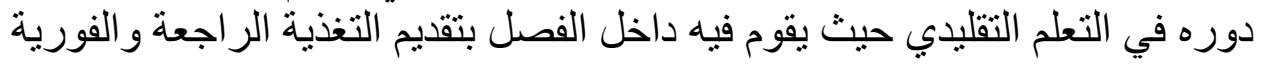

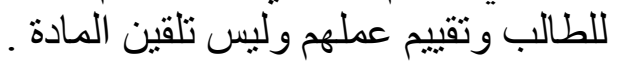

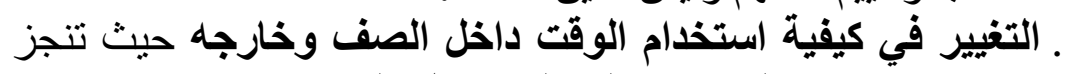
كانت تعتبر من الواجبات المنزلية داخل الصفي داخل الصف وختجز

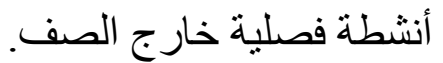

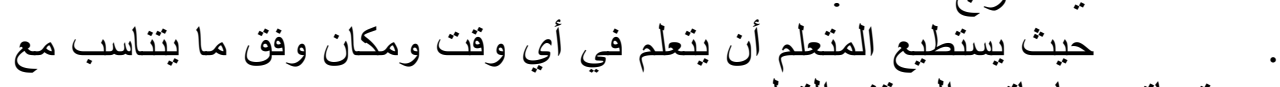

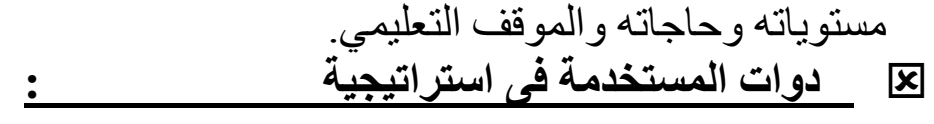

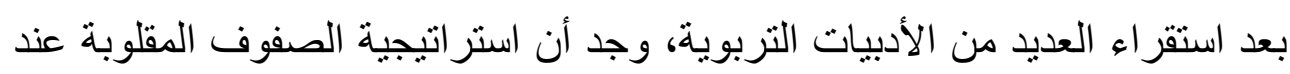

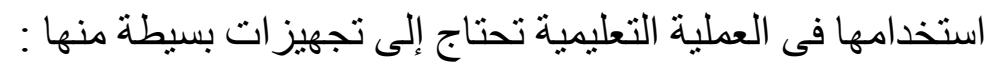
$\checkmark$

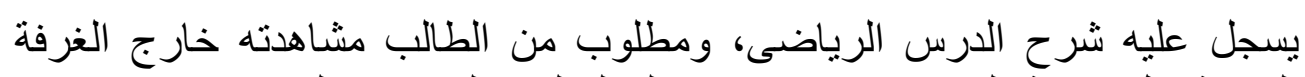

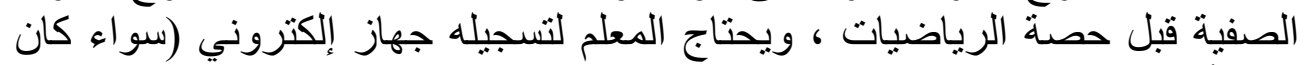

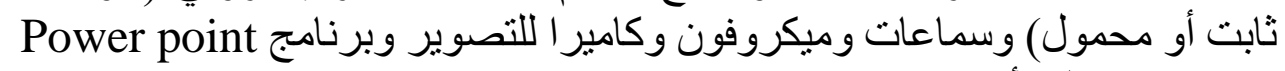
flash

ويتم نسخه على أقر اص مدمجة (CD) لرفعه على يوتيوب أو البريد الإلكتروني بين المعلم و الطلاب ، ومانئ ومانحتاجه من الطالب

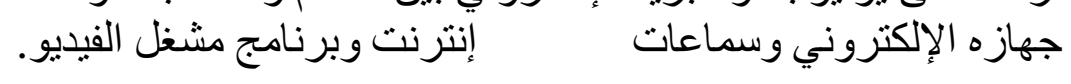

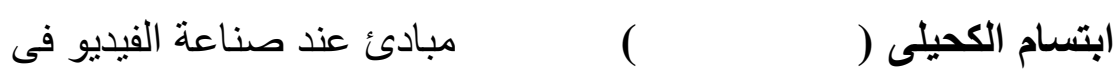

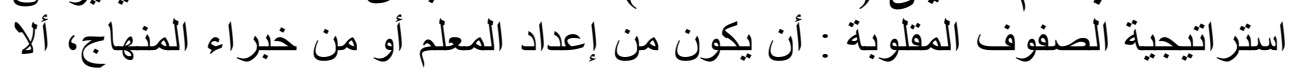

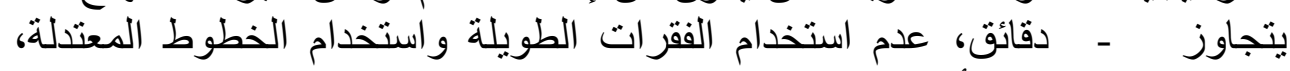

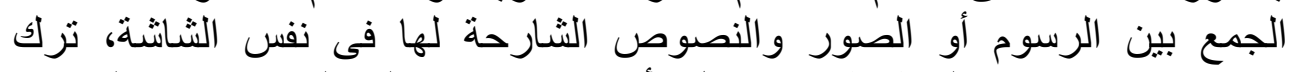

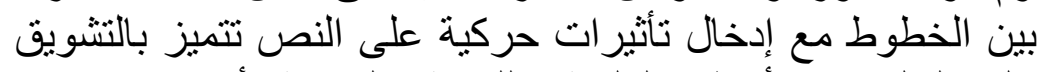

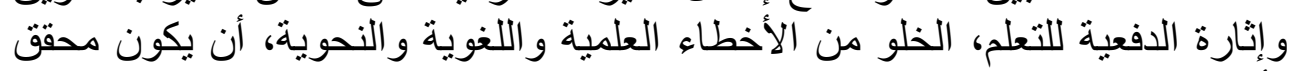

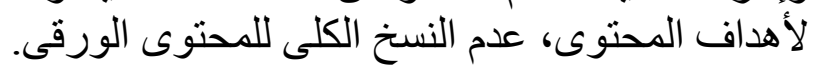

\section{MV7}


ويمكن تلخيص بعض المعايير للفيديو التعليمى لزيادة فعاليته فى العملية التعليمية

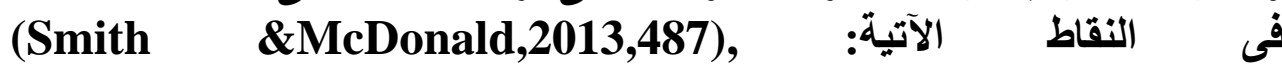
(Bergmann\& Sams,2012,67)

• يكون قصير ومركز ، ومر اعاة الفروق الفردية للطلاب و أساليب تعلمهم المختلفة.

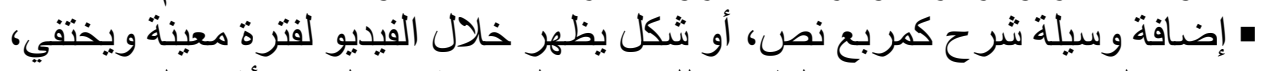

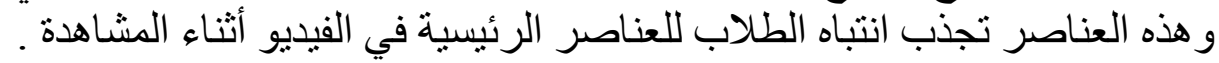

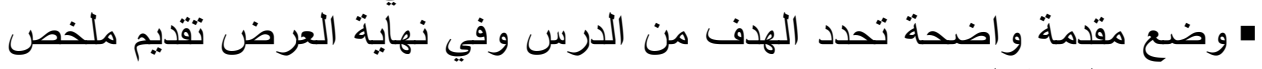
يعرض النقاط الرئيسة. • يسمح للمعلمين باستخدام وقت الرئة الحصص في دعم عمليات التعلم لدى الطلاب

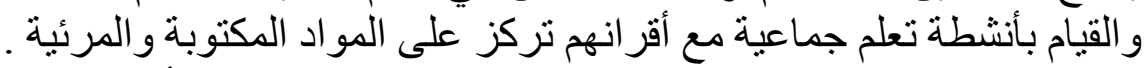

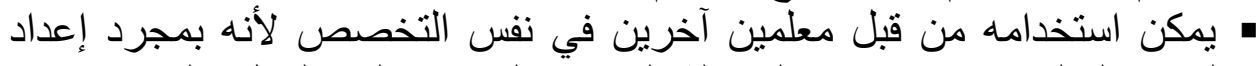

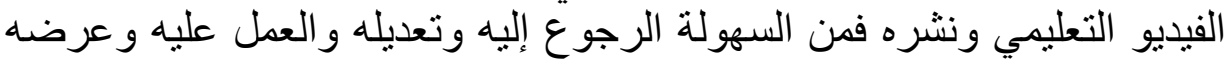

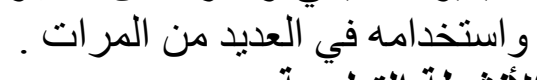

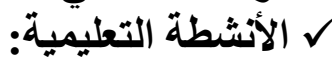

الأنشطة داخل الفصول المقلوبة لها معايير و اشتثراطات ليتحقق الهدف منها تتمثل

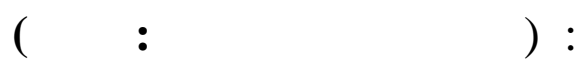

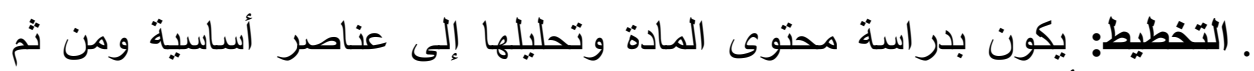
صياغة الأنشطة والمهمات الثرية التي تمكن المتعلم من ممارسة الخبرة السابقة

إنارة الاهتمام: خلق روح الفضول والرغبة في التفاعل يتوقف على أسلوب

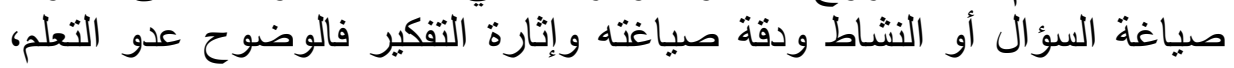

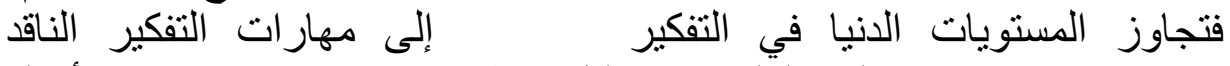

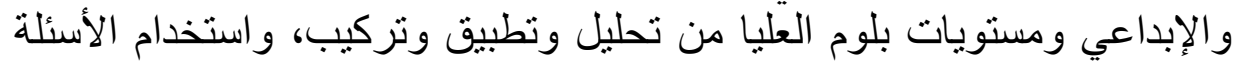

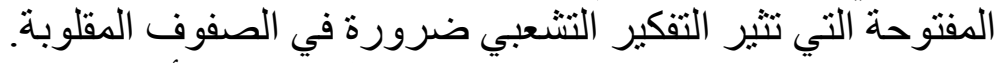

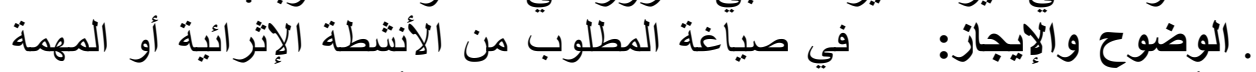

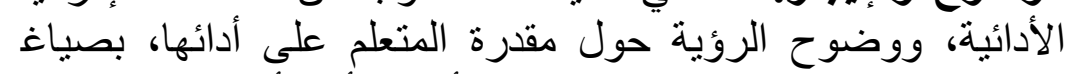

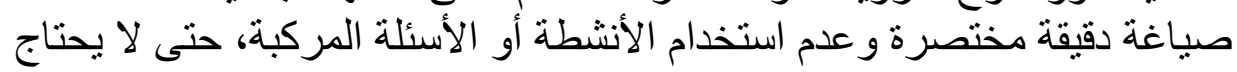

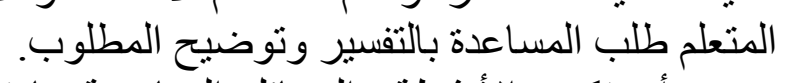

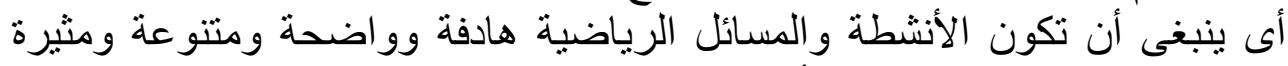

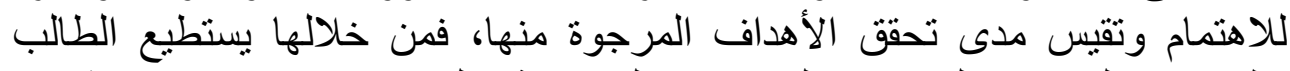
تطبيق ماتعلمه من المفاهيم والتعميمات الرياضية (التى نم استبعابها بعد مشاهدة

\section{rVV}


الفيديو التعليمى) أثناء حصص الرياضيات مع وجود المعلم الذى يوفر لله تغذية التئية

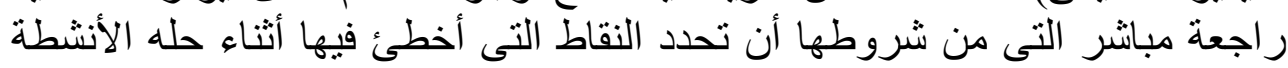

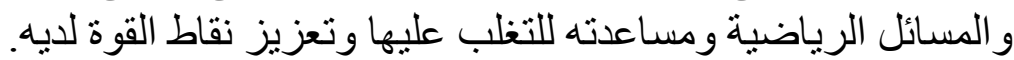

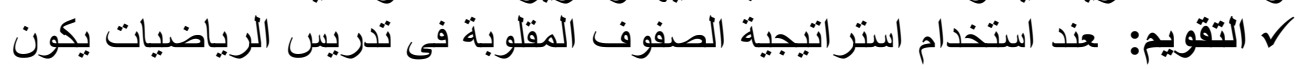

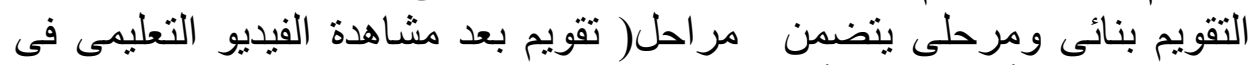

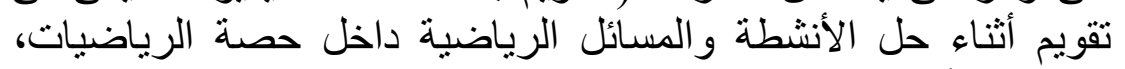

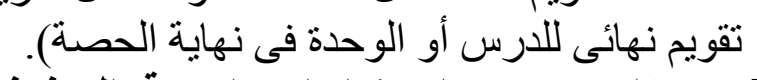
凤 مميزات وعيوب استخدام استراتيجية الصفوف المقاية المقوبة في العملية التعليمية:

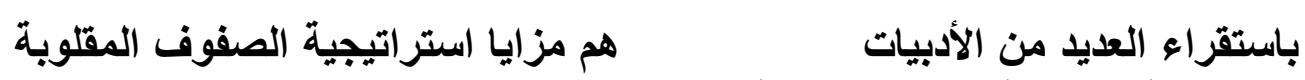
في العملية التعليمية في النقاط الاتية :

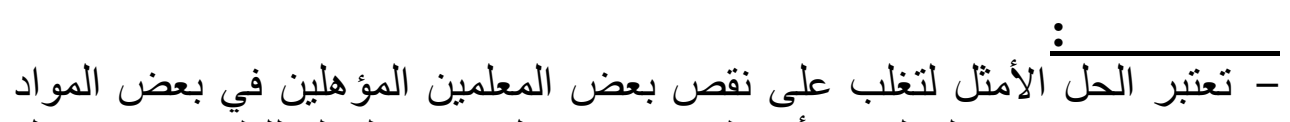

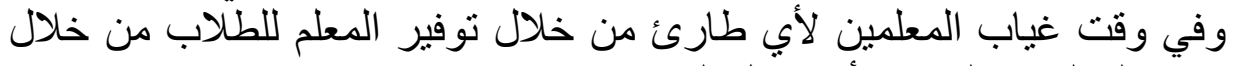
اللتقنية الحديثة في التعليم، توفير تغذية راجعة التهانة شرح المعلم في الفيديو كأنه داخل الصفئ طارئ دن

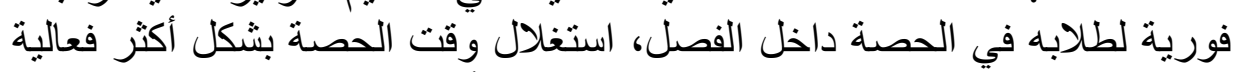

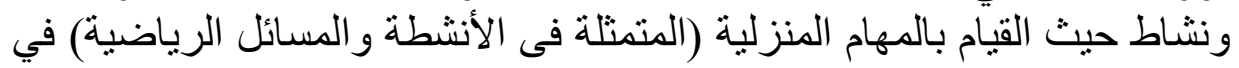

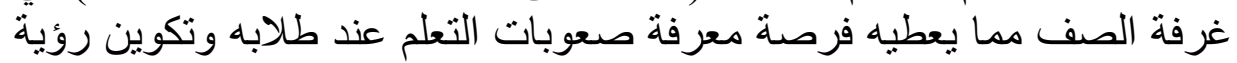
حول مسنوى طلابه في الإنجاز و الاهنمام و المشاركة.

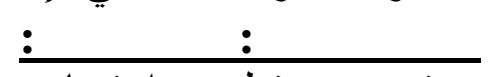

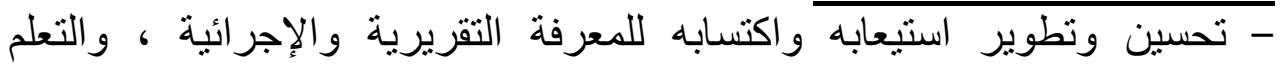

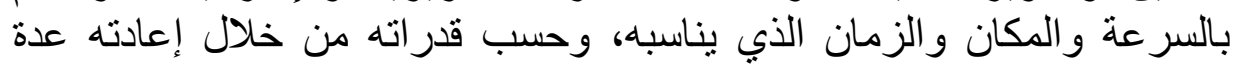
مرات.(أى تر اعى الفروق الفردية الزية ).

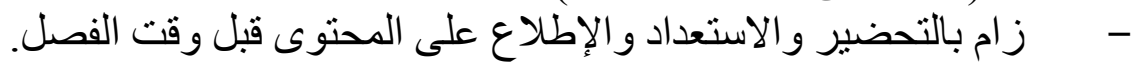

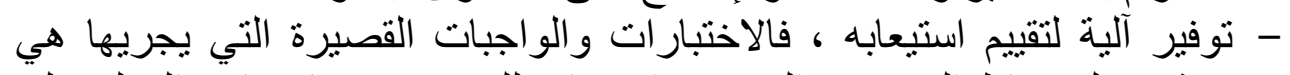

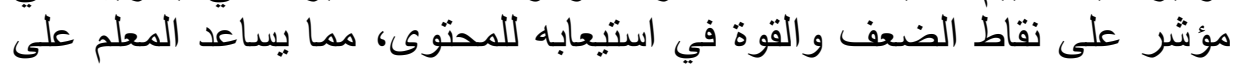
التعامل معها.

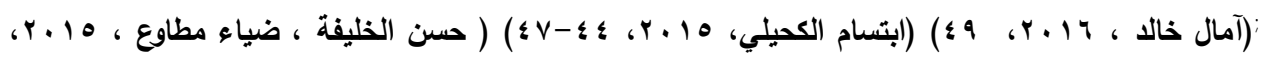

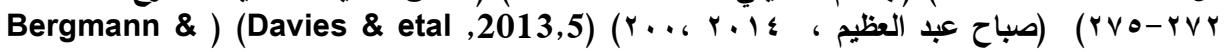

(Sams,2012,68 
- الحصول على المحتوى بشكل مقاطع فيديو بشكل دائم يتمكن من مشاهدته بأي

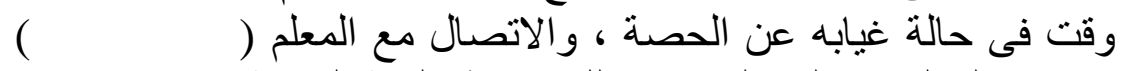

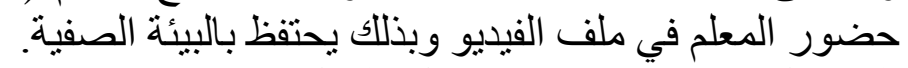

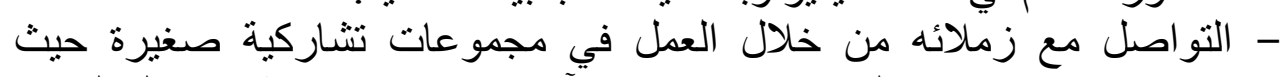

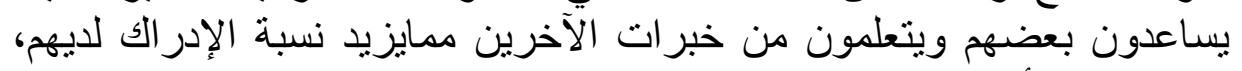
وتزيد ثقتهم بأنفسهم و وغير هم.

وبالرغم من مميزات استخدام الصفوف المثيد المقلوبة في العملية التعليمية فقد يواجهنا

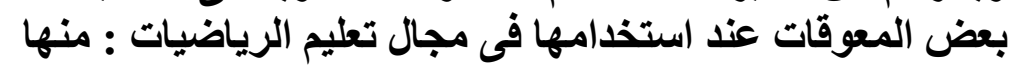

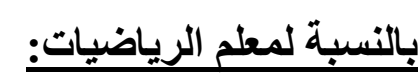

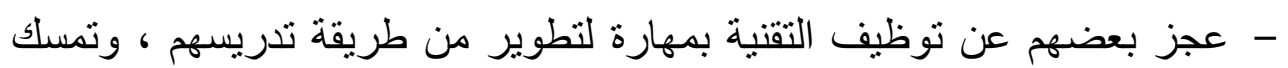

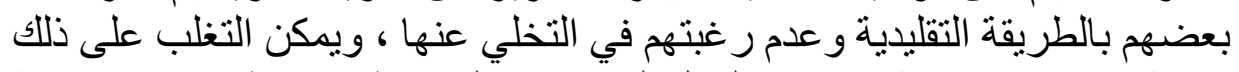

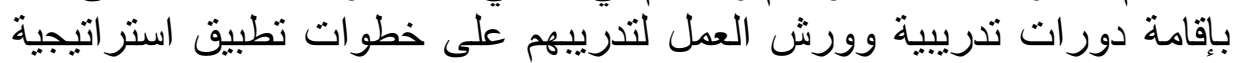

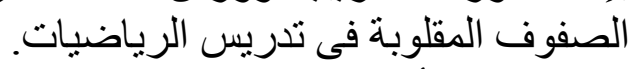

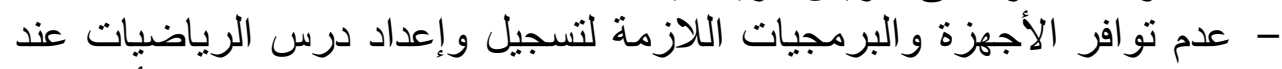

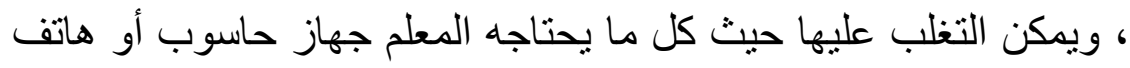

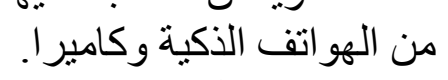

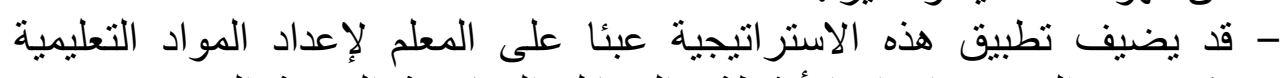

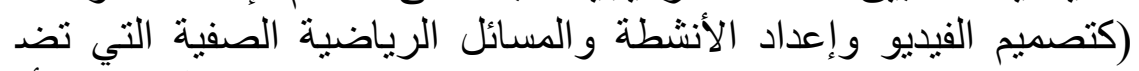

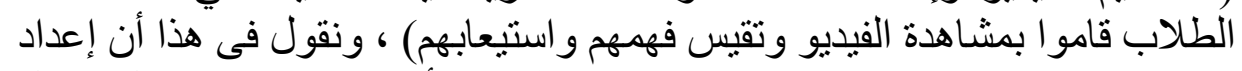

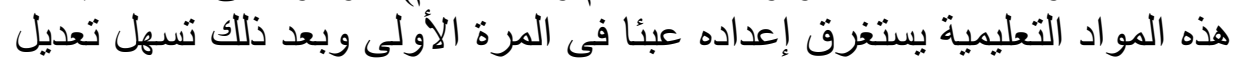

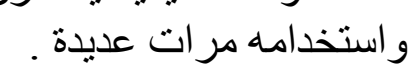

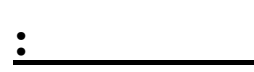

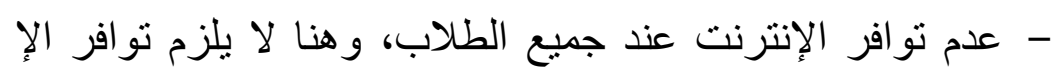

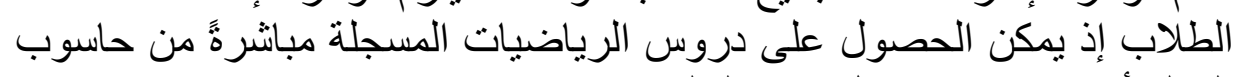

المعلم أو شبكات الاتصال غير السلكي (Wireless/ Bluetooth)

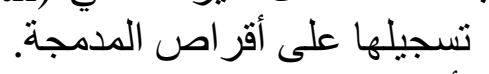

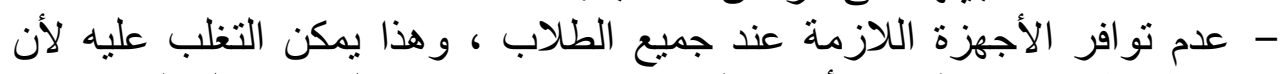

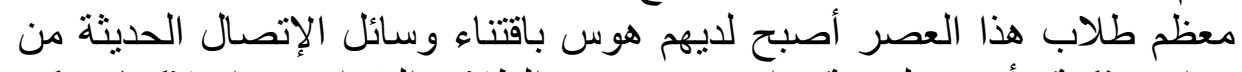
هو اتف ذكية وأجهزة لوحية وإن عجز بعض الطهلاب الفقراء عن امتلاكها فيمكن الإنئ

\section{rvq}


إيجاد طريقة لتوفير ها لهم كمساعدتهم من طرف إدارة المدرسة أو المؤسسات

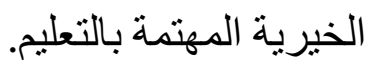

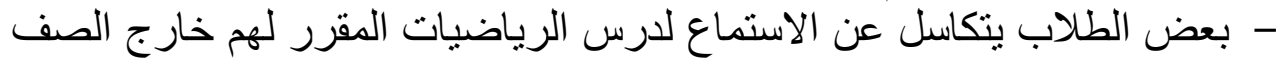

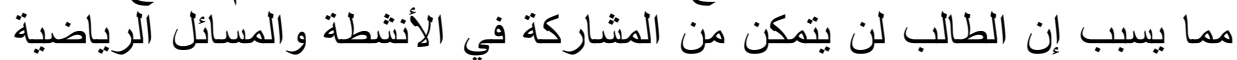

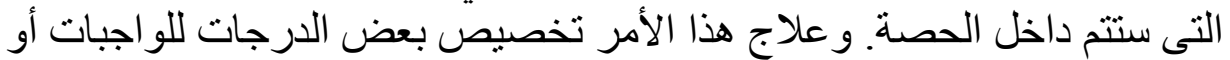

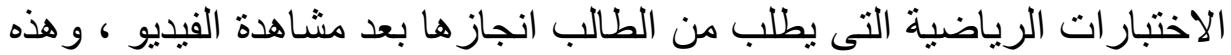
درجات تعكس مدى اجتهاد الطالب في فهم واستيعاب مايتضمنه الفئه الفيديو التعليمى.

\section{خطوات تنفيذ استراتيجية الصفوف المقلوية في العملية التعليمية:}

هات

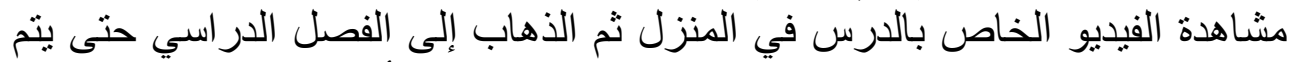

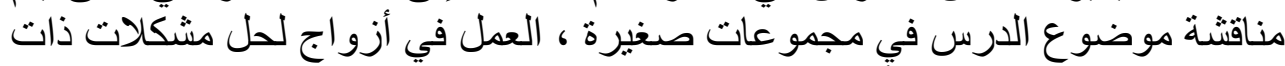

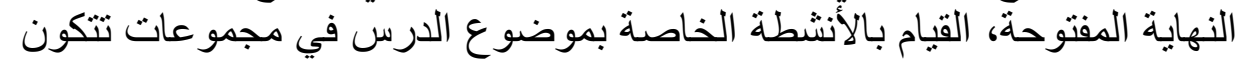

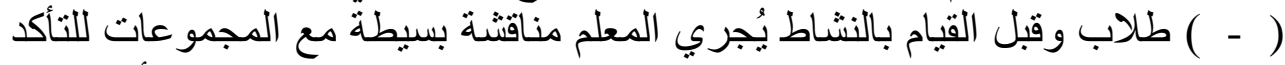

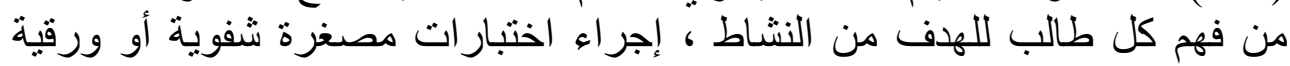
بصورة دورية مع تقديم اختبار في نهاية كل وحدة.

استراتيجية الصفوف المقلوبة

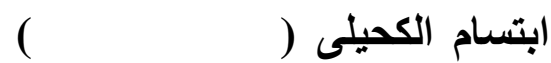

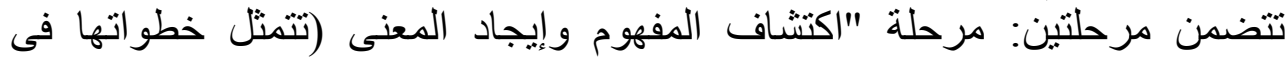

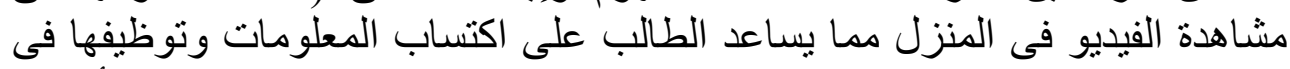

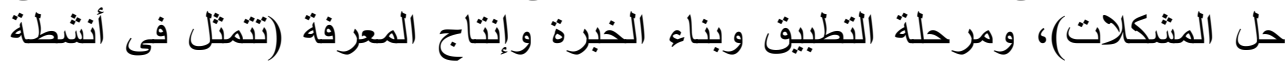

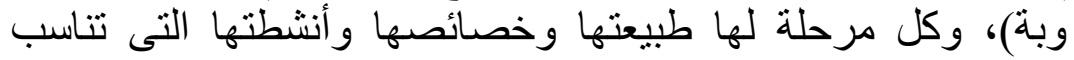

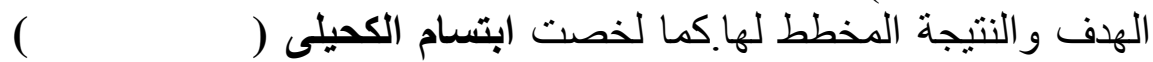

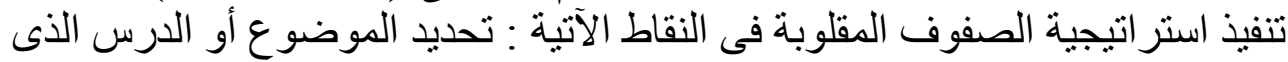

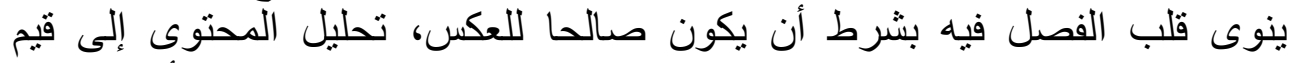

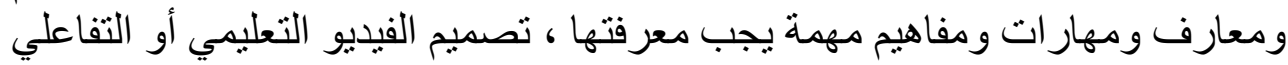

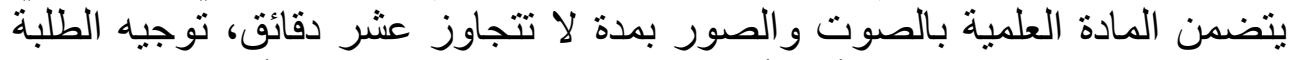

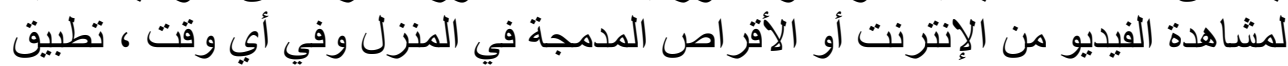

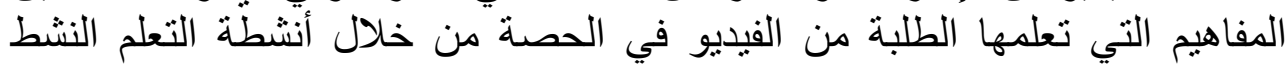

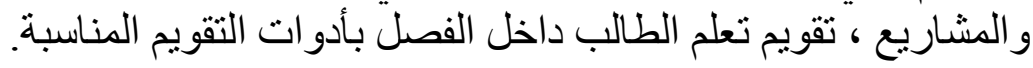

ويمكن توضيح خطوات تنفيذ استراتيجية الصفوف المقلوبة فى العملية التعليمية

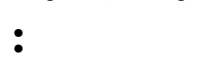




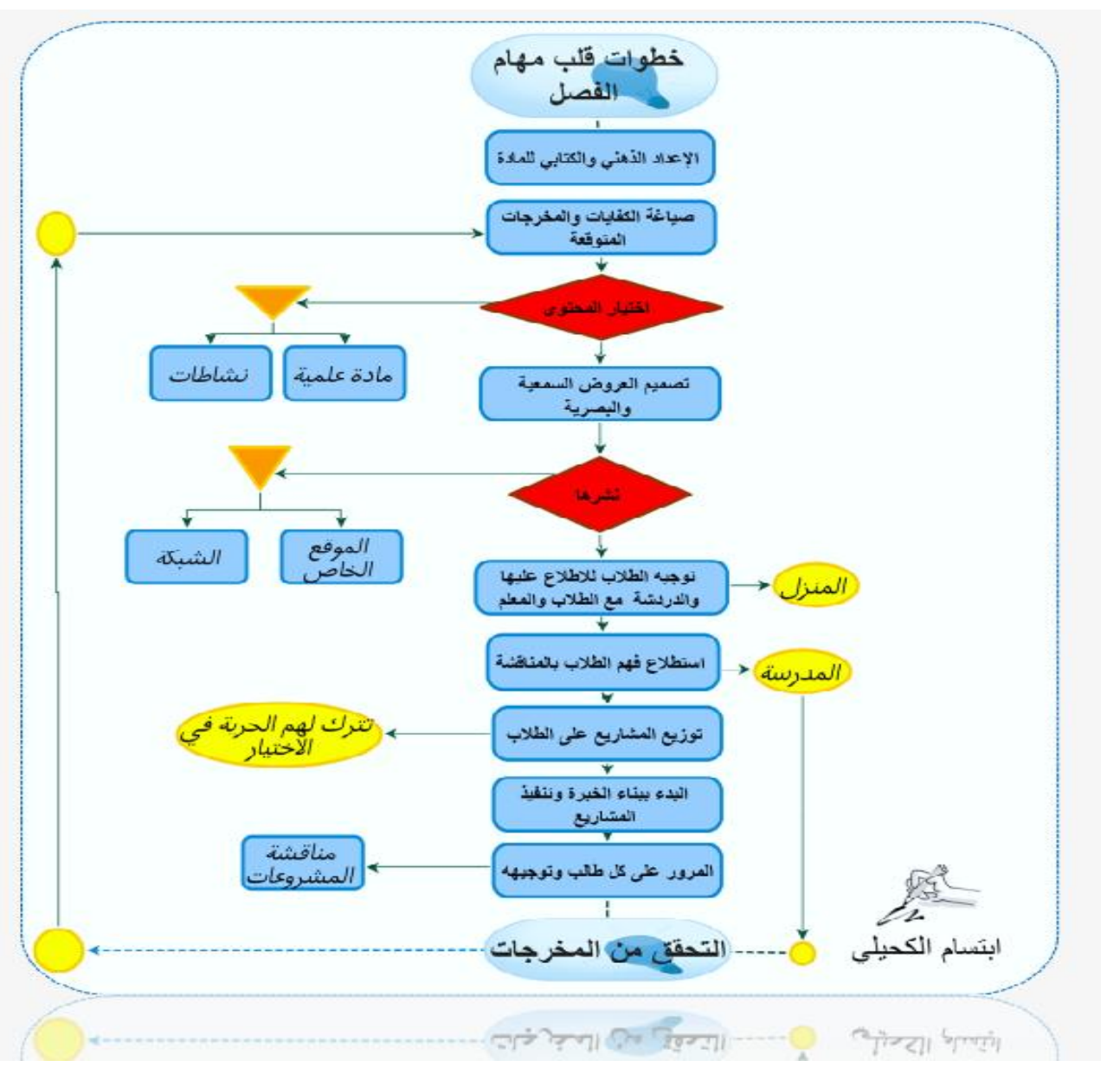

\section{شكل (r) (r)}

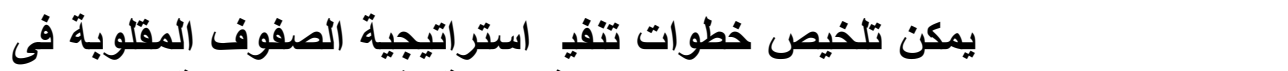

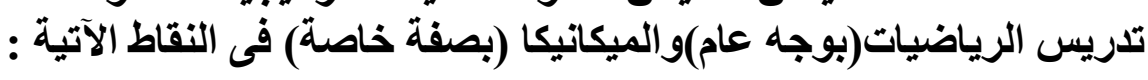

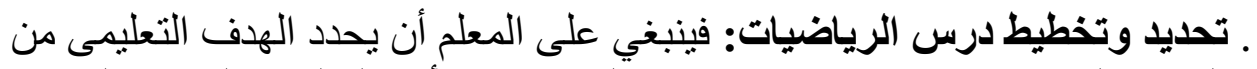

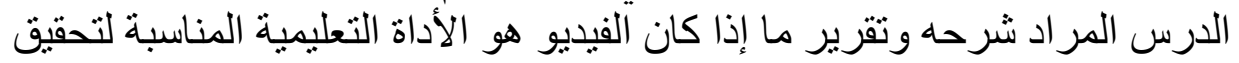

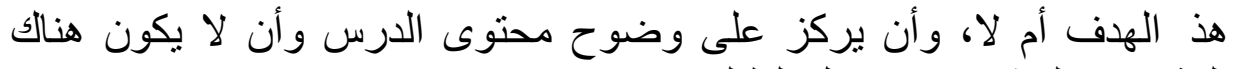

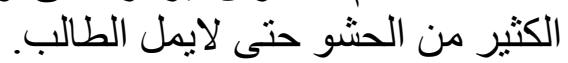

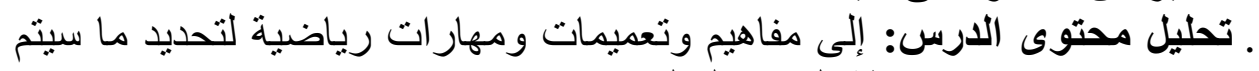
شرحه وتوضيحه بواسطة الفيديو التعليمى . 
ـ تصميم الفيديو التعليمى: متضمن درس الرياضيات بدقة وعناية بحيث يتم

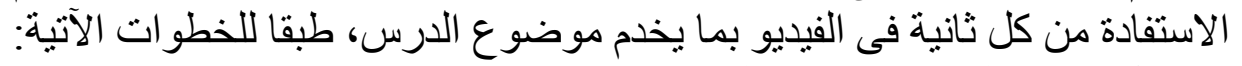

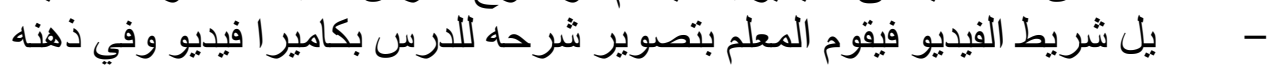

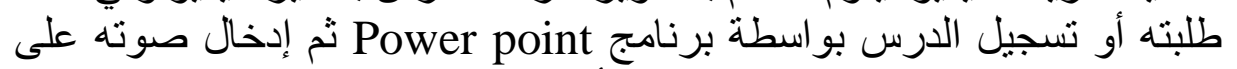

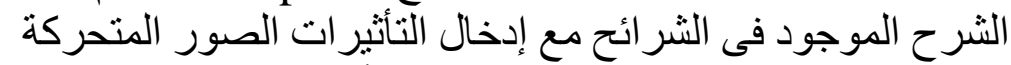

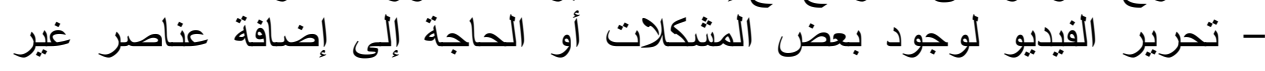

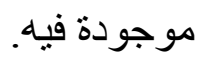

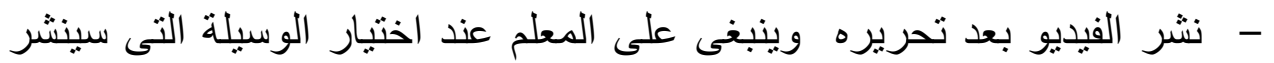

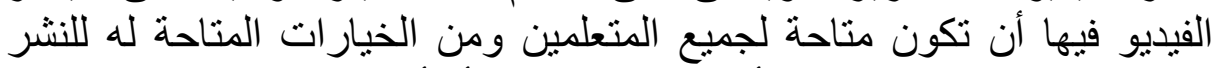

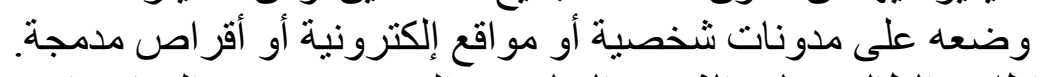

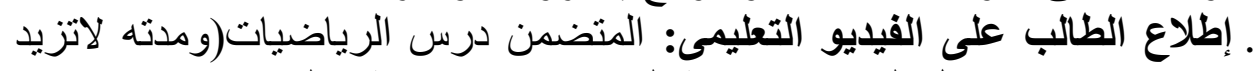

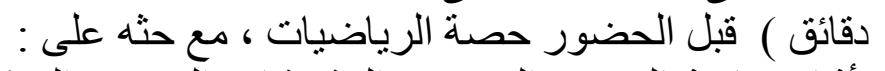

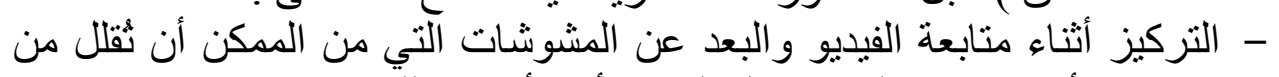

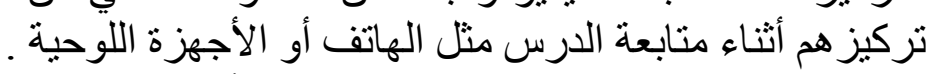

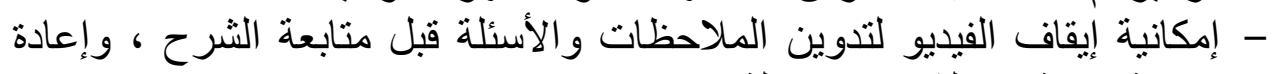

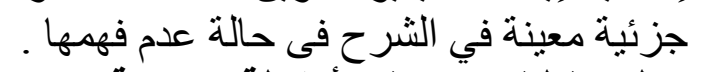

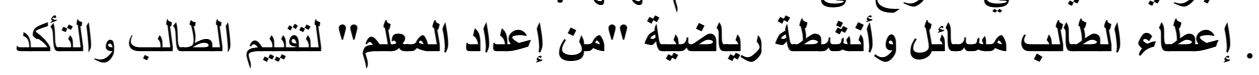

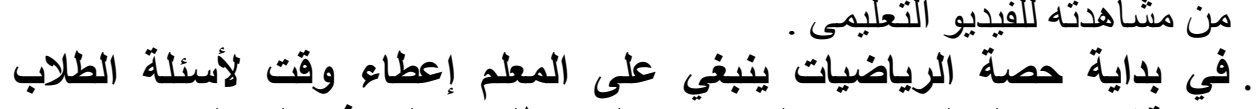

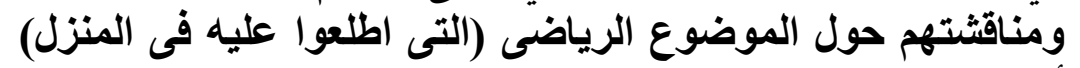

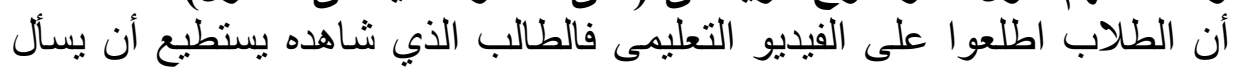

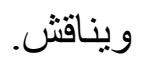

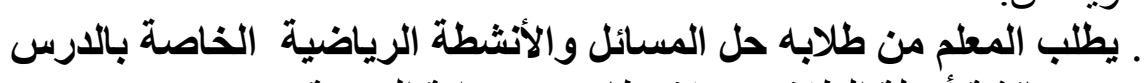

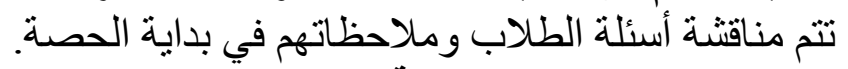

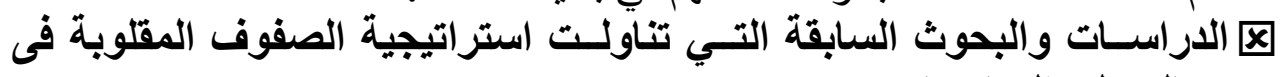

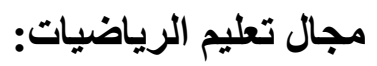

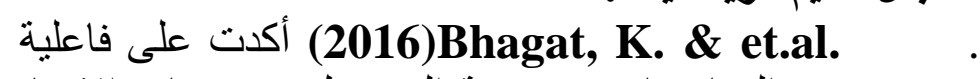

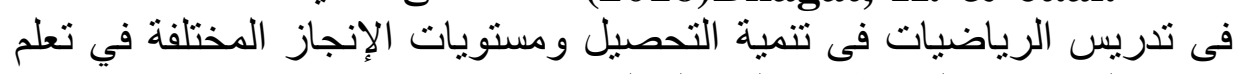

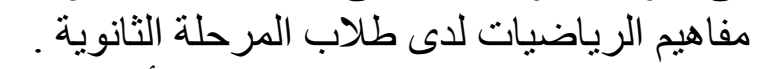

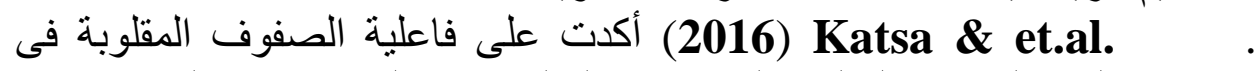

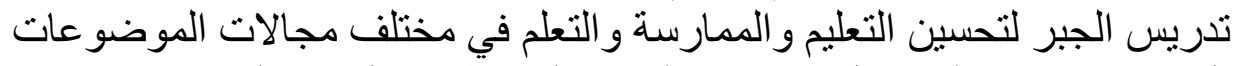

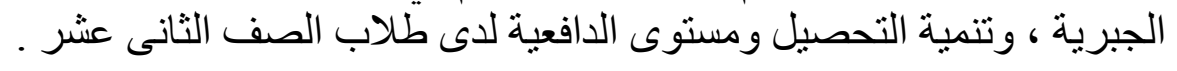




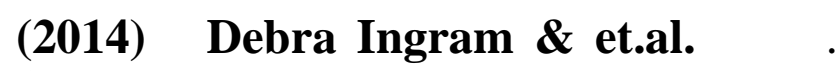

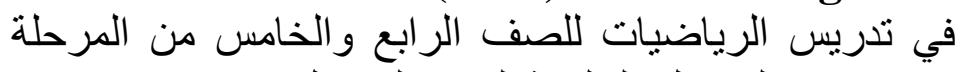

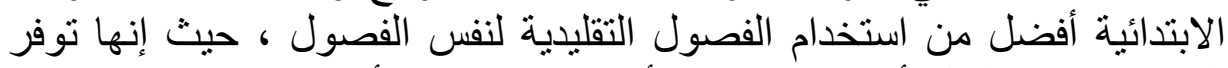

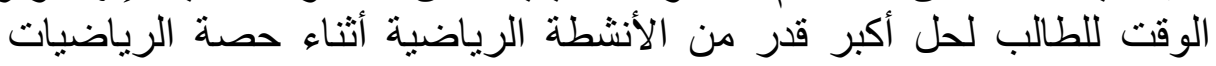

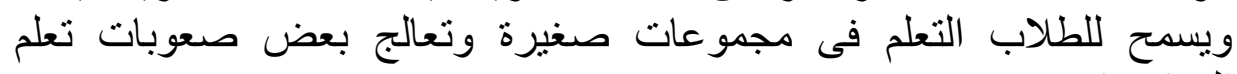

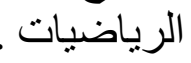

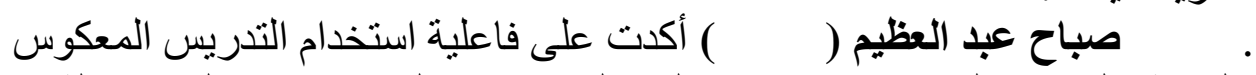

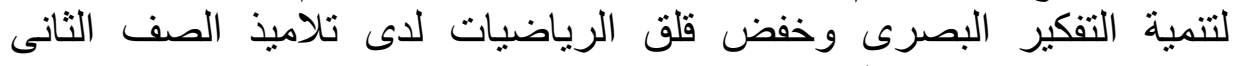
الإعدادى ذوى الإعاقة السمعية .

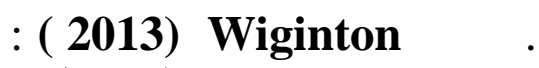

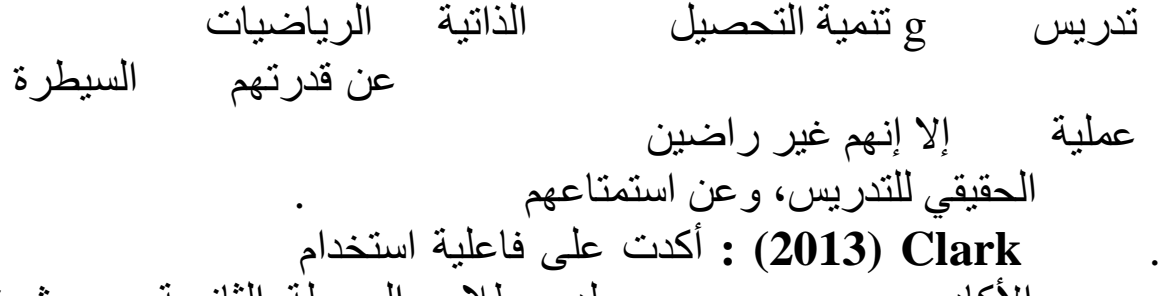

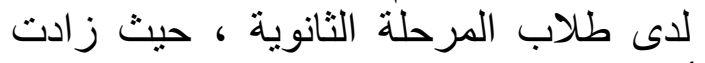

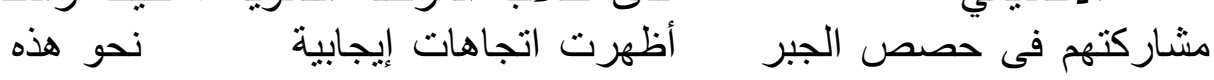

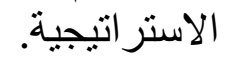

. درلسة Schwankl (2013) : أكدت على فاعلية

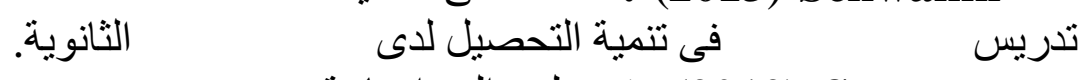
. دراسة Snowden (2012): توصلت إلى إيجابية المقلوبة في التدريس حيث أكدوا على إنها

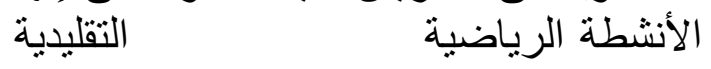

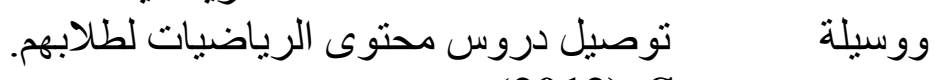
. دراسة Strayer (2012):

تدريس الإحصاء لطلاب الجامعة أكثر انفتاحأ وتأثيرأ من استخدام الفصول التقليدية في التدريس. يليد: الإملاع على البحوث والدرلسلت الساقة الخاصة بهذا المحور نستخلص ما منها فى وضع الإطار النظرى الخاص باستر اتيجية الصفوف المقلوبة ، و إعداد الأدوات التعليمية وتفسير النتارئج. 
• قلة الدراسات التى استخدمت هذه الاستراتيجية فى مجال تعليم الرياضيات الإنيات

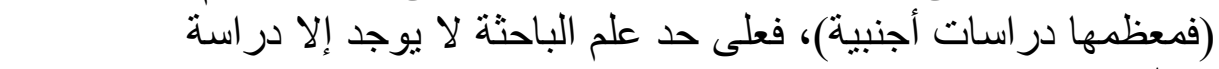

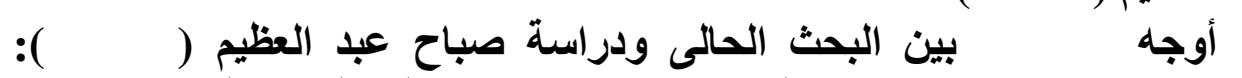

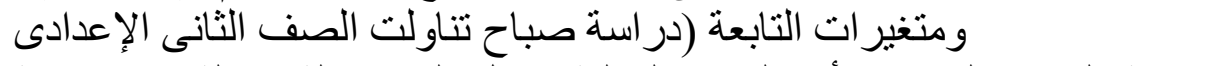

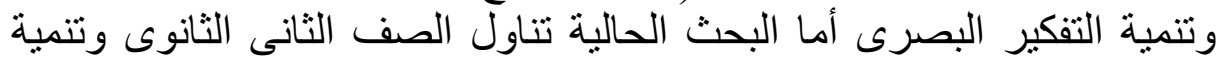

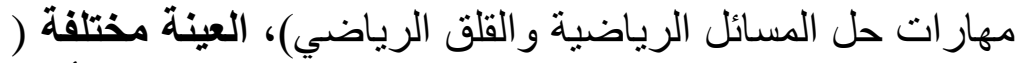

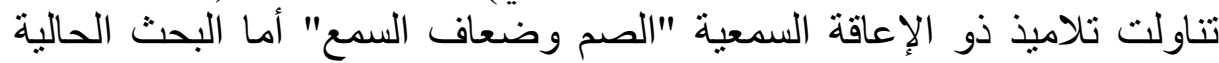

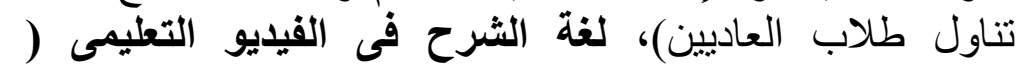
استخدمت التدريس المعكوس من خلال فيديوهات تعليمية لوحئية لوحدة الهندسة

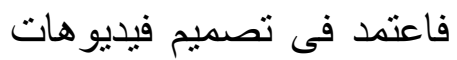

تعليمية لدروس الميكانيكا على صوت المعلم فى شرح الدروس والتأثيرات

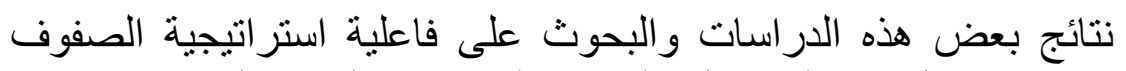

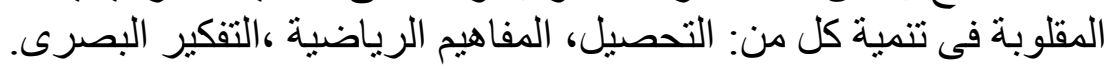

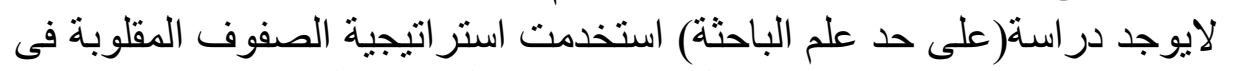

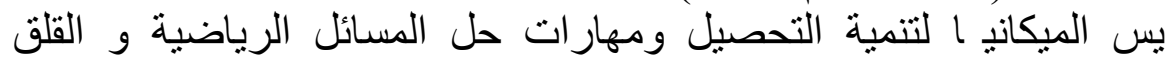
الرياضى نحو دراستها.

ثانياً: مهارات حل المسألة الرياضية:

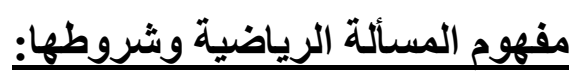

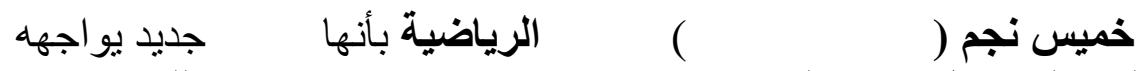

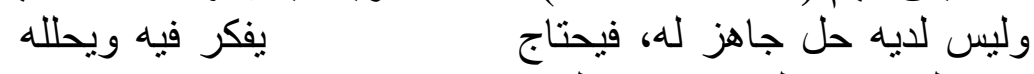

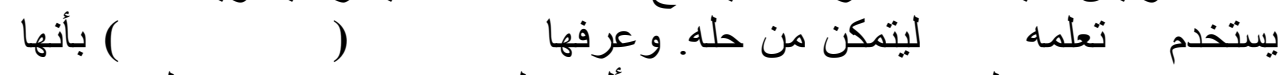
لايه

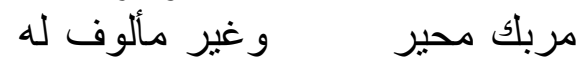

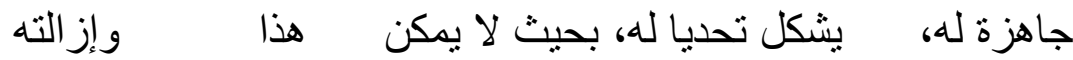

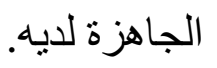

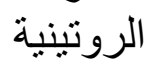

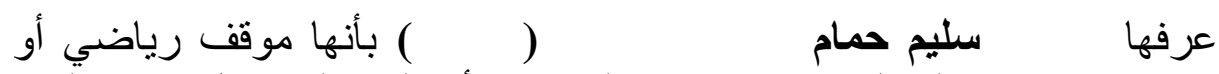

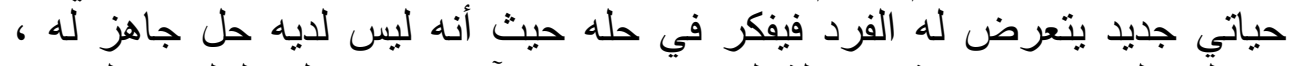

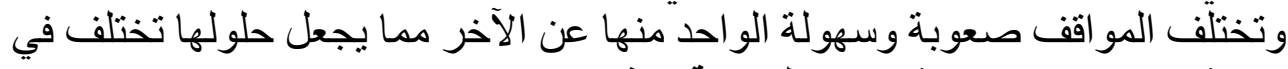

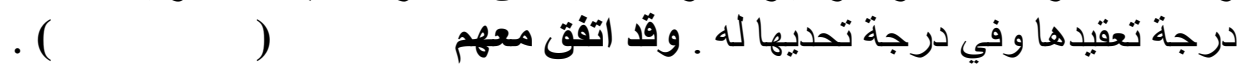




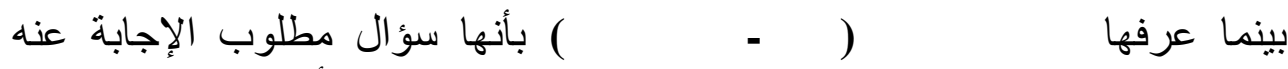

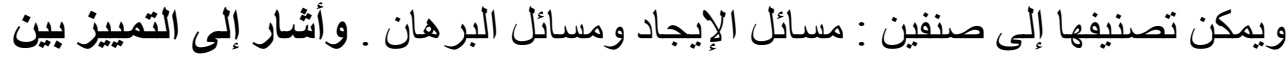

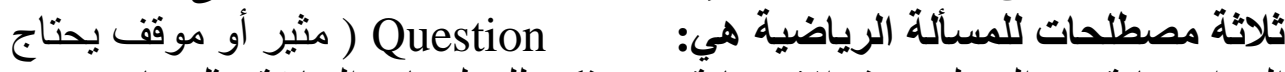

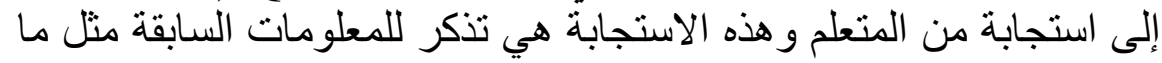

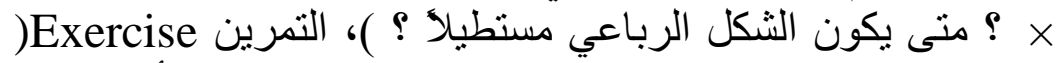

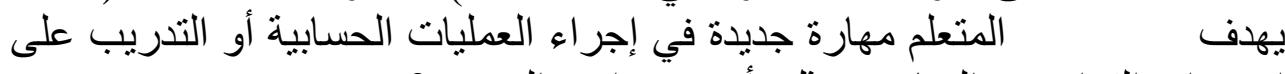

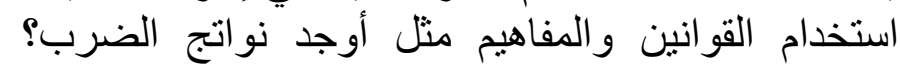

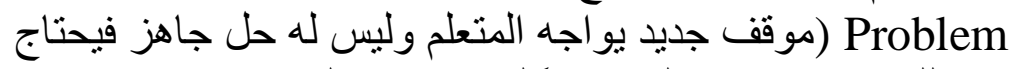
المتعلم أن يفكر فيه ويحلاه ويستخدم ما تعلمه سابقاً ليتمكن من حله ) .

ومحير تنظيم معرفته بناءً على ما سبق عرفت المسألة الرياضية بأنها

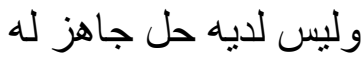
يو اجهه

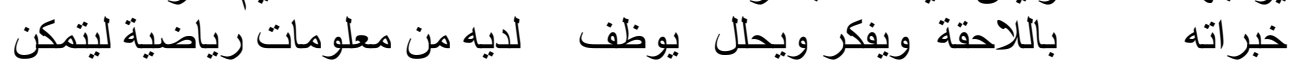
حلها.

الرياضية : بكون : يكون قوى لتحقيقه، يوجد يحاول

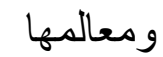

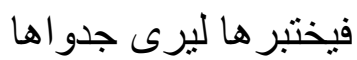

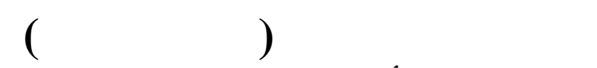
يكون له هدف الفي (القيام حيث يقوم بتحديد فرضيات
بالمسألة وينبغني

تحقيق هدفه

للإف

ه المسألة وتتبين ه له

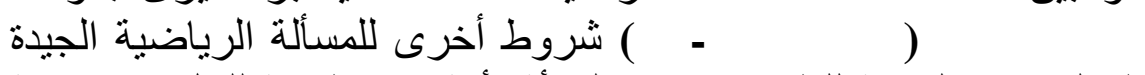

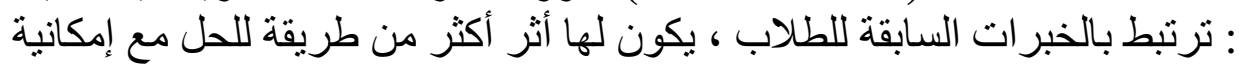

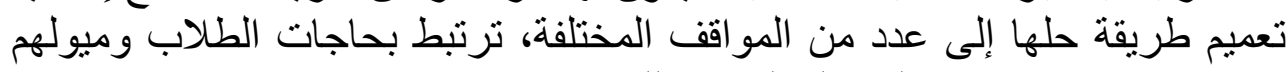
وتثير اهتمامهم ، تتاسب المرحلة العمرية للطلاب.

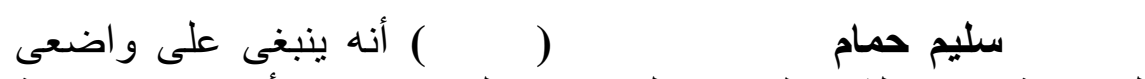

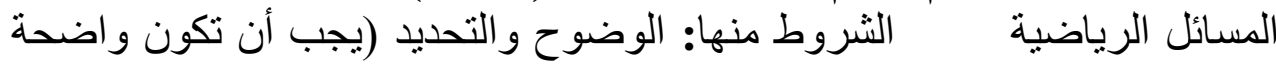

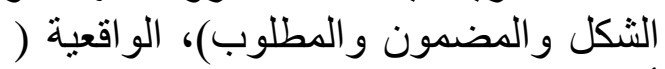

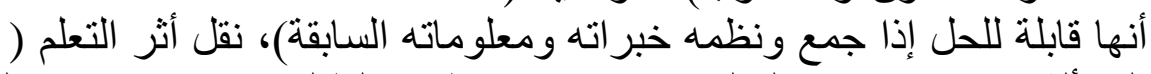

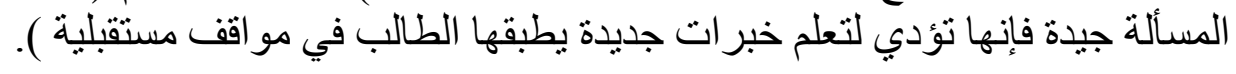

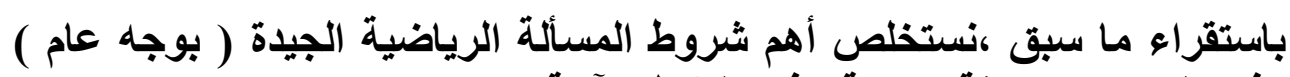

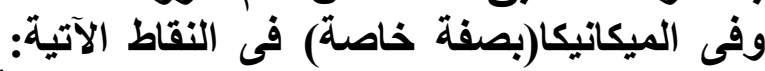

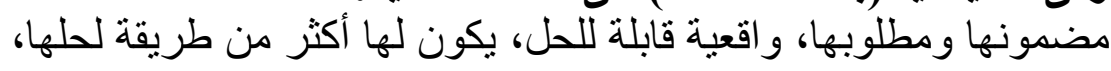


خصائص نمو المتعلم، تكف المعطيات المتضمنة بها لإيجاد الحل المطلوب، مثيرة

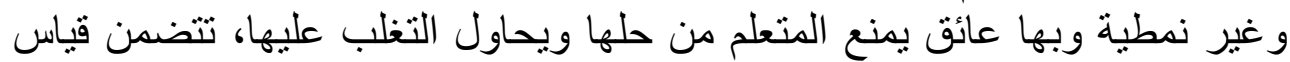

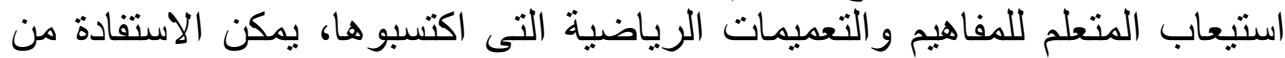

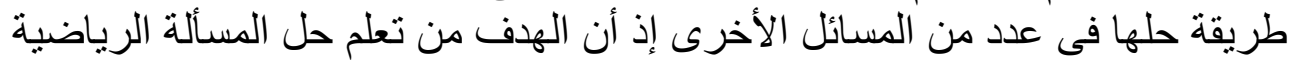

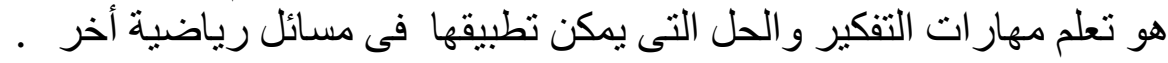

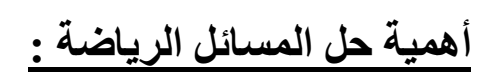

حل المسألة الرياضية له أهمية عظمى في تعليم وتعلم الرياضيات منهاء:

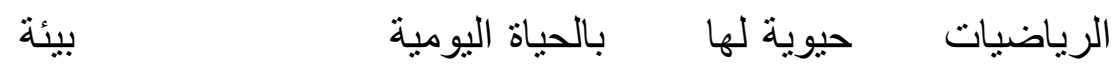
ومثيرة للتفكير و الاستقصاء وحب الاستطلاع و الدافعية للتعلم لدى لينة

كثير آ ما يتذكر المتعلم المفاهيم و التعميمات الرياضية كان قد نسيها نظر أ لحاجته إليها في حلها. الإكنا. • وسيلة لإكساب المفاهيم والتعميمات و المهارات الرياضية

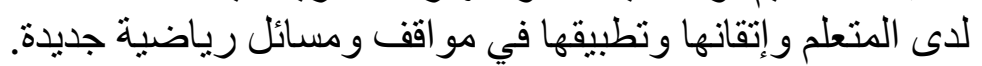

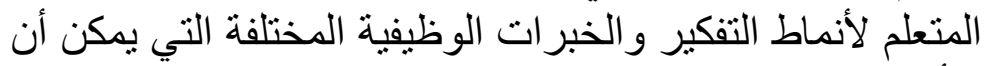
• موسيلة

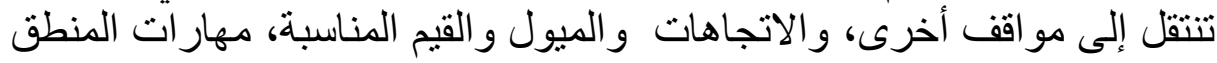
مستويات المعرفة إلى ما ور اء المعرفة ، القيام الرياضي و المنطق الجَّلَي. بعمليات عقلية عليا فيصوغ الفرضيات و يختبر ها حتى يصل إلى الى الحل الصحيح.

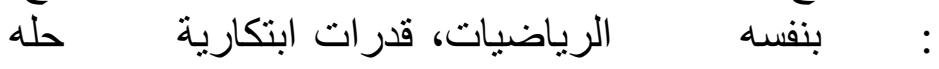

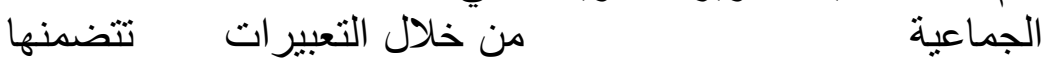
للمسألة ينظم هذه

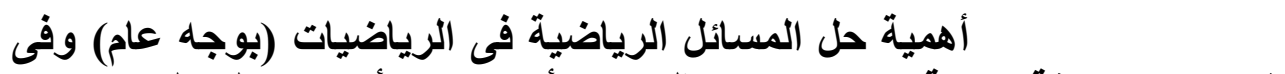

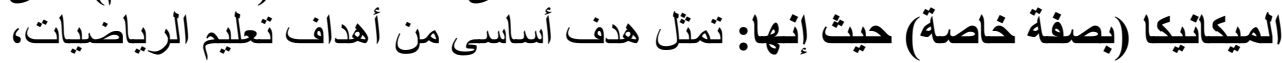

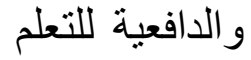
بيئة للتفكير الدافعية لتعلم الرياضيات

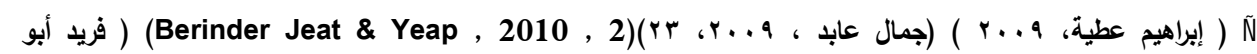

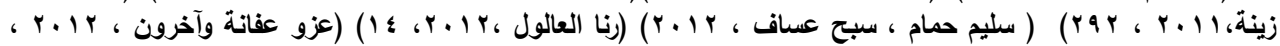

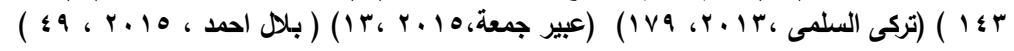


لايه، تدربه على ربط ما لديه من مفاهيم وتعميمات ومهار ات رياضية سابقة بالجديدة

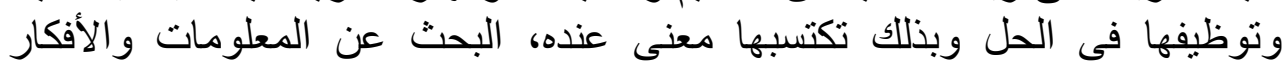

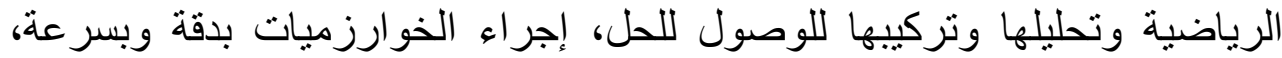

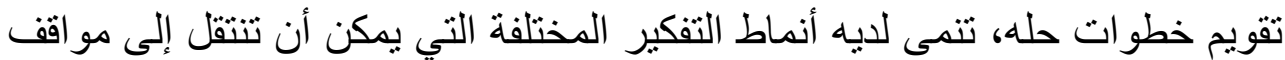

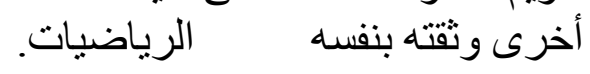

\section{مفهوم مهارات حل المسائل الرياضية:}

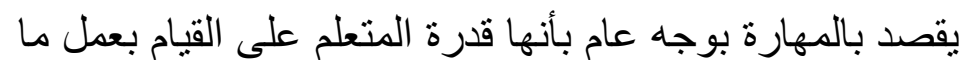

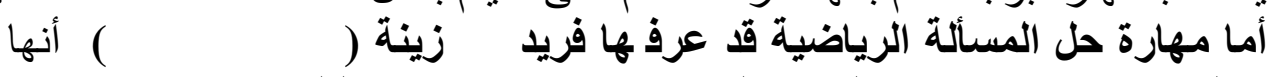

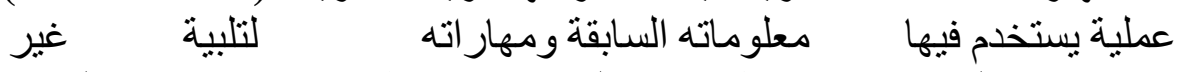
يواجهه، و عليه يعيد تنظيم تعلمه سابقا ويطبقه

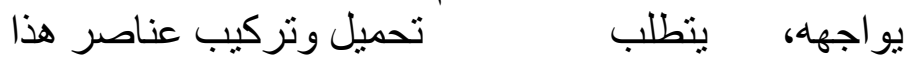

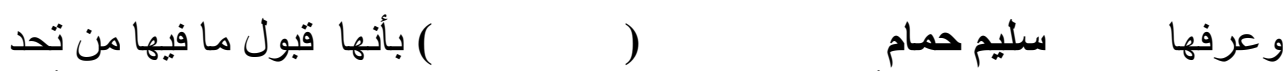

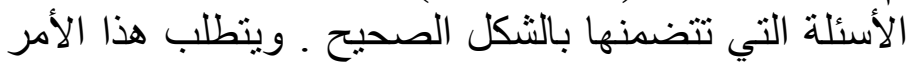

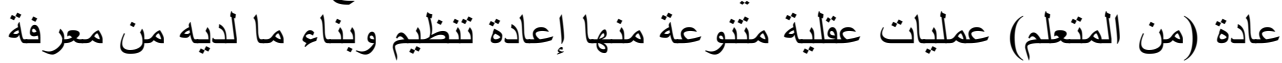
ومعلومات سابقة واستخدامها وتوظيفها في حل المسألة .

بناءً على ما سبق ، تعرف مهارات حل المسائل الرياضية إجرائيا بأنها قدرة

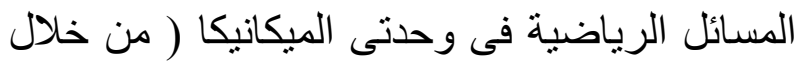

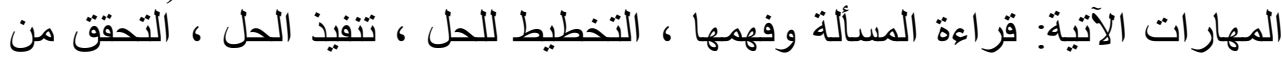

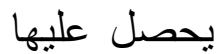

نستنتج أن اكتساب المتعلم لمهارات حل

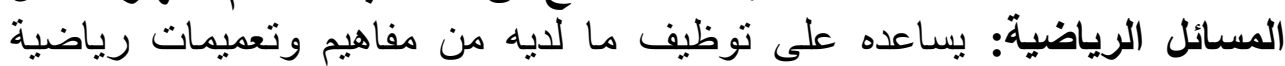

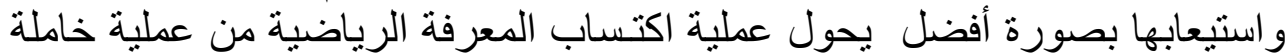

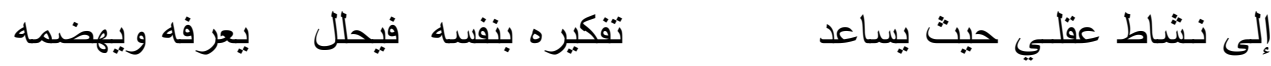

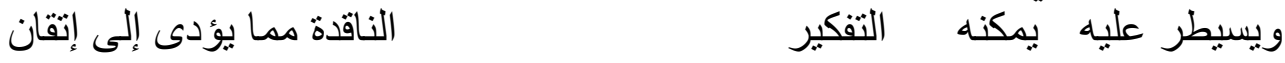
يعتبر همزة الوصل بين علم الفي إنمان

الرياضيات المجرد وبين ممارسته لمهار ات حل المسألة الرياضية. 
مهارات حل المسائل الرياضية:

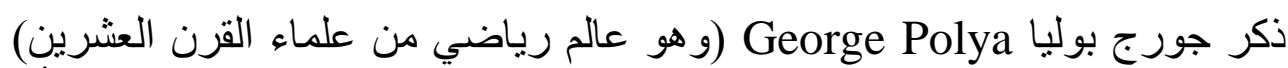

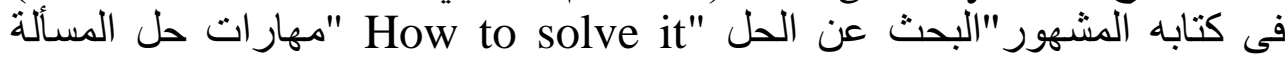

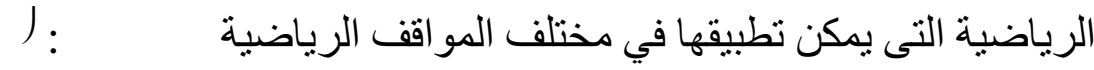

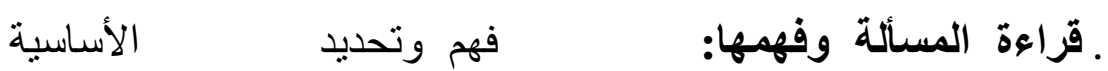
الرياضية وهى المعطيات بلغته

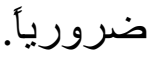

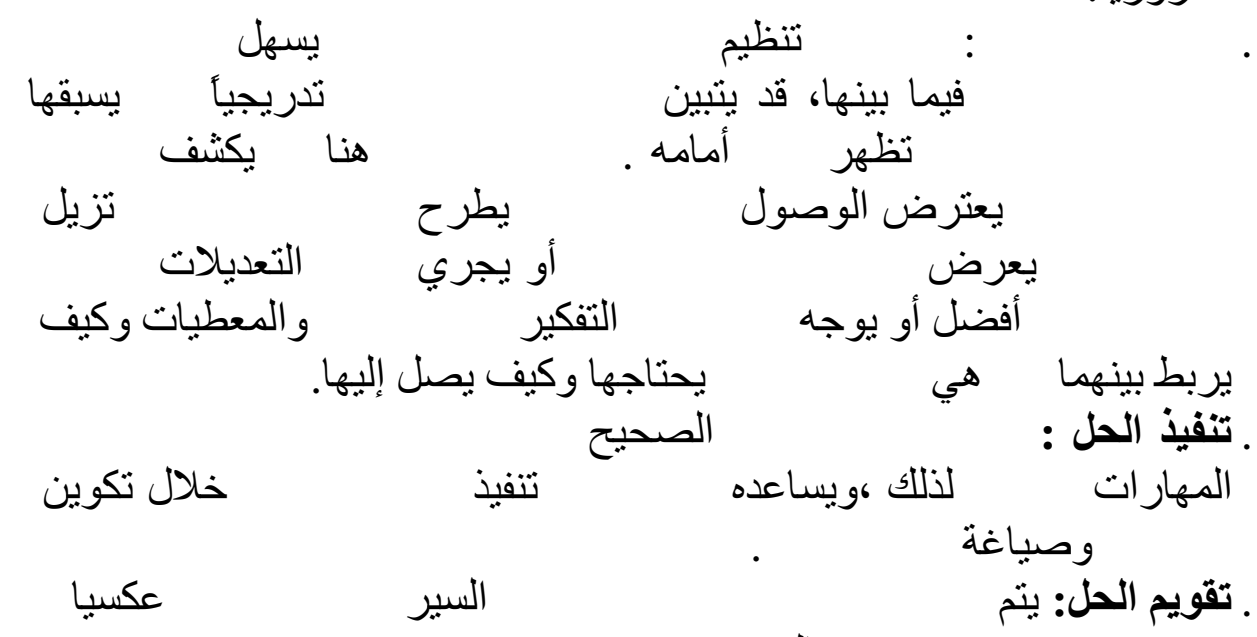

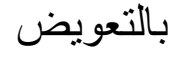

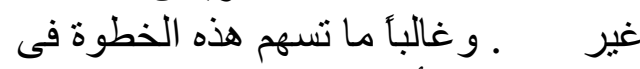
الخطوات الناقصة أو الجواب النهائى غير صحئ صليح.

ونستخلص مما سبق مهارات حل المسائل الرياضية فى الرياضيات ( بوجه أنه عام )

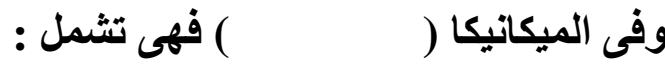

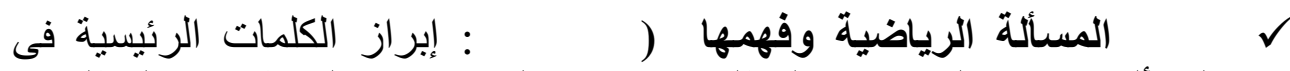

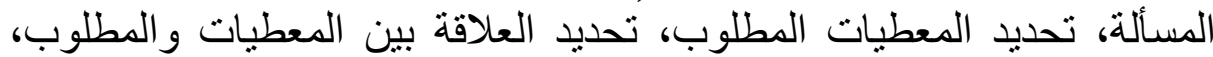

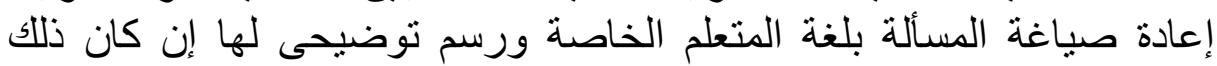
ضروريأ، تحديد المعلومات الناقصة و اللازمة للحل). 


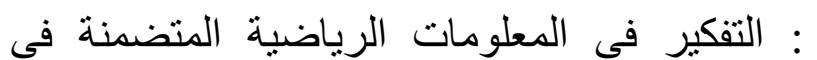

) ل

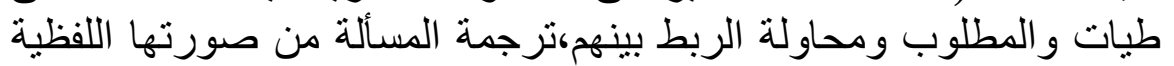

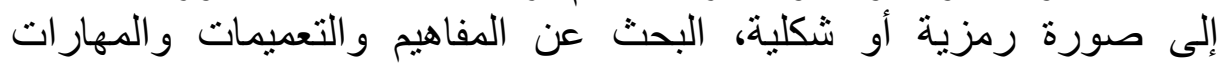

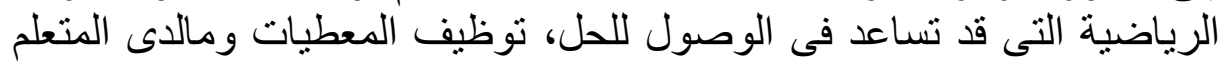

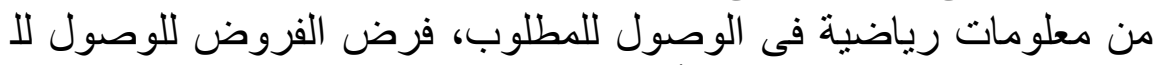

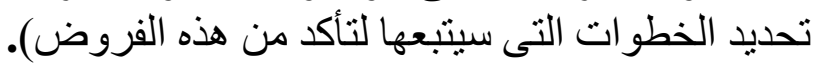

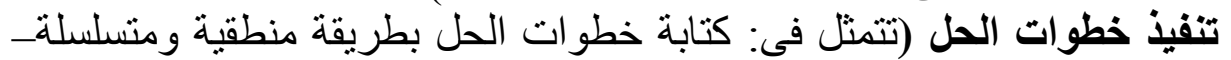
التأكد من كل خطوة من خطو ات الحل وتبرير هاــ كتابة الحل النهائى للمسألة ). عكسياً،

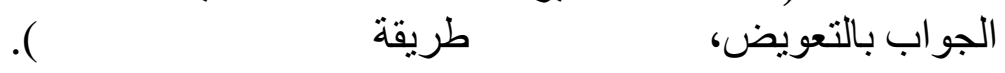

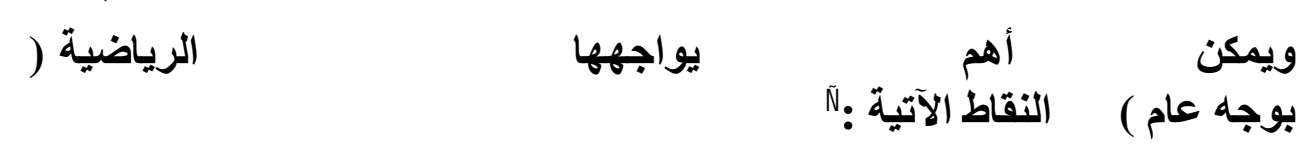

المسألة الرياضية من مفاهيم

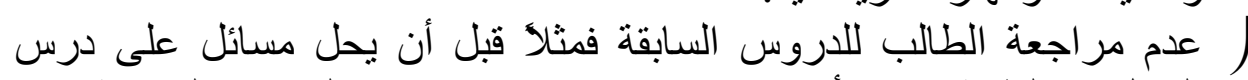

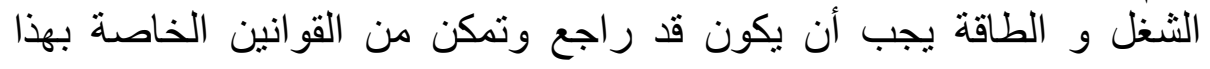

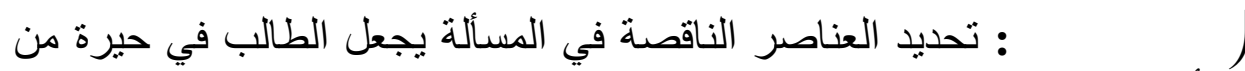

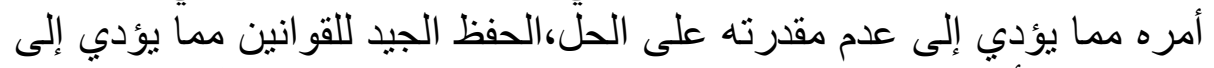

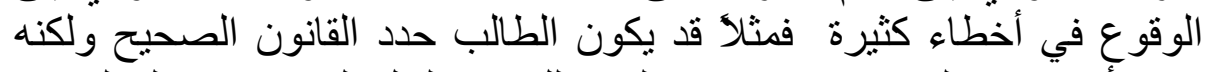

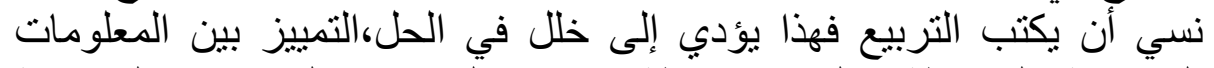

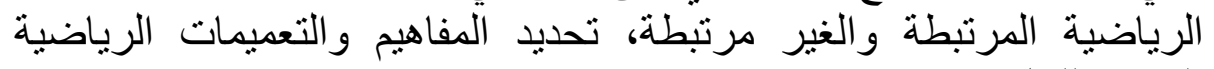

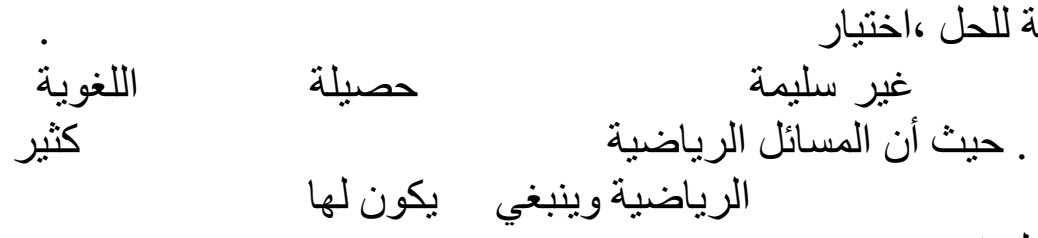
اللازمة للحل ، اختيار

يتسنى لله فهم

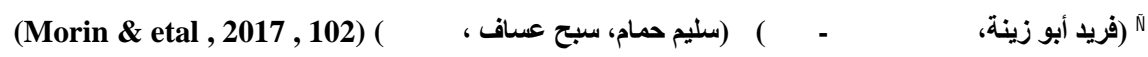




$$
\text { وعدم تنظيمها والقدرة }
$$

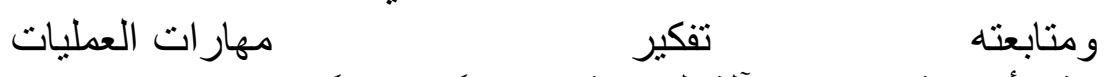

الحسابية الأساسية استخدام الآلة الحاسبة استخدامًا صحيحًا .

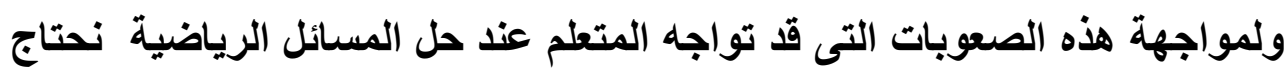

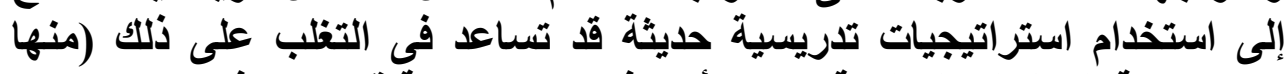

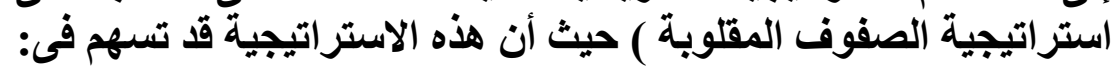

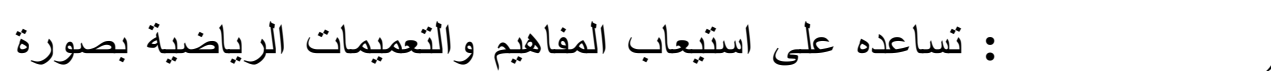

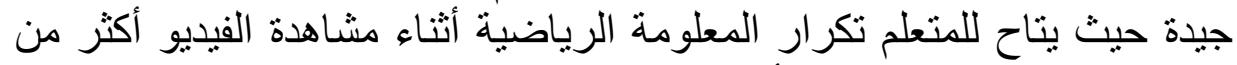

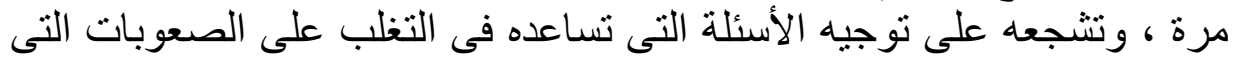

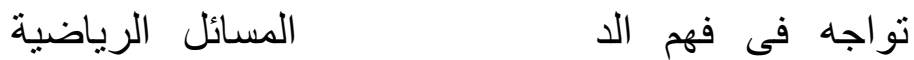

$$
\begin{aligned}
& \text { و الموضو المية في في الحكم على خطو ات الحل. }
\end{aligned}
$$

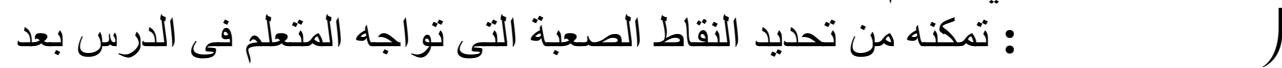

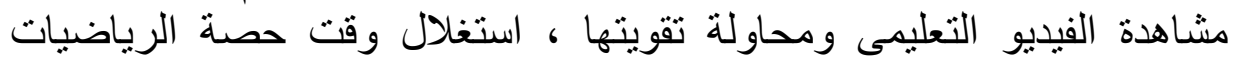
لتوفير الوقت للطلاب على التدريب على حلى الكير أكبر عدد من المسائل الرياضية الرياضية

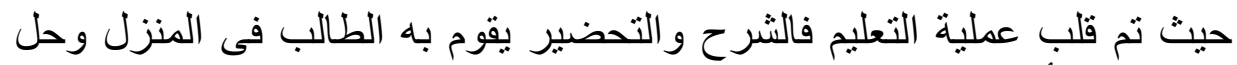

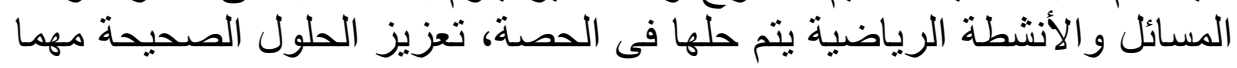

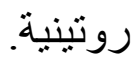

ومسن الاراســات والبحوث السابقة التـى اهتمت بتنمية مهارات حل المسائل

$$
\text { الرياضية: }
$$

. دراسة Morin\& et.al.

نموذج الرسم وحل المشكلة فى تنمية مهار اتل حل المسائل الرياضية لإى تلاميذ المرحلة الإبتدائية.

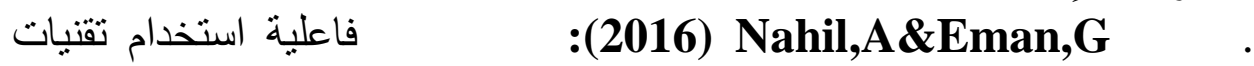

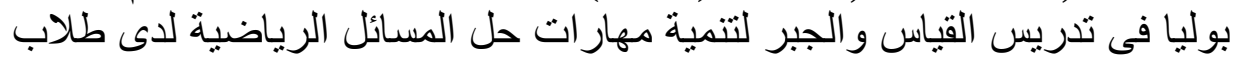

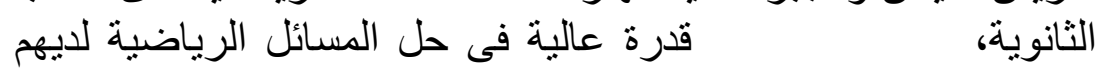

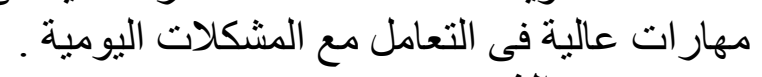

استر اتيجية التدريس

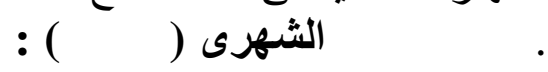

$$
\text { تلتمية مهار ات }
$$




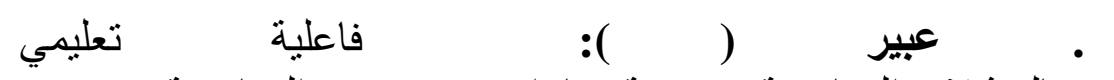

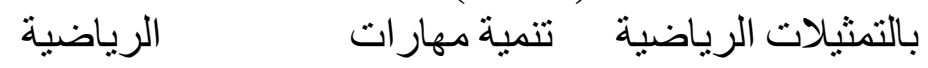

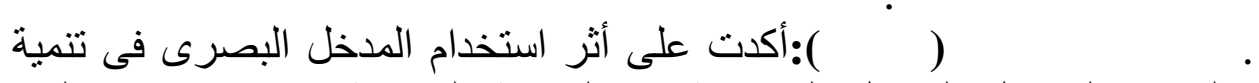

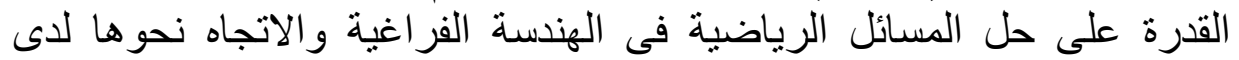

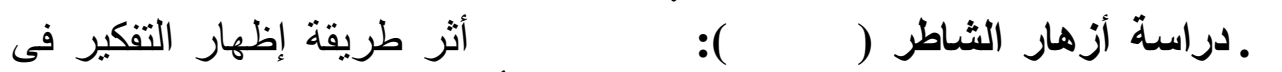

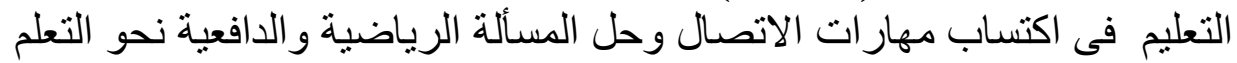

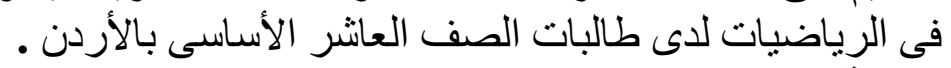

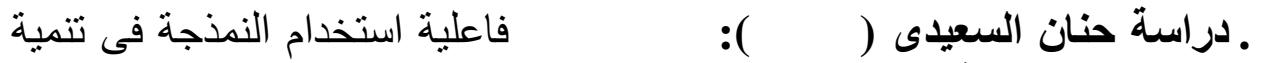

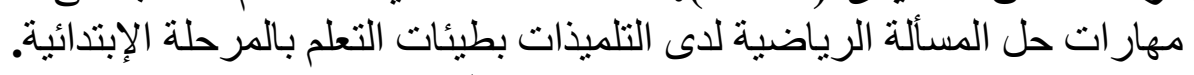

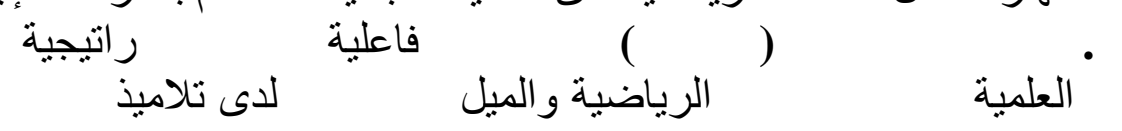

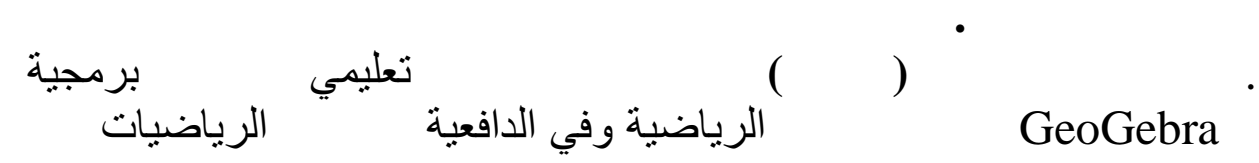

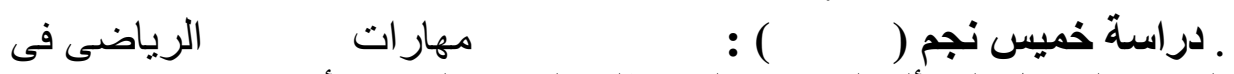

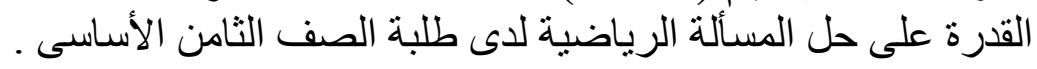

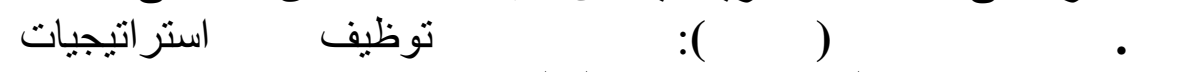

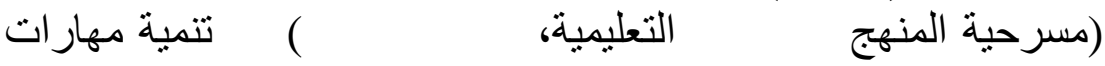

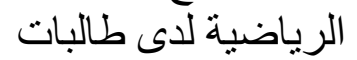

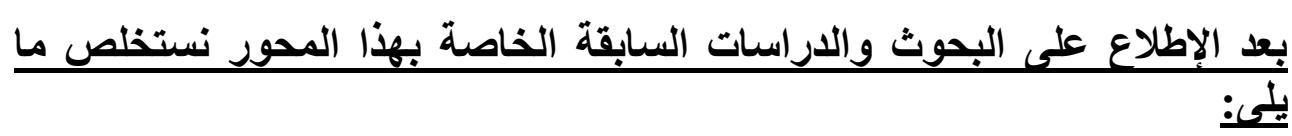

منها فى وضع الإطار النظرى الخاص بمهار ات حل المسألة الرياضية،

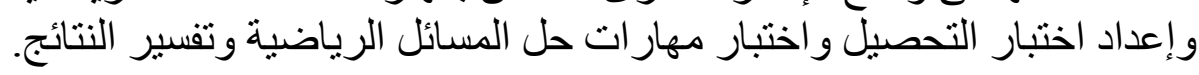

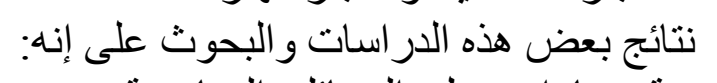

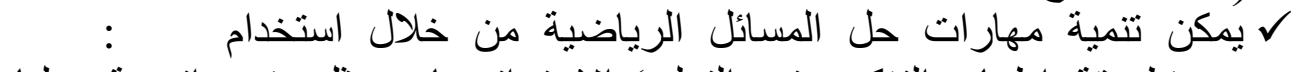

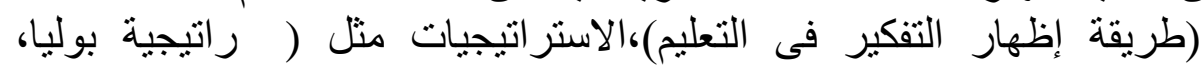

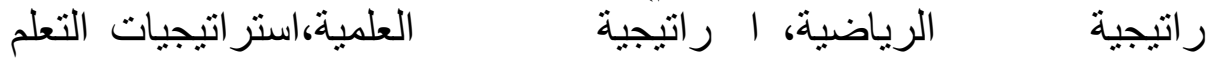


بالتمثيلات

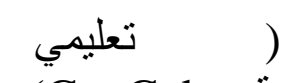

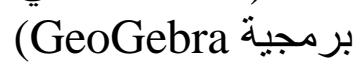

V هناك علاقة طردية بين التحصيل ومهار اتل حل المسائل الرياضية.

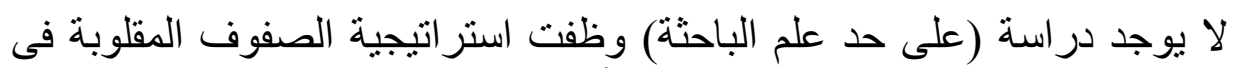
تدريس الميكانيكا لتنمية مهار ات حل المسألة الرياضية الخاصة بلئة بها.

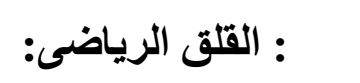

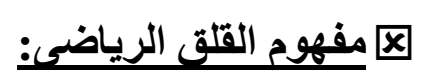

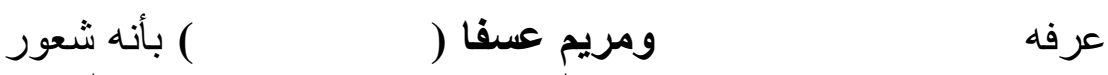

$$
\begin{aligned}
& \text { يعتريه }
\end{aligned}
$$

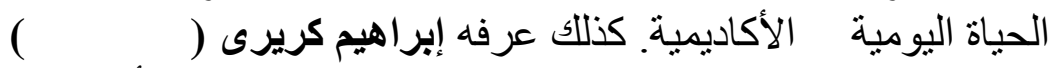

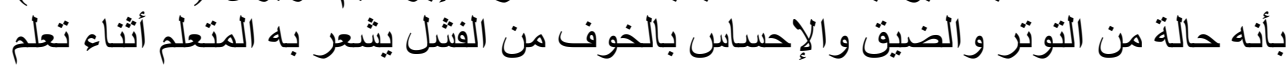

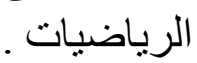

و عرفه المفاهيم و التعميمات الرياضية وحل

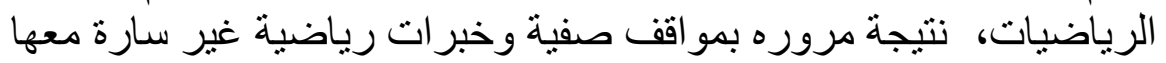

مما يؤثر سلبياً على تعلمه للرياضيات ونيات وتحصيله وقدرته على حل المسائل الرياضية.

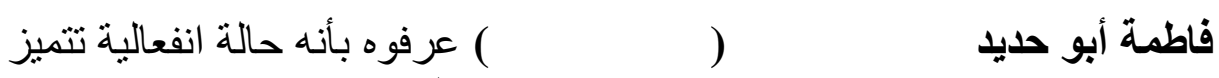

$$
\text { نحو الرياضيات وكر اهيتهاية }
$$$$
\text { يشعر خارجها. }
$$

بناء على ما سبق ، يمكن تعريف القلق الرياضى نحو دراسة مادة الميكانيكا بأنه

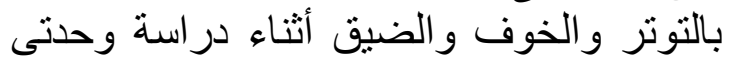

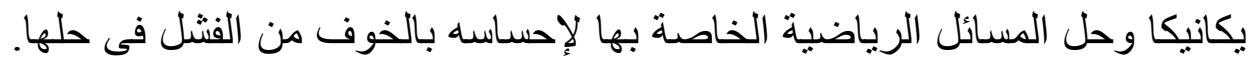

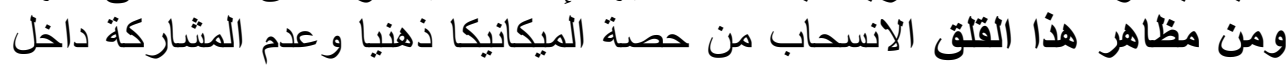

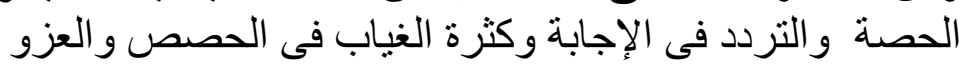
الرياضية وحلها. 
وباستقراء العديد من الأدبيات التربوية، يمكن تلخيص أهم الأسباب التى يعزى إليها القلق الرياضى :

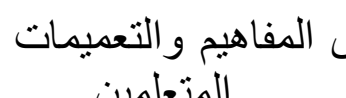
المتعلمين المغيمات

للمفاهيم

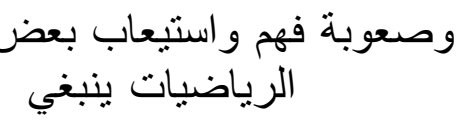

$$
\text { الاكتثاف و التفكير و البعد }
$$

$$
\text { و التعميمات و المهار ات لرياضية. }
$$

السلبية

تقدير

• ضعف قرر ات الطالب و انخفاض تحصيله في الرياضيات.

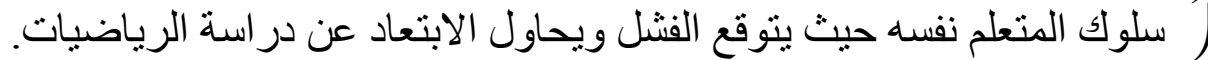
ه المعلم و استر اتيجيات التدريس و الأنشطة و الوسائل التعليمية و أساليب التقويم التئى التئي

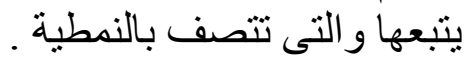

$$
\text { ه الضغط الأسرى المتمثل فى العقاب من الو الدين . }
$$

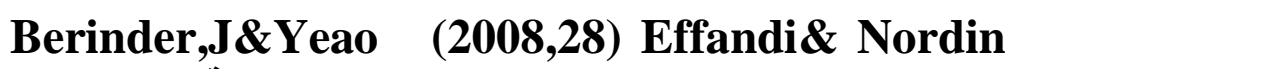

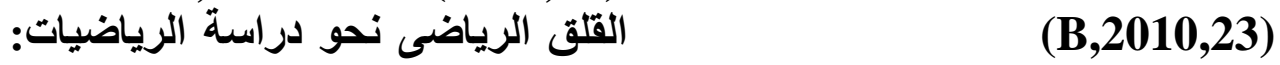

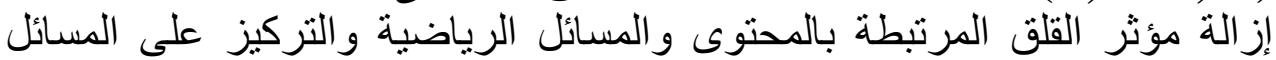

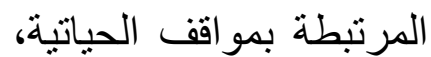

تدريب الطلاب على مهارات حل المسائل الرياضية وليس الحل النهائى ولئي

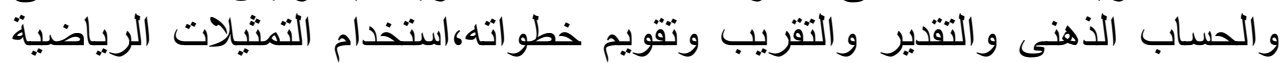

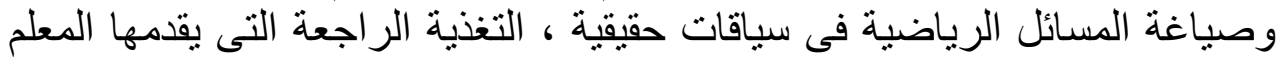

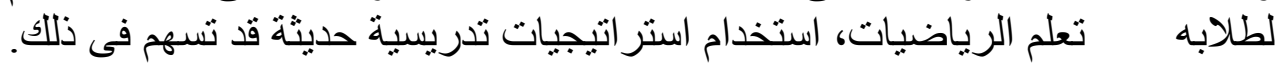

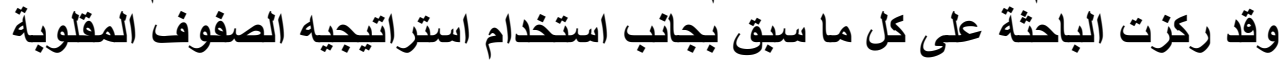

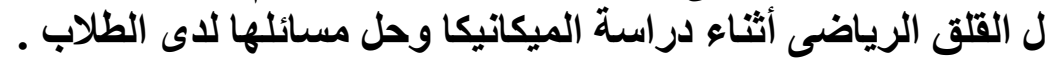
囚 العلاقة بين القلق الرياضى ويين كل من التحصيل ومهارات حل المسائل العلاقة بين التحصيل و القلق الرياضى،

يؤدي زيادة التحصيل و هذا ما يسمى بئي يمكن يسهم 


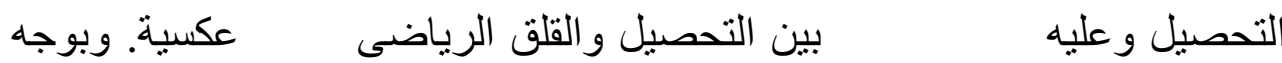

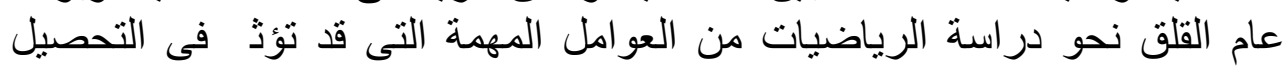

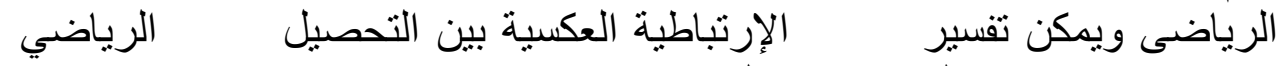

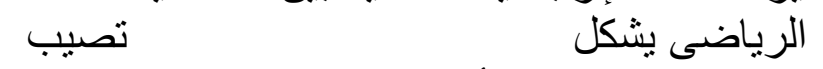

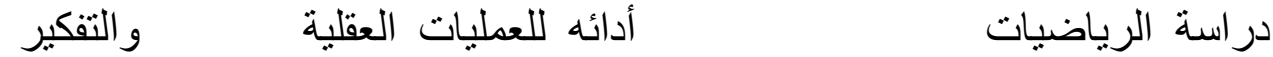
و التركيز وكلها عمليات لازمة لتحسين التحصيل

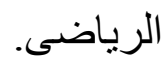

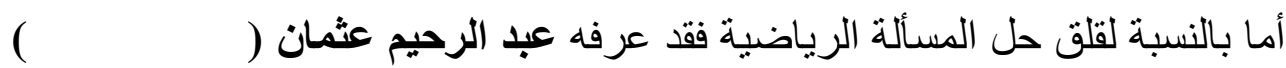

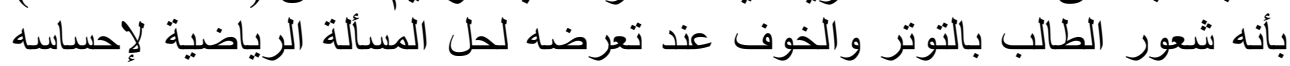
بعدم تحقيق النجاح فى حلها.

\section{ودرلسة(عدنان العابد، سهيلة (Maloney \& Beiock,2012)}

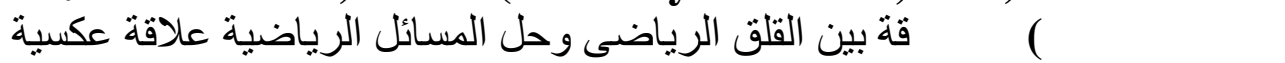

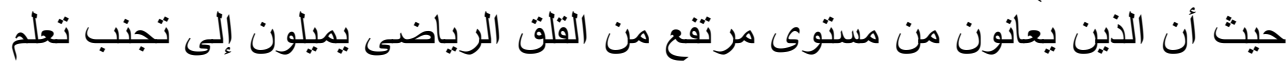

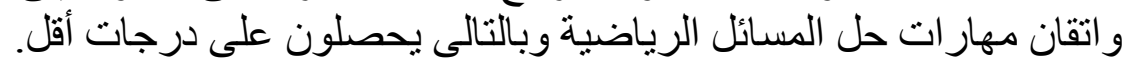

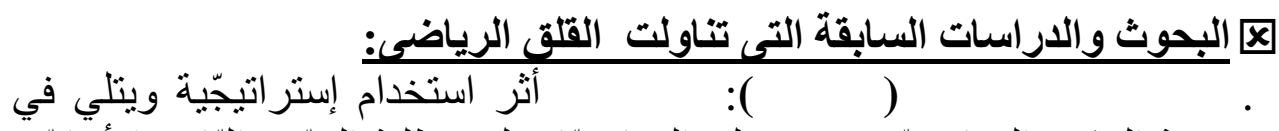
تتمية التفكير الرياضيّ وخفض فلق الرياضيّات لدى طلبة الصّف الثّاسع الأستاستي فيّي

دراسة Arturo, G \& etal د):أكدت على أن القلق الرياضي شعور

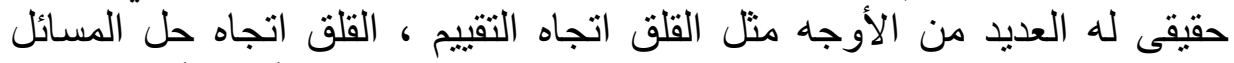

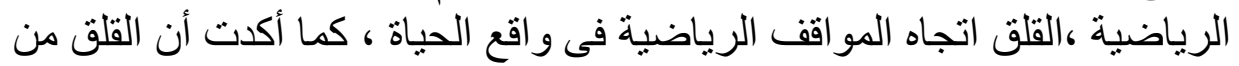

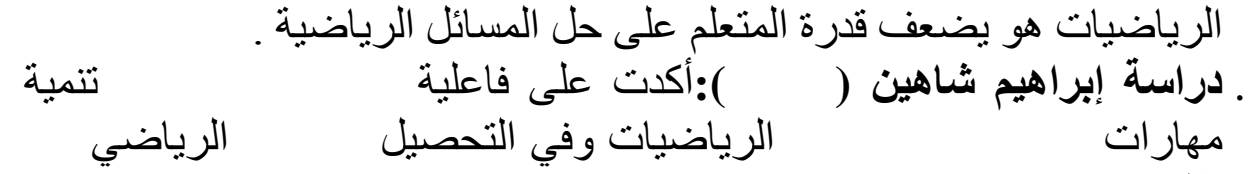
برمجية الرياضيّة

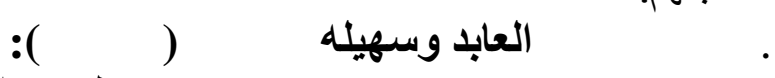
دراسة عدير. الأساسية العليا.

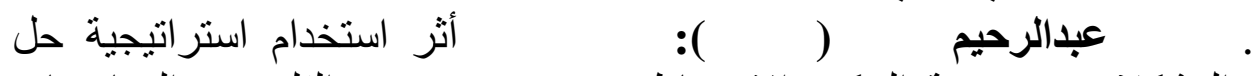

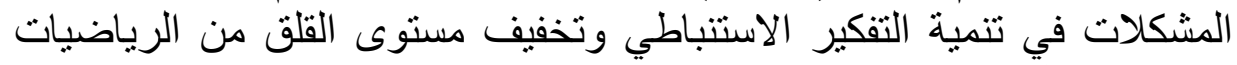
لاى تلاميذ الصف في الثانى الإعدادى. 


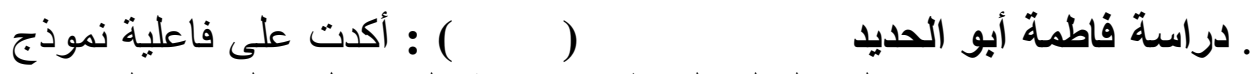

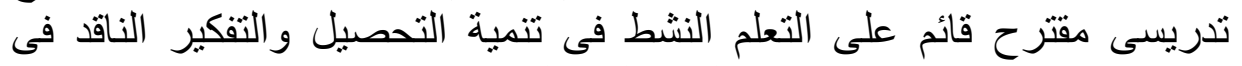

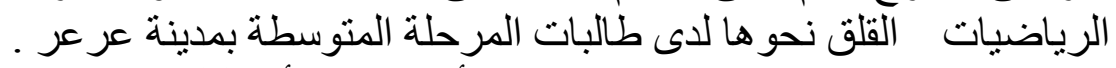

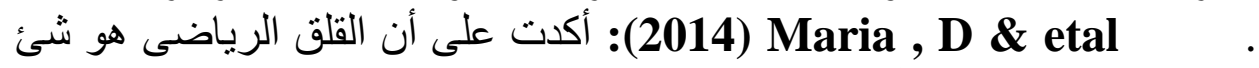

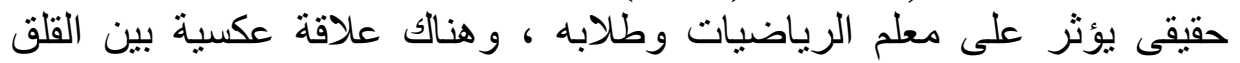

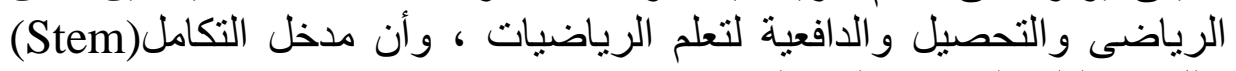
يقلل من القلق الرياضى لإى الطيلاب. .

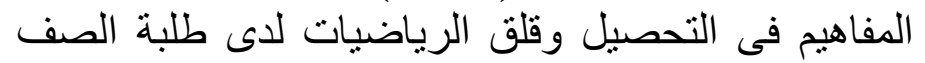

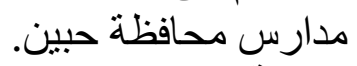

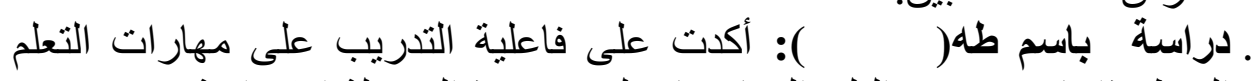

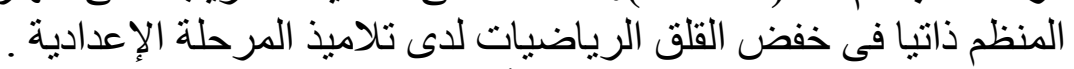

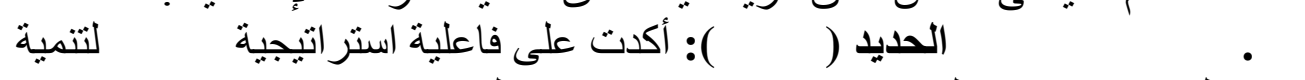

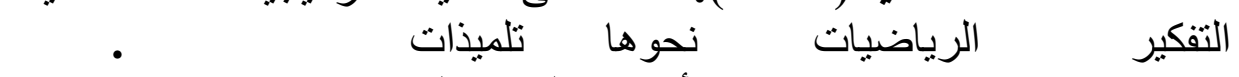

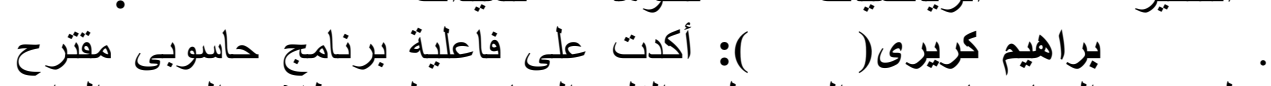

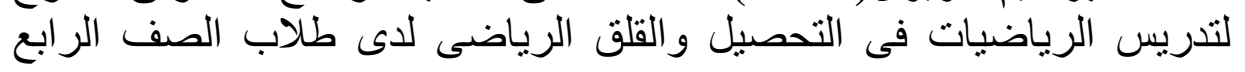

بعد الإبلاع على السحوث والدرلسات الساقة الخاصة بهذا المحور نستخلص ما يليع:

منها فى وضع الإطار النظرى الخاص بالقلق الرياضى، وإعداد مقياس القلق الرياضى نحى وضع دراسة الميكانيكا وتفسير النتائج .

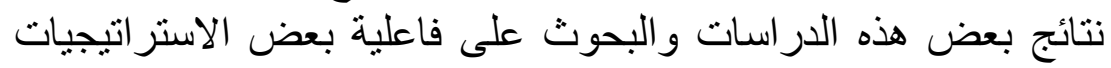

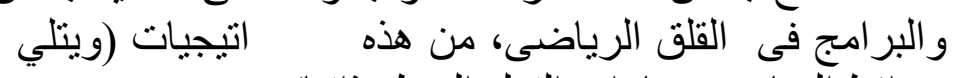

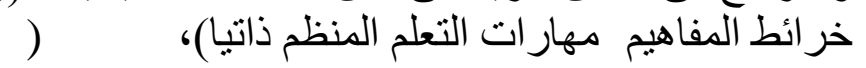
برمجية جيوجبر GeoGebra ) ، نموذج تدريسى مقترح قائم على التعلم

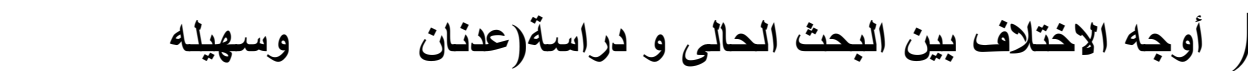

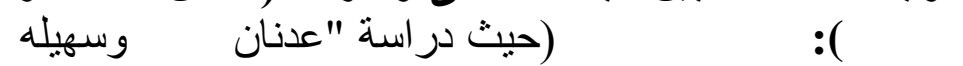

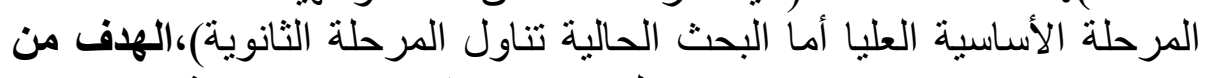

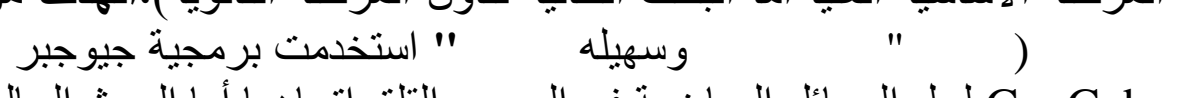
GeoGebr لحل المسائل الرياضية فى الجبر و القلق اتجاهها أما البحث الحالي لئي 
الصفوف المقلوبة فى تنمية مهارات حل المسائل الرياضية فى دي

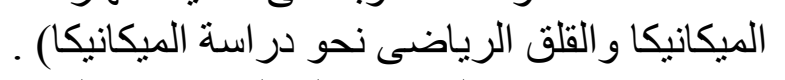

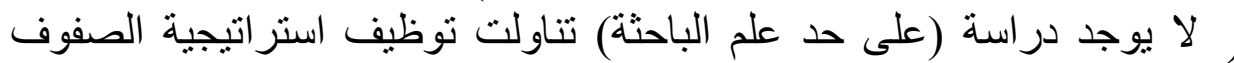

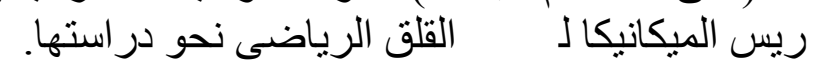

الدراسة التجريبية (أدواتها وإجراع|تهانيان)

أولاً : إعداد أدوات السمث: وتشتطل على:

$$
\text { أ- إعداد الأدوات التعليمية : تتضمن التوني }
$$

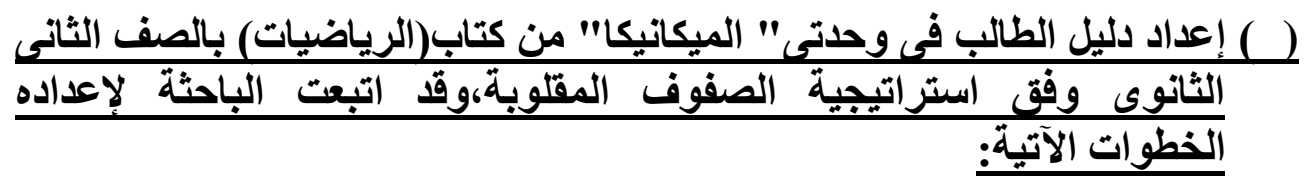

• • لحليل محتوى وحدنى" الميكانيكا" وفقاً للخطوات التالية:

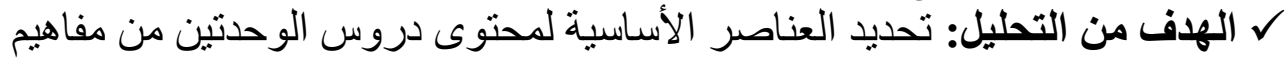
وتعميمات ومهار ات رياضية تعريف كل منهم إجر ائيا كما يلى:

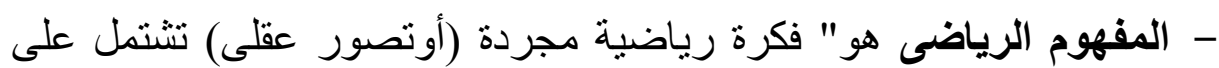

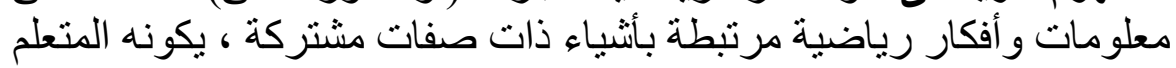

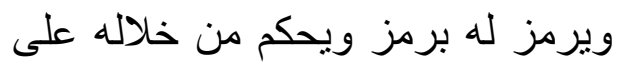

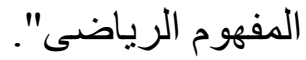

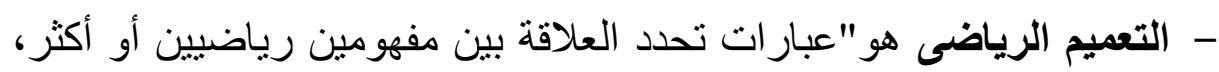

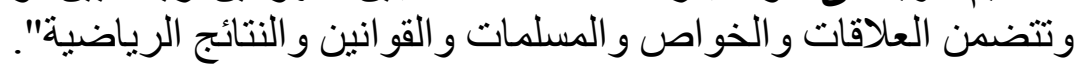

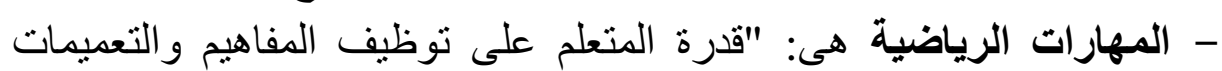

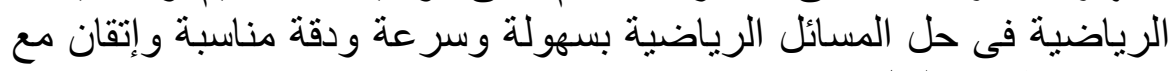

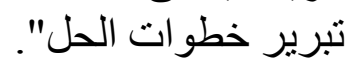

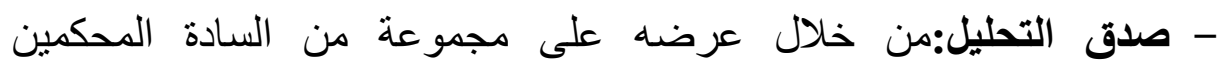

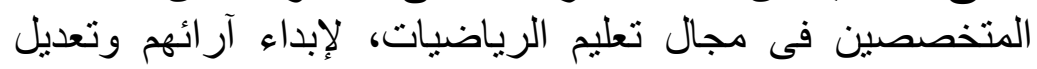
التحليل فى ضوئهيا.

- ثبلت التحليل عبر الزمن: من خلال قيام الباحثة بإجر اء عملية التحليل مرتين

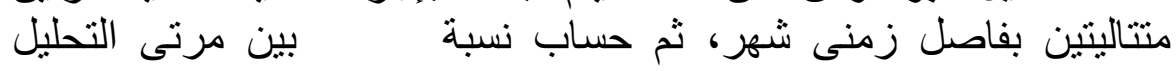




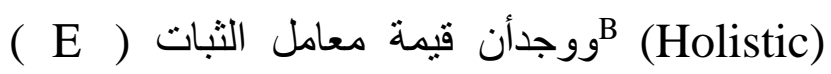

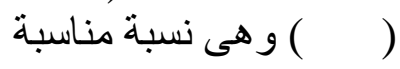

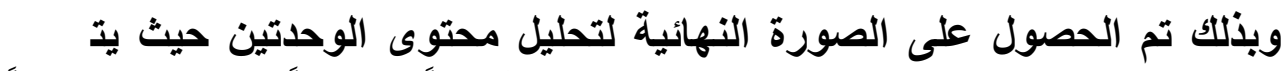

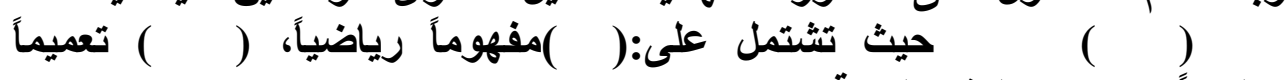
رياضياً، (OA ) مهارة رياضية.

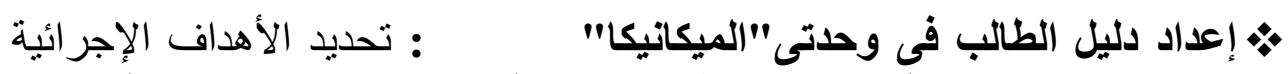

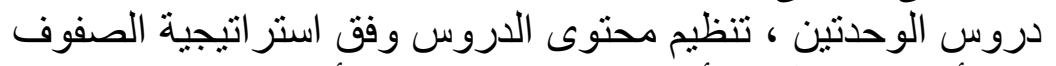

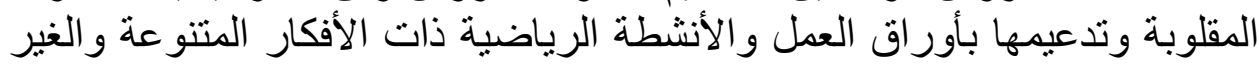

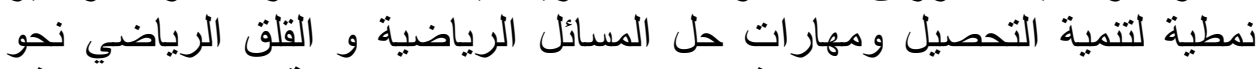

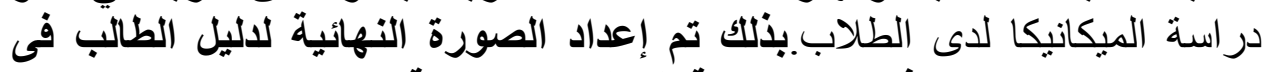
وحدتى" الميكانيكا" وفق استراتيجية الصفوف المات المقلوبة.

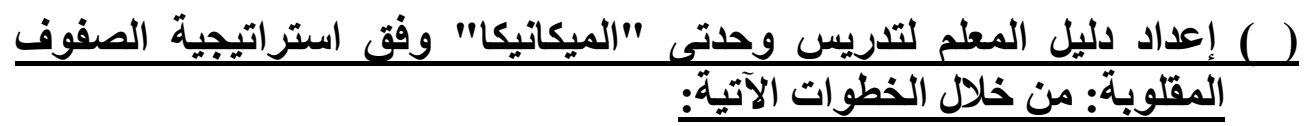

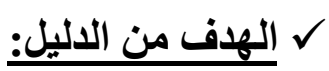

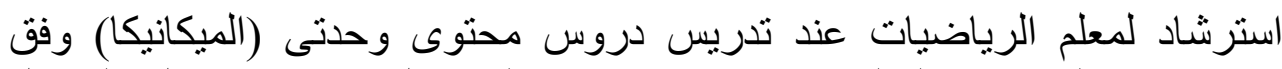

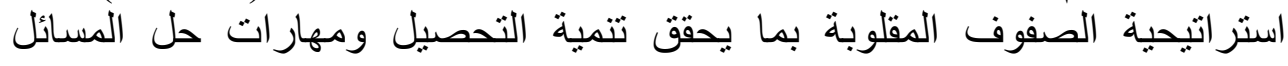
الرياضية و القلق الرياضي نحو دراسة الميكانيكاً لدى الطلاب . لونيل

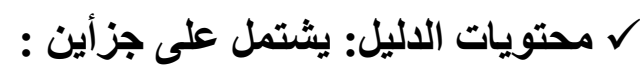

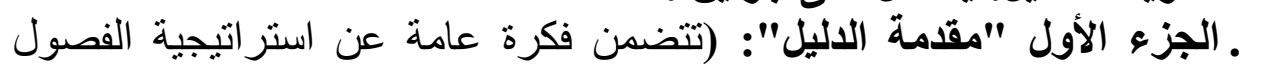

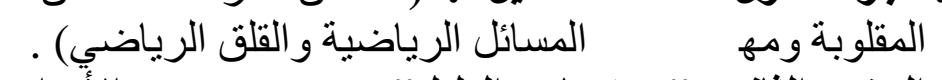

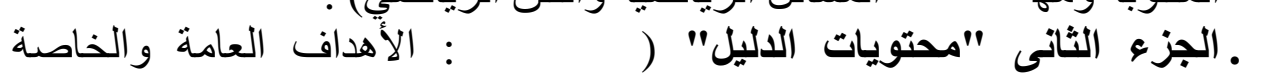

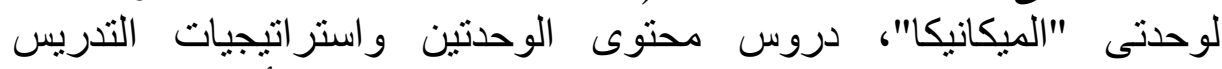

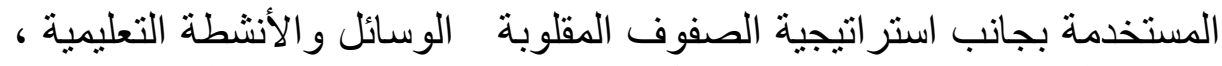

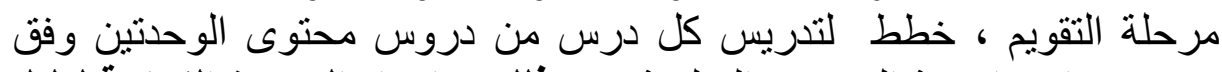

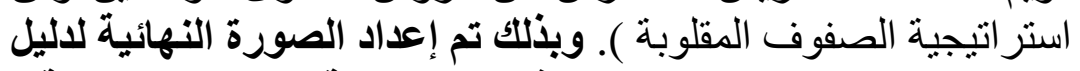

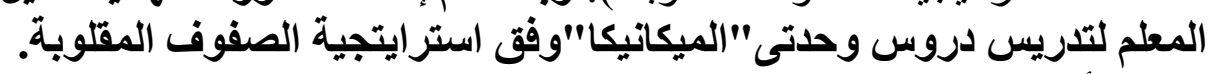

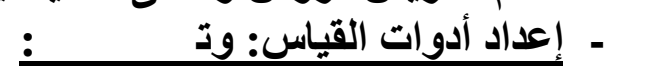


(1) إعداد اختبار التحصيل في وحدتى "الميكانيكا" وفق الخطوات الآتية:

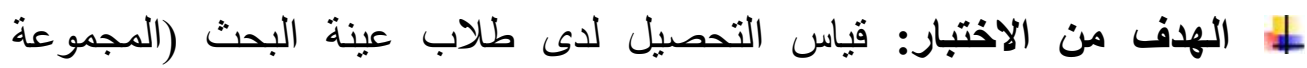

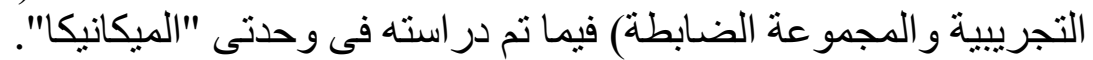

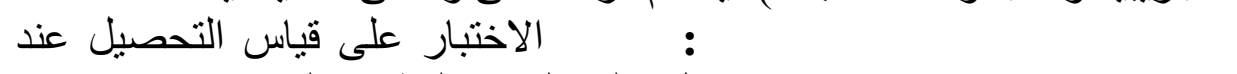

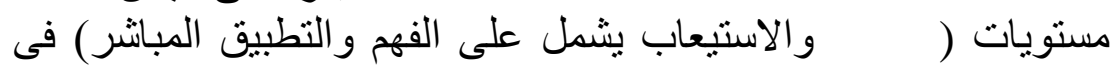

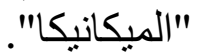

\section{نوع مفردات الاختبار:}

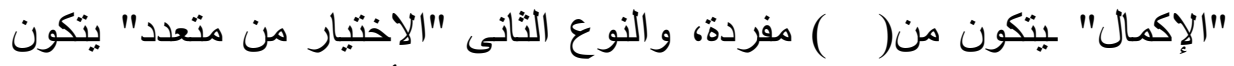

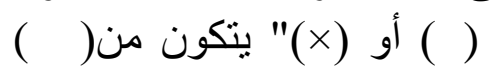

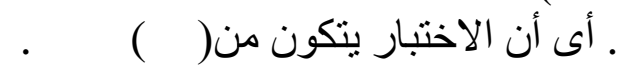

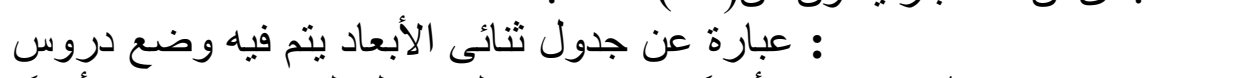

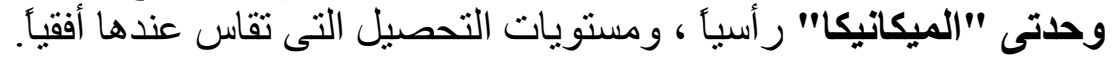

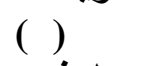

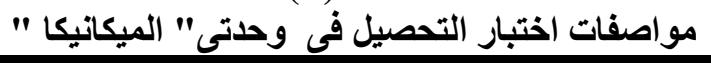

\begin{tabular}{|c|c|c|c|c|c|c|c|}
\hline \multicolumn{3}{|c|}{ الاستيعاب(الفهم +التطبيق المباشر) } & \multicolumn{3}{|c|}{ 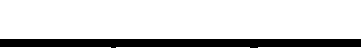 } & \multicolumn{2}{|l|}{ مستويات التحصيل } \\
\hline السؤل الثالث & الألفؤل & الأسؤل & المأل المول & الثأف & الأسؤل & 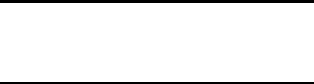 & م \\
\hline \multicolumn{8}{|c|}{ الوحدة الاولى " الاستاتيكا" } \\
\hline$\varepsilon$ & $\mathbf{I \Lambda}$ & Ir & rV & rV & 1 & القوى - محصلينة فق نقطين & 1 \\
\hline r & IV & $\varepsilon$ & $\varepsilon \cdot$ & rI & $\mathbf{V}$ & تحليل القوى & $\mathbf{r}$ \\
\hline$\varepsilon 1$ & r & 11 & $\varepsilon r$ & rl & 17 & محصلة عدة قوى مستوية & $\boldsymbol{r}$ \\
\hline \&V & זץ & 10 & ץ & 19 & $r$ & 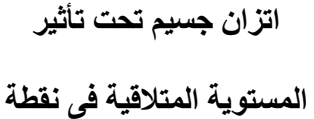 & $\varepsilon$ \\
\hline \multicolumn{8}{|c|}{ الوحدة الثاتية " الديناميكا" } \\
\hline ro & r1 & IE & $\varepsilon 0$ & $r$ r. & $\mu$ & الحركة المستقيمة & 0 \\
\hline rq & r & 0 & 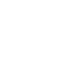 & rq & 9 & الحركة منتظمة التغير مستقيم & 7 \\
\hline$\varepsilon$ & r. & 1 . & $\mu$ & r & 7 & السقوط الحر & $\mathbf{V}$ \\
\hline rA & rA & Ir & $\varepsilon \varepsilon$ & ro & $\boldsymbol{\Lambda}$ & قانون الجذب العل & $\Lambda$ \\
\hline
\end{tabular}

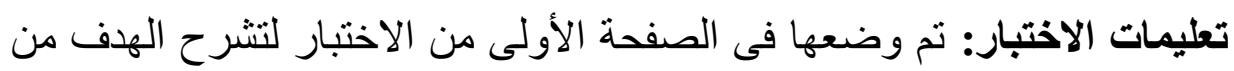
الاختبار وكيفية الإجابة عليه ، وزمن الاختبار ونهايته العظمى. 
نظام تقدير درجات الاختبار: يختلف درجة كل سؤ ال حسب الخطو ات المستخدمة

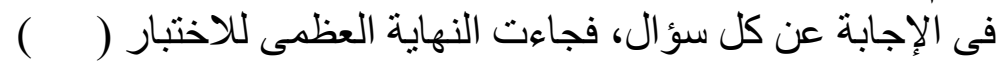

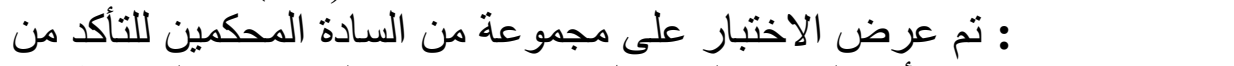

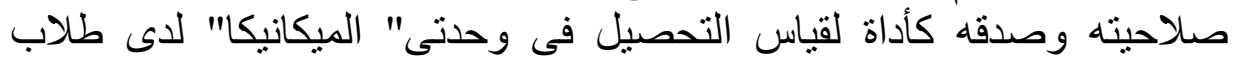

التجربة الاستطلاعية للاختبار: تم تطبيق الاختبار فى صورته الأولية على عينة

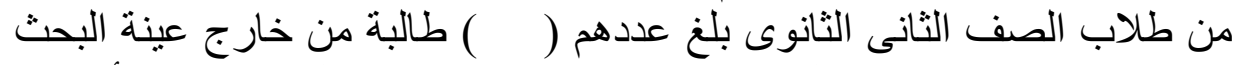

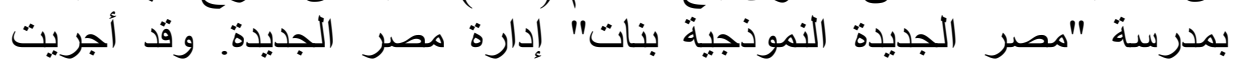

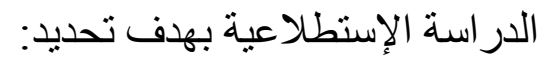

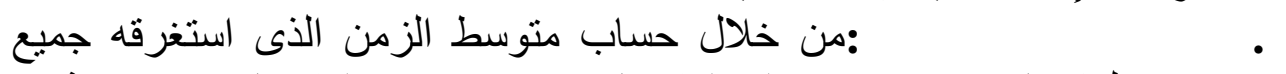

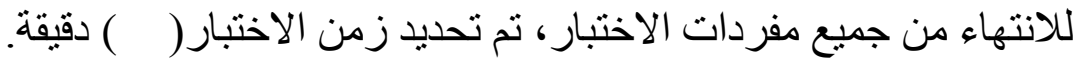

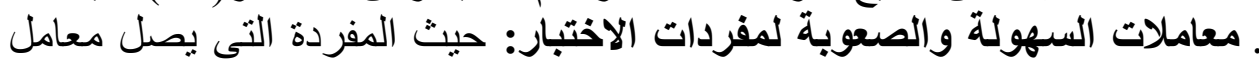

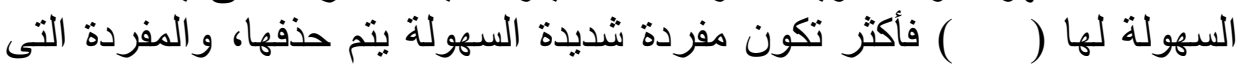

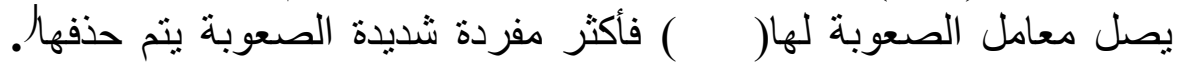

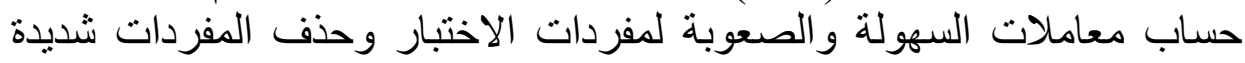

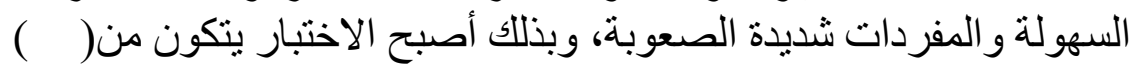

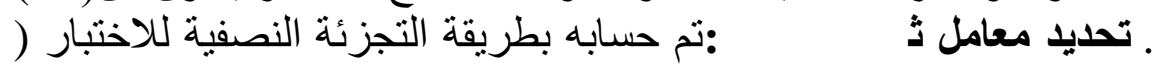

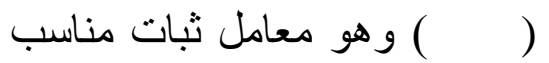
يمكن الوثوق فيه.

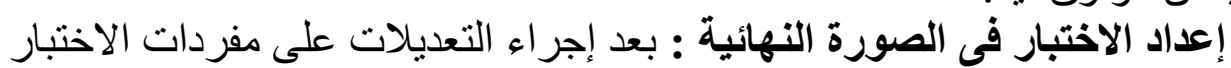

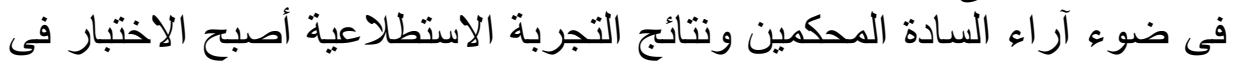
صورته النهائية.

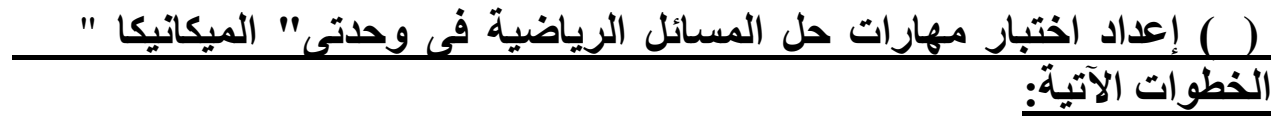
الهذف من الاختبار: قياس مهارات

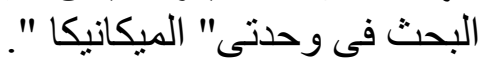

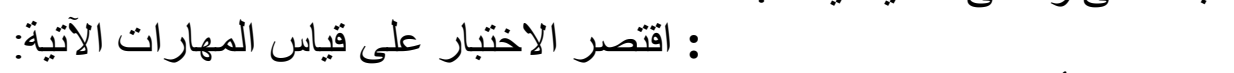

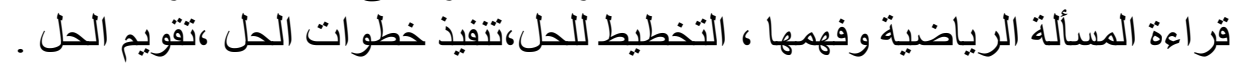


نوع مفردات الاختبار : يتكون الاختبار من جز أين، الجزء الأول "مسائل رياضية

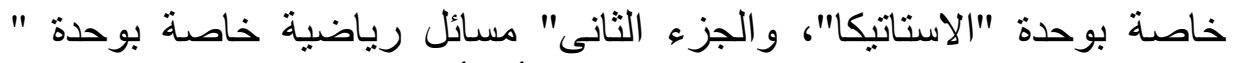

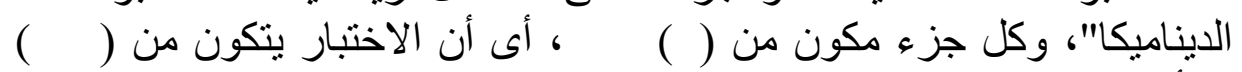

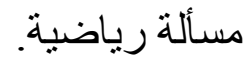
تعليمات الاختبار: تم وضعها فى الصفحة الأولى، وروعى فيها الوضوح الإنها

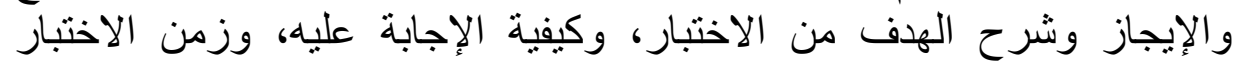
ونهايته العظمى.

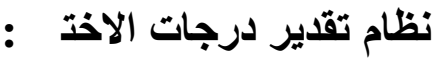

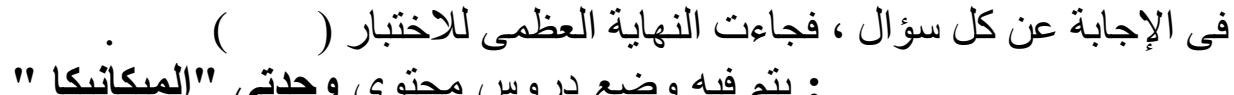

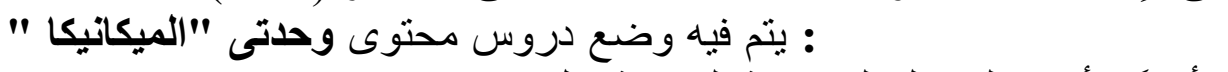
رأسيأ، وأرقام المسائل الرياضية الخاصة بكل درس.

\section{جدط (r)}

مواصفلت اختبار مهارات حل المسائل الرياضية في وحدتى" الميكانيكا " المئية

\begin{tabular}{|c|c|}
\hline الأسئلة & دروس الوحلتين \\
\hline \multicolumn{2}{|r|}{ وحدة الاستاتيكا } \\
\hline$\varepsilon-1$ & ا. القوى - محصلة قوتين متلاقيتين فى نقطة \\
\hline$\Lambda-V$ & r. r. ت تحليل القوى \\
\hline 7-ץ & ب. F. محصلة عدة قوى مستوية متلاقية في نقطة \\
\hline r-r & ع. اتزان جسيم تحت تأثير مجموعة من القوى المستوية المتلاقية فى نقطة \\
\hline \multicolumn{2}{|r|}{ وحدة الايناميكا } \\
\hline $17-9$ & ا ل ا. الحركة المستقيمة \\
\hline$|Y-1|$ & r r. الحركة منتظمة التغير في خط مستقيم \\
\hline $\mid \varepsilon-1$. & 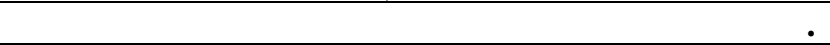 \\
\hline $10-1 Y$ & 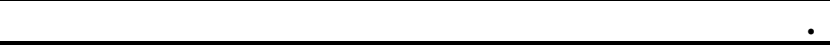 \\
\hline
\end{tabular}

صدق الاختبار: تم عرض الاختبار على مجموعة من السادة الإن المحكمين

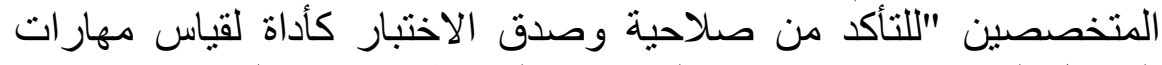

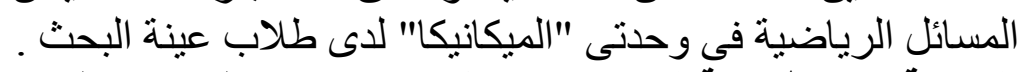
التجربة الاستطلاعية للاختبار:تم تطبيق الاختبار على لفي لفس العينة السابقة بهدف

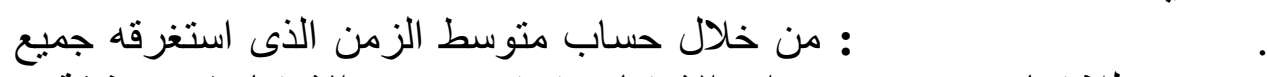

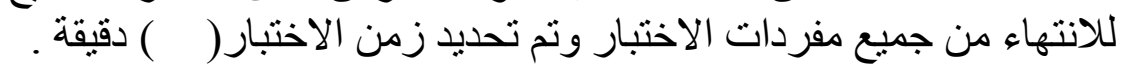
ـ معاملات السهولة والصعوبة لمفردات الاختبار:

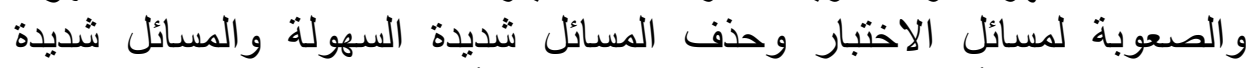

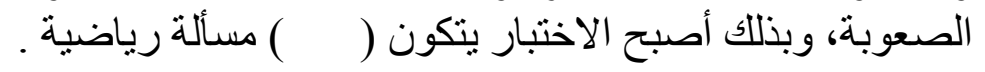


معاطل ثبات الاختبار:باستخدام طريقة التجزئة النصفية للاختبار ووجد أنه يساوى

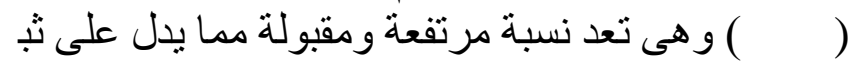

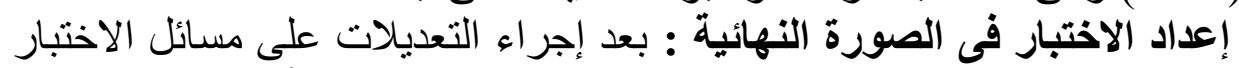

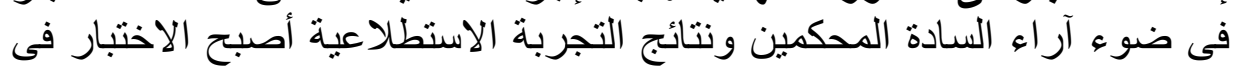

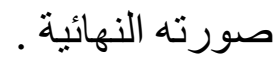

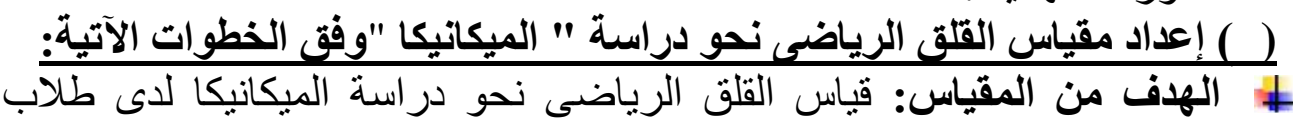

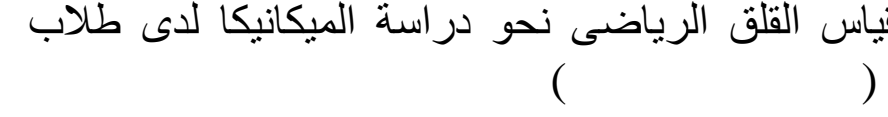

$$
\text { بنود المقياس:تمبكانيكان وضع مجمو عة من البنود تحت المحاور الآتية) }
$$

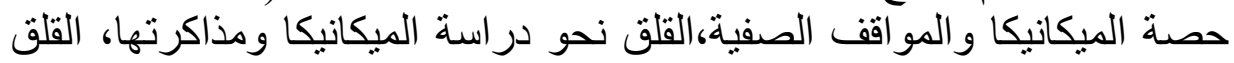

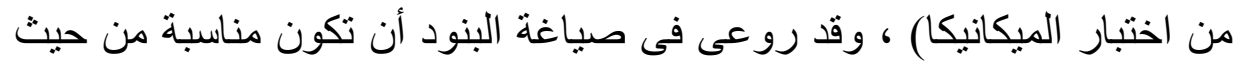

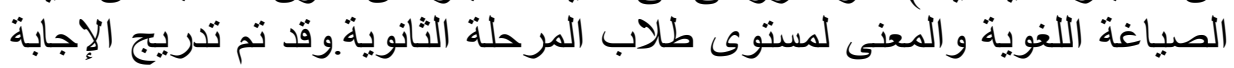

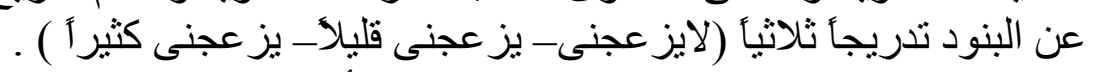

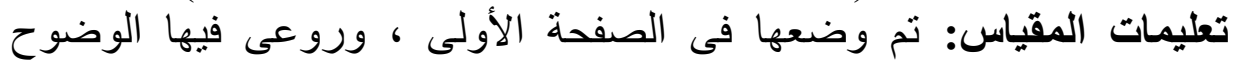

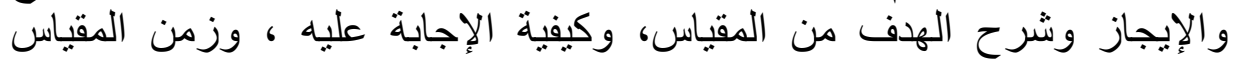
نظام تقدير درجات المقياس:

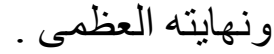

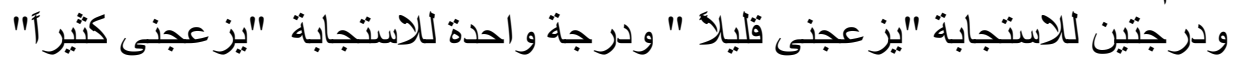

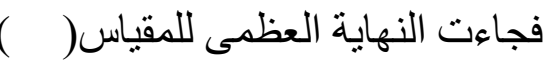

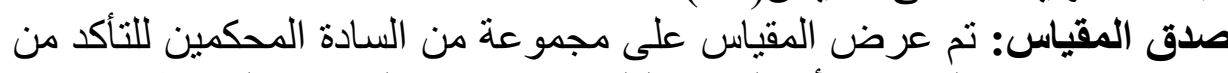

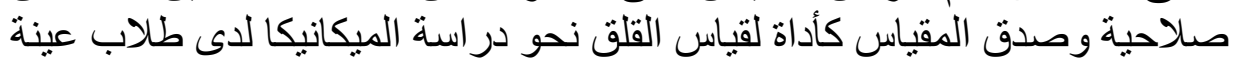

التجربة الاستطلاعية للمقياس: تم تطبيق المقياس على نفس العينة السابقة بهدف

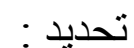
ـ الزمن المناسب للمقياس: من خلال حساب منوسط الزمن الذى استغرقه جميع

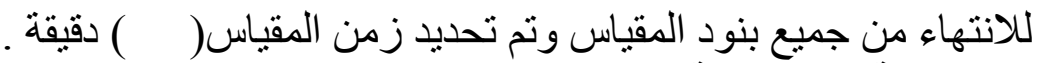

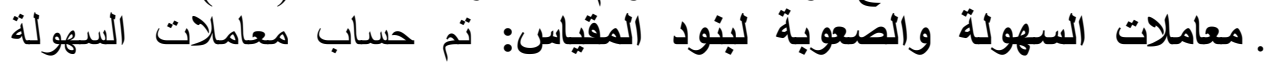

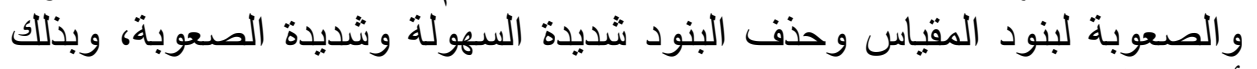

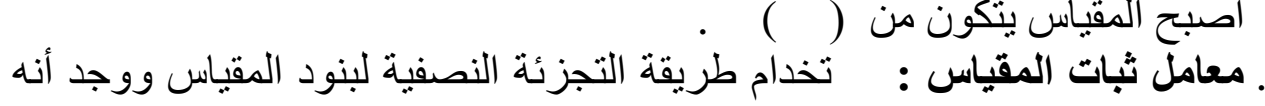

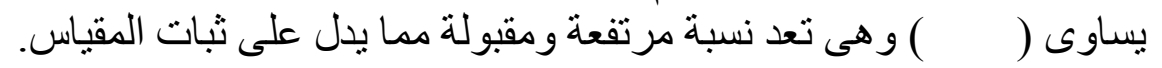


إعداد المقياس فى الصورة النهائية: بعد إجراء التعديلات على المقياس تم التوصل إلى صورتنه النهائية .

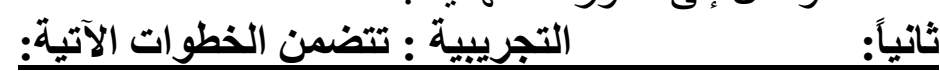

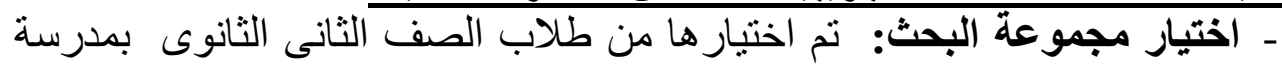

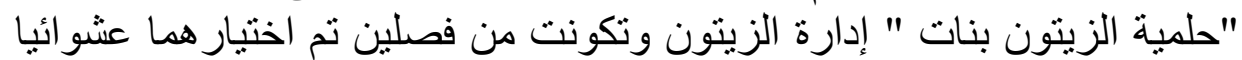

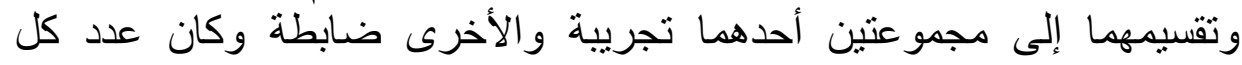
ـ ضبط متغيرات البحث: تم التأكد من تكافؤ المجمو عنين (التجريبية والضابطة) من

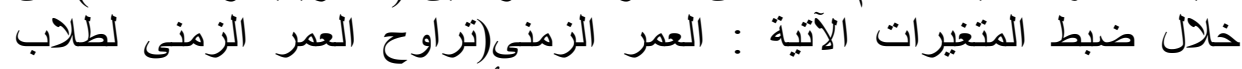

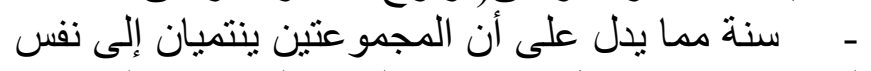

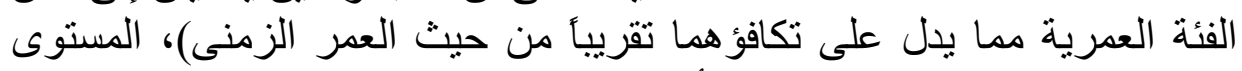
(متقارب لأن معظمهم من نفس المنطقة ولهم نفس التمن الثقافة

و ونفس ظروف البيئة المحيطة).

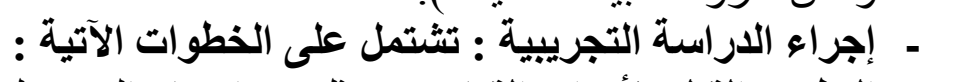

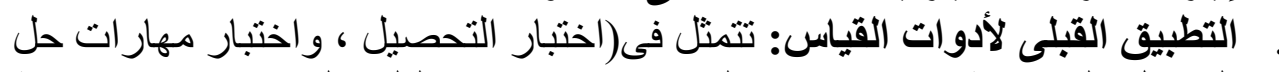

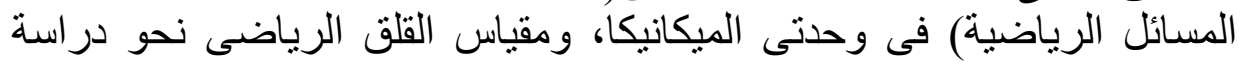

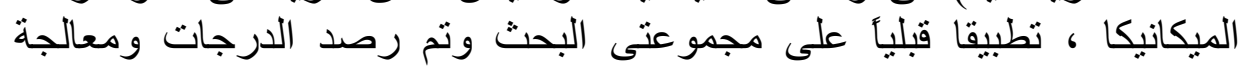
البيانات إحصائياً باستخدام البرنامج الإحصائى SPSS وفئا يلى ونى نتائج التطبيق

جدط (r)

نتائج (ت) لالالة الفرق بين متوسطى درجات مجموعتى البحث في التطبيق القبلى لأدوات القياس

\begin{tabular}{|c|c|c|c|c|c|c|c|c|c|}
\hline \multicolumn{4}{|c|}{ اختبار (ت) } & \multirow[b]{2}{*}{$\varepsilon$} & \multirow[b]{2}{*}{ م } & \multirow[b]{2}{*}{0} & \multirow[b]{2}{*}{ المجموعة } & \multirow[b]{2}{*}{ الاختبار } & \\
\hline \multicolumn{2}{|c|}{ الدلالة } & المسوبة & الحرية & & & & & & \\
\hline \multirow{6}{*}{ دولالة } & \multirow{2}{*}{ 促, } & \multirow{2}{*}{$\cdot, \varepsilon \cdot 1$} & \multirow{2}{*}{$\varepsilon \Lambda$} & $\cdot, 0 \mathrm{VI}$ & $0, \cdot 1$ & ro & ضاجطة & \multirow{2}{*}{ اختبار التحصيكانيكا في } & \\
\hline & & & & 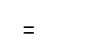 & $0, \varepsilon$. & ro & تجريبية & & \\
\hline & \multirow{2}{*}{ רזז, • } & \multirow{2}{*}{ זד ع, · } & \multirow{2}{*}{$\varepsilon \Lambda$} & $\cdot, 1 \% \varepsilon$ & $0, Y \Lambda$ & ro & ضاجطة & \multirow{2}{*}{ الأسنتّل الرياضيكية فلى الميكي } & \\
\hline & & & & $\cdot, 09$. & $\varepsilon, \Lambda \Lambda$ & ro & تجريبية & & 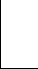 \\
\hline & \multirow{2}{*}{$\cdot, 0 \mathrm{~V}}$. & \multirow{2}{*}{ |r|, } & \multirow{2}{*}{$\varepsilon \Lambda$} & $\cdot, \Lambda \backslash 1$ & $\mathbf{v}, \cdot \cdot$ & ro & ضابطة & \multirow{2}{*}{ مقياس دالقلق الميكياضيكا } & \\
\hline & & & & $\therefore, 91$ & $7, \Lambda \varepsilon$ & ro & تجريبية & & \\
\hline
\end{tabular}




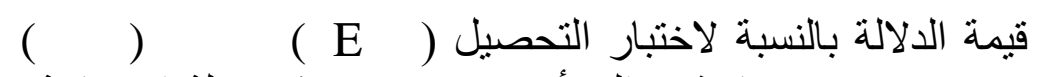

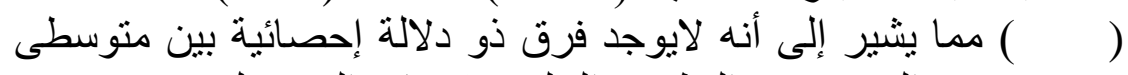

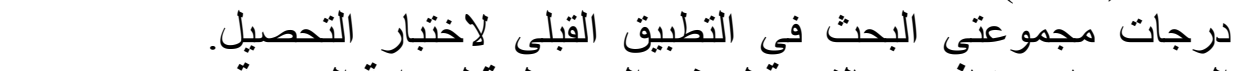

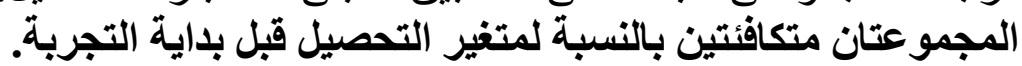

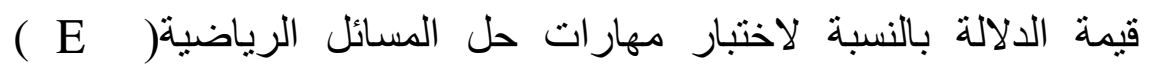

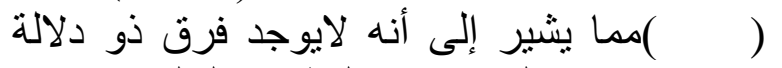

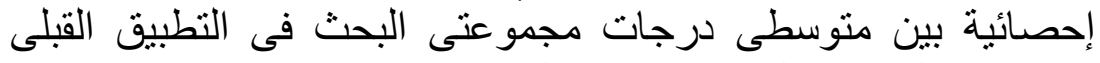

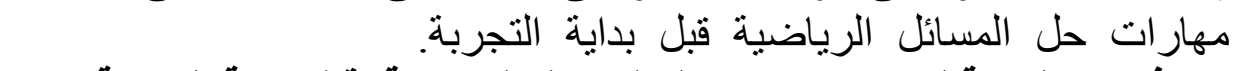

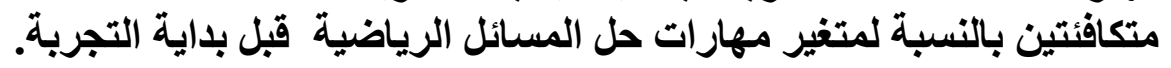

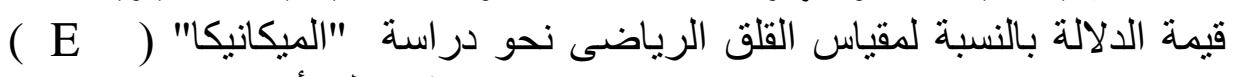

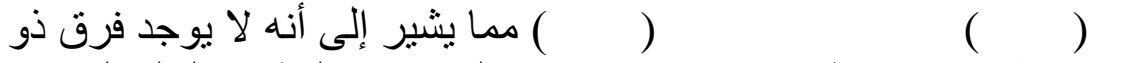

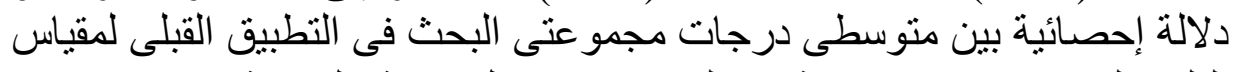

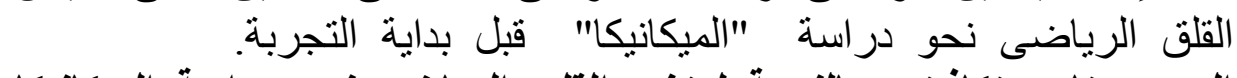

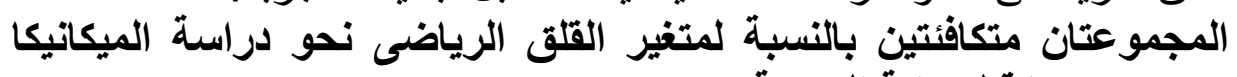

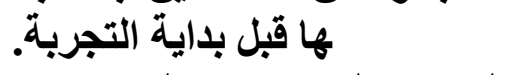

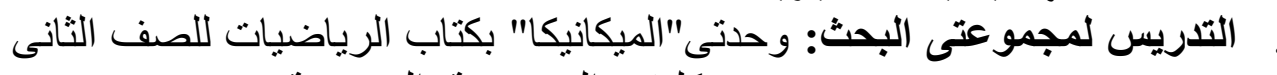

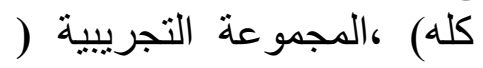

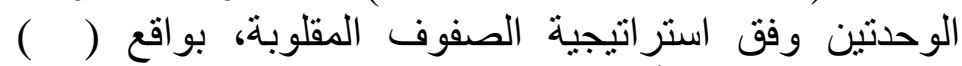

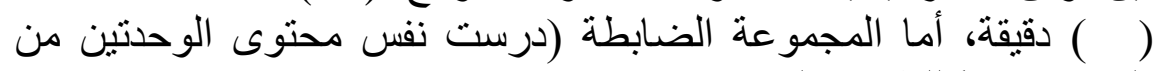

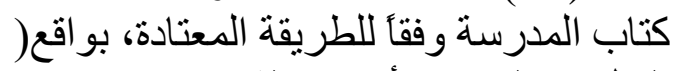

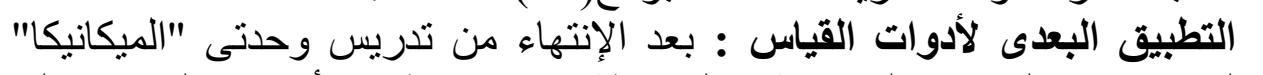

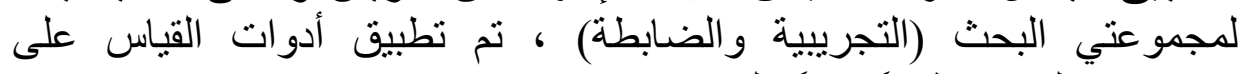
مجمو عتى البحث تطبيقاً بعدياً عليهم.

نتائج الدراسة التجريبية (وتفسيرها ومناقشتها)

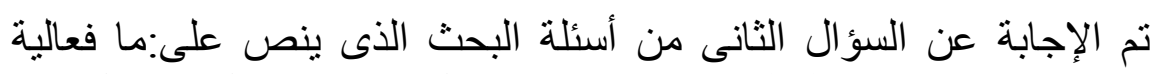

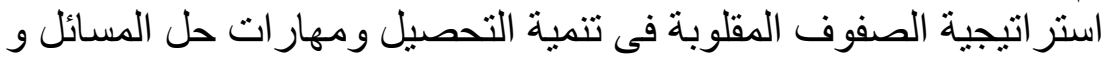

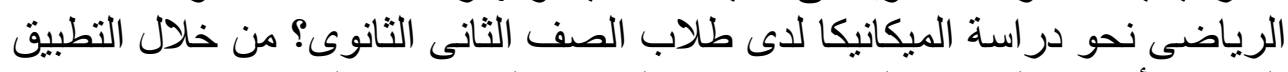

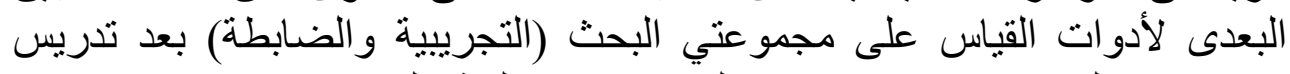

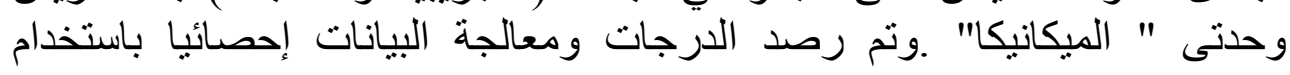
.SPSS 
نتائج تطبيق اختبار التحصيل فى وحلتى "الميكانيكا":

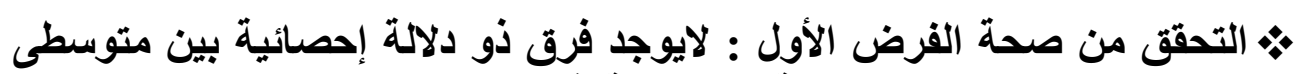

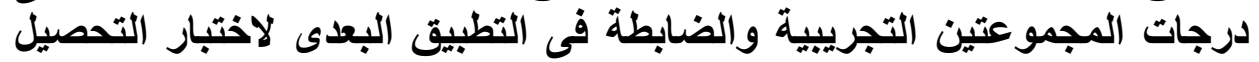

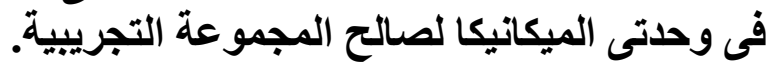

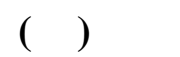

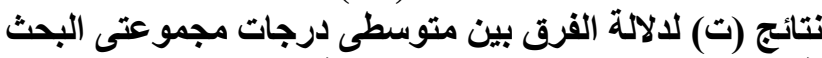

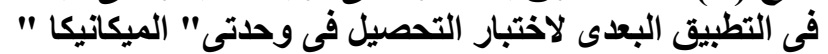

\begin{tabular}{|c|c|c|c|c|c|c|c|}
\hline \multicolumn{4}{|c|}{ اختبار (ت) } & \multirow[b]{2}{*}{$\varepsilon$} & \multirow[b]{2}{*}{ م } & \multirow[b]{2}{*}{ ن } & \multirow[b]{2}{*}{ التطبيق } \\
\hline \multicolumn{2}{|c|}{ الدلالة } & المهسمة (ت) & الحرجة & & & & \\
\hline \multirow{2}{*}{ دلوالة } & \multirow[b]{2}{*}{$\cdot, \cdots$} & \multirow{2}{*}{ 1,Vع 9} & \multirow{2}{*}{$\varepsilon \Lambda$} & $\cdot, \mathrm{VOI}$ & $\mathbf{V \varepsilon , \Lambda \Lambda}$ & ro & التجريبية \\
\hline & & & & $1, \vee 9 \%$ & $71, v 1$ & ro & الضاطة \\
\hline
\end{tabular}

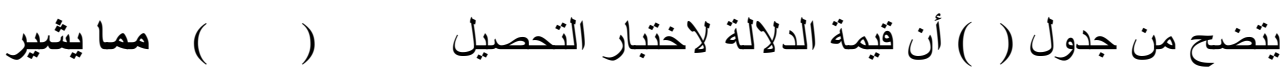

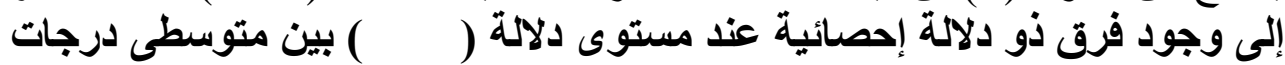

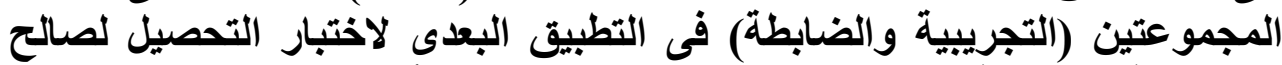

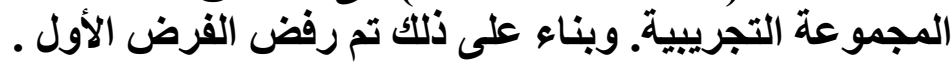

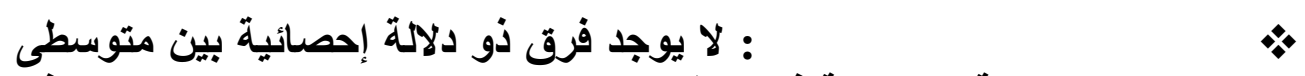

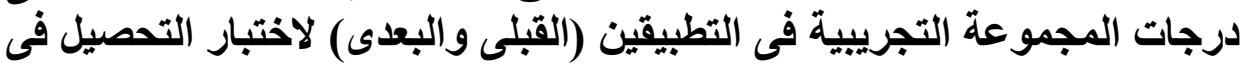
وحلتى الميكانيكا لصالح التطبيق البعدى " .

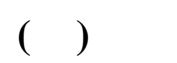

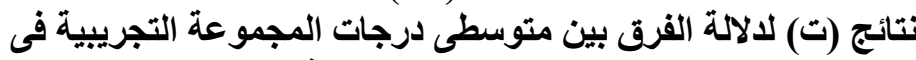

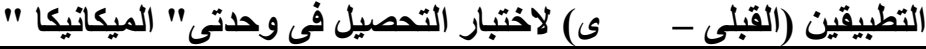

\begin{tabular}{|c|c|c|c|c|c|c|c|}
\hline \multicolumn{4}{|c|}{ اختبار (ت) } & \multirow[b]{2}{*}{$\varepsilon$} & \multirow[b]{2}{*}{ م } & \multirow[b]{2}{*}{ ن } & \multirow[b]{2}{*}{ التطبيق } \\
\hline & & قالمهمة (ت) & درجة & & & & \\
\hline \multirow{2}{*}{ ديولة } & \multirow{2}{*}{. } & \multirow{2}{*}{$r \cdot 9,11$} & \multirow{2}{*}{ r } & $\cdot, 0 \varepsilon r$ & $0, \varepsilon$. & ro & القبل \\
\hline & & & & $\cdot, \mathrm{VOI}$ & $\mathbf{V} \boldsymbol{\varepsilon}, \mathbf{\Lambda \Lambda}$ & ro & البعدى \\
\hline
\end{tabular}

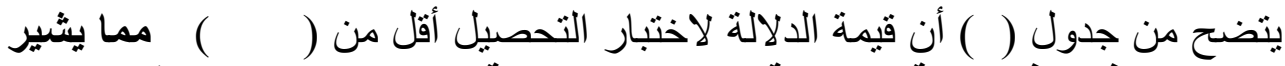

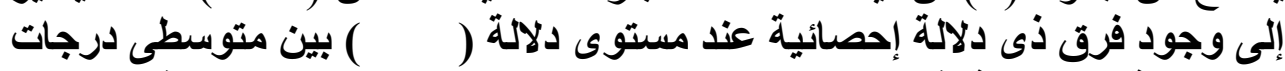

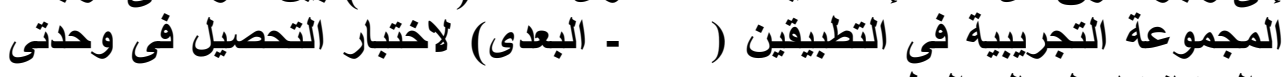

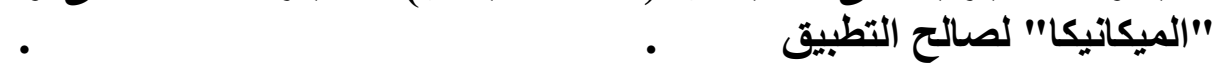




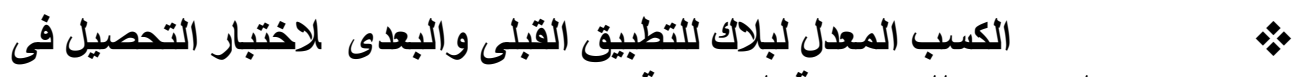

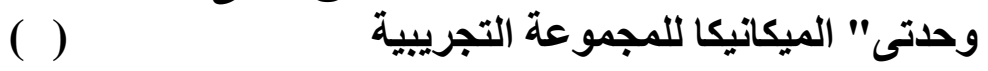

جدرل (1) 17 )

نسبة الكسب المعدل لبلاك للتطبيق القبلى والبعدى لاختبار التحصيل

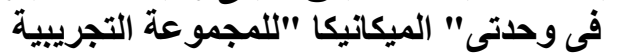

\begin{tabular}{|c|c|c|c|c|}
\hline 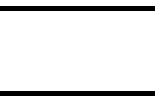 & نهاية العظمى & متوسط درحلت & متوسط در جات & الأداة \\
\hline $\mathbf{I}, \mathbf{\Lambda}$ & $\Lambda$. & $\mathbf{V} \varepsilon, \Lambda \Lambda$ & $0, \varepsilon$. & ختبار التحصيل \\
\hline
\end{tabular}

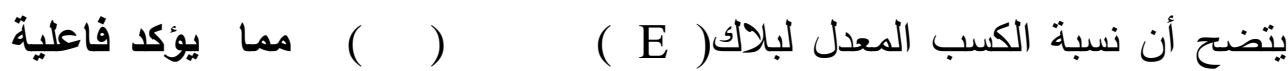
الستخدال استراتيجية الصفوف المقلوبة فى تنمية التحصيل لدى طلاب المجموعة التجريبية .

نتائج تطبيق اختبار مهارات حل المسائل الرياضية فى وحدتى " الميكانيكا " :

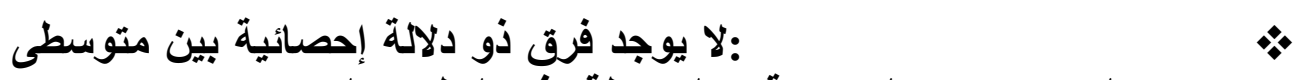

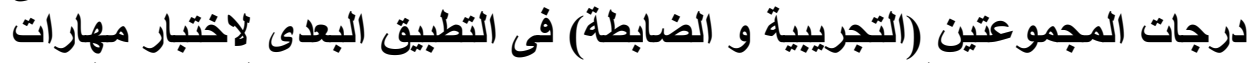

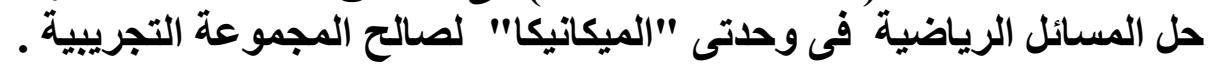

\section{جدول ( )}

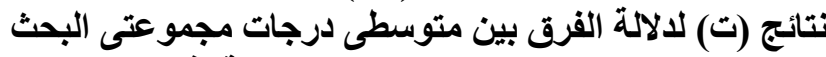

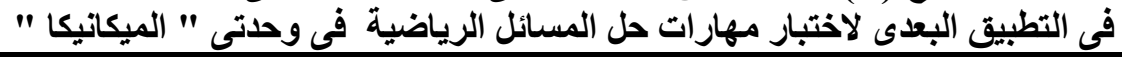

\begin{tabular}{|c|c|c|c|c|c|c|}
\hline \multicolumn{3}{|c|}{ اختبار (ت) } & \multirow[b]{2}{*}{ ₹ } & \multirow[b]{2}{*}{ p } & \multirow[b]{2}{*}{ ن } & \multirow[b]{2}{*}{ التطبيق } \\
\hline & قيمة (ت) & درجرة & & & & \\
\hline \multirow{2}{*}{ ريولة } & \multirow[b]{2}{*}{0, rาo } & \multirow[b]{2}{*}{$\varepsilon \Lambda$} & $1, \cdots 1$ & $9 \mathrm{Yr}, \mathrm{Y \Lambda}$ & ro & التجريبية \\
\hline & & & r,rVV & $v \varepsilon, Y \varepsilon$ & ro & الضاطة \\
\hline
\end{tabular}

يتضح من جدول ( ) أن قيمة دلالة اختبار مهار ات حل المسائل الرياضية

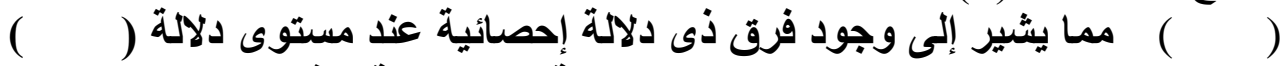

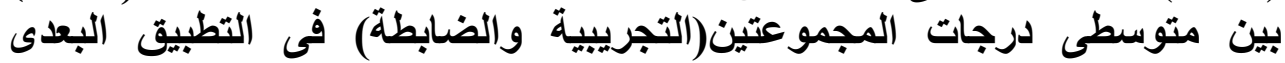

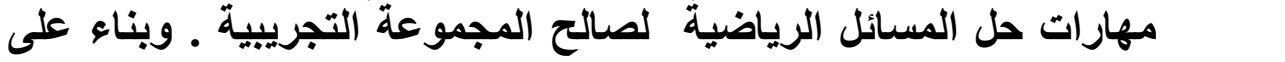
ذاك تم رفض مض الفرض الثار حل المنائ. 


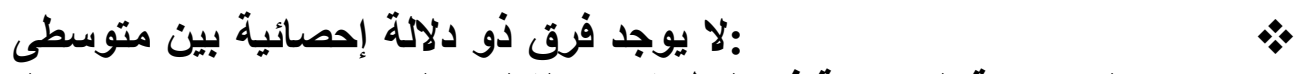

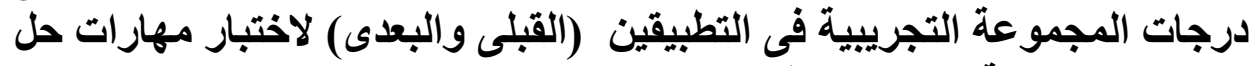
المسائل الرياضية لصالح التطبيق البعدى".

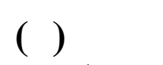

نتائج (ت) لالالة الفرق احصائيا بين متوسطى درجات المجموعة التجريبية التوبية فى التطبيقين

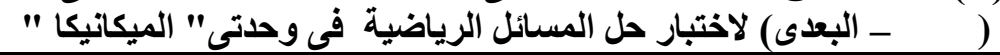

\begin{tabular}{|c|c|c|c|c|c|c|c|}
\hline \multicolumn{4}{|c|}{ اختبار (ت) } & \multirow[b]{2}{*}{$\varepsilon$} & \multirow[b]{2}{*}{ م } & \multirow[b]{2}{*}{0} & \multirow[b]{2}{*}{ التطبيق } \\
\hline & & المصسوة (ت) & الحرجة & & & & \\
\hline يوجد & & V7 ruy & rs & .09. & $\varepsilon, \Lambda \Lambda$ & ro & القبلd \\
\hline دلالة & & TI,ITV & & $1, \cdots 1$ & $\mathrm{QY}, \mathrm{YA}$ & ro & البعدى \\
\hline
\end{tabular}

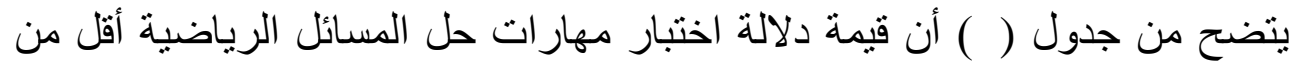

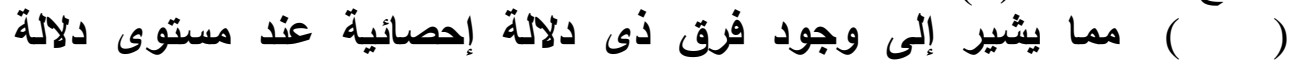
( ا ، ، ) بين متوسطى درجات المجموعة التجريبية فى التطبيقين(القبلى-البعدى) لاختبار مهارات حل المسائل الرياضية لصالح التطبيق البعدى. وبناء على الته ذالك تم رفض الفرض الرابع.

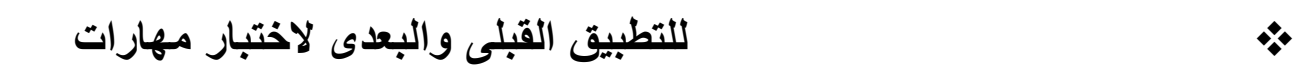

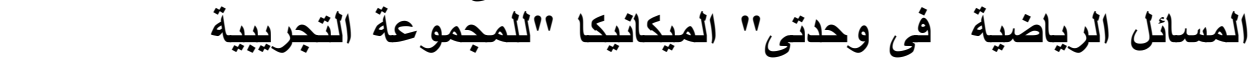

(9) بجدط الرياف

\section{(9) حدو (9)}

نسبة الكسب المعدل لبلاك للتطبيق القبلى والبعدى لاختبار مهارات

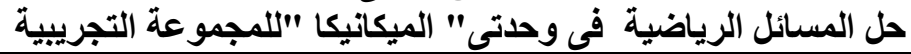

\begin{tabular}{|c|c|c|c|c|}
\hline كسب المعل & نهاية العظمى & متوسط درحات & متوسط در جلت & الأداه \\
\hline I,V१ & 1. & גז, & 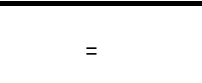 & المتبار مهاراتل حلي \\
\hline
\end{tabular}

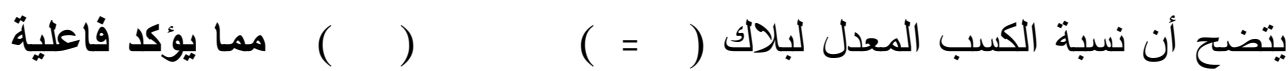
استخلام استراتيجية الصفوف المقلوبة لئلة في تنمية مهارات حل المسائل الرياضية لاى طلاب المجموعة التجريبية. 
نتائج تطبيق مقياس القلق الرياضى نحو دراسة الميكانيكا:

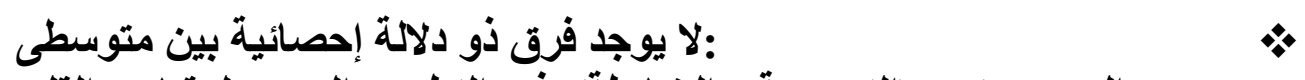

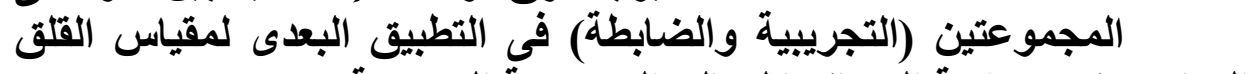

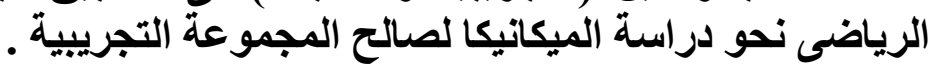

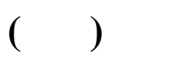

نتائج (ت) لالالة الفرق بين متوسطى درجات مجموعتى البون البحث

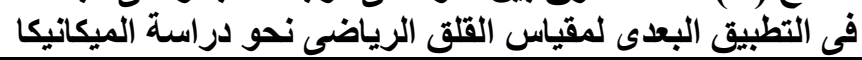

\begin{tabular}{|c|c|c|c|c|c|c|c|}
\hline \multicolumn{4}{|c|}{ اختبار (ت) } & \multirow[b]{2}{*}{$\varepsilon$} & \multirow[b]{2}{*}{ م } & \multirow[b]{2}{*}{ ن } & \multirow[b]{2}{*}{ التطبيق } \\
\hline \multicolumn{2}{|c|}{ الدلالة } & قالمحسوبة & الحرجية & & & & \\
\hline \multirow{2}{*}{ دولة } & \multirow{2}{*}{$\cdot, \cdots$} & \multirow{2}{*}{$0, r}$. & \multirow{2}{*}{ ع } & $1, \cdots 0$ & $\Lambda \mathrm{r}, \mathrm{Or}$ & ro & التجريبية \\
\hline & & & & r,VYq & $7 V, 9 \mathrm{Y}$ & ro & الضاططة \\
\hline
\end{tabular}

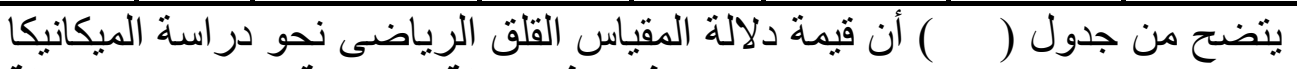

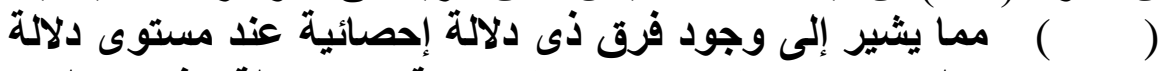

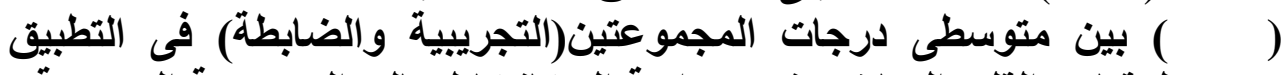

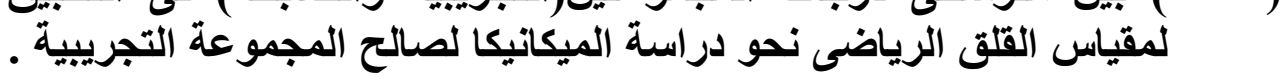

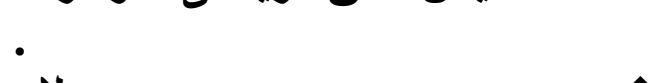

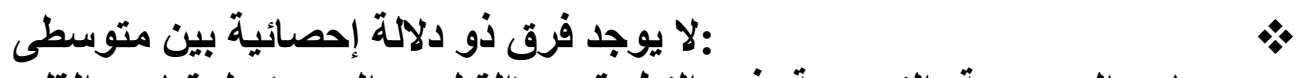

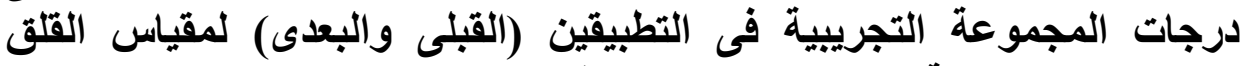
الرياضى نحو دراسة الميكانيكا لصالح التطبيق البعدى".

جدول (II) التط )

نتائج (ت) لالالة الفرق احصائيا بين متوسطى درجات المجموعة التجريبية فى التطبيقين

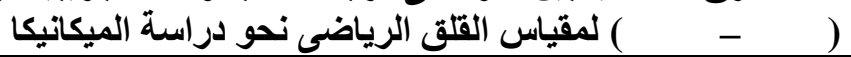

\begin{tabular}{|c|c|c|c|c|c|c|c|}
\hline \multicolumn{4}{|c|}{ اختبار (ت) } & \multirow[b]{2}{*}{$\varepsilon$} & \multirow[b]{2}{*}{ م } & \multirow[b]{2}{*}{ ن } & \multirow[b]{2}{*}{ التطبيق } \\
\hline \multicolumn{2}{|c|}{ الدلالة } & قالمصسة (ت) & درجرية & & & & \\
\hline \multirow{2}{*}{ يوجلة } & \multirow{2}{*}{ י } & \multirow{2}{*}{ r T } & \multirow{2}{*}{ 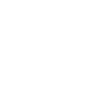 } & $\cdot, 91$. & $1, \Lambda \varepsilon$ & ro & القبل \\
\hline & & & & $1, \cdots 0$ & $\Delta \mathrm{R}, \mathrm{Or}$ & ro & البعدى \\
\hline
\end{tabular}

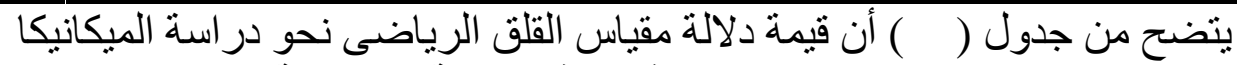

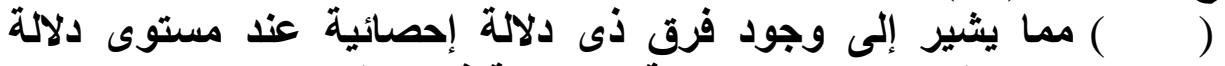

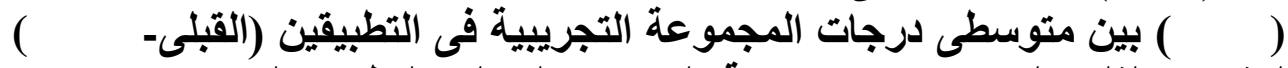

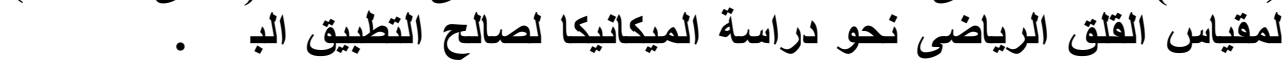
ذلك تم رفض الفرض الساسن. 
هُ وبحساب نسبة الكسب المعدل للتطبيق القبلي والبعدي لمقياس القلق الرياضى

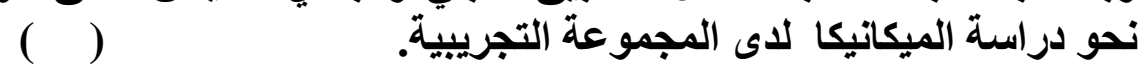

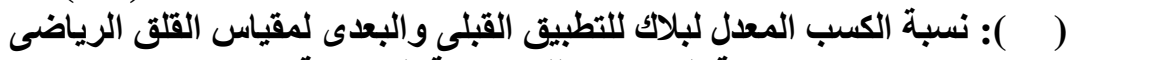

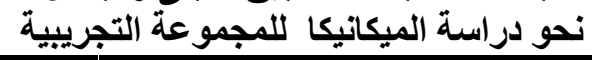

\begin{tabular}{|c|c|c|c|c|}
\hline كسب المعط لبلاكs & نهاية العظمى لاختبار & متوسط درحات البعدى & متوسط درجات القبل & الأداة \\
\hline $\mathrm{I}, \mathrm{VO}$ & १. & Ar,or & $1, \wedge \varepsilon$ & مقياس القلق الرياضى نحو المبكاتيكا \\
\hline
\end{tabular}

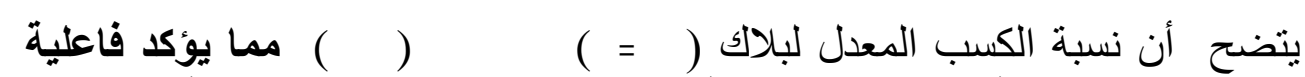
استخذام استراتيجية الصفوف المقلوبة في القلق الرياضى نحو دراسة الميكانيكا لاى طلاب المجموعة التجريبية .

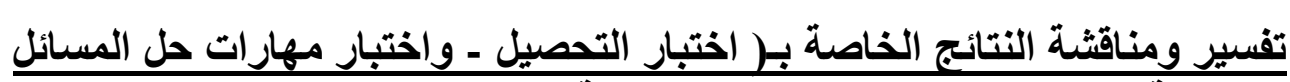

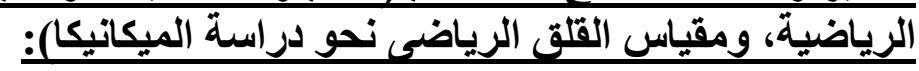

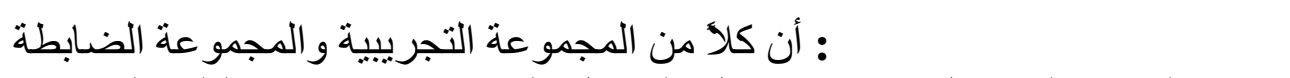

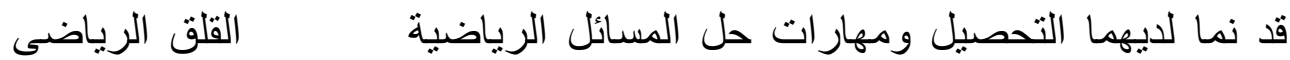

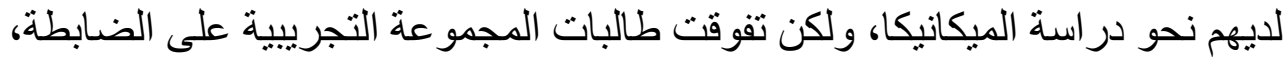
ويرجع ذلك إلى زوظيف استراتيجية الصفوف المقلوبة في تدريس الميكانيكا، حيث اليثابئ

زادت التفاعل بين الطالبات والمعلم من خلال وجود المعلم مع الطالبة في المنزل بطريقة حية تفاعلية من خلال الفيديو التعليمى وفي غرفة الصف للفي للتوجية فيك

. جذبت انتباه الطالبات وتثويقهن للرياضيات من خلال توظيف الأشكال و الألوان

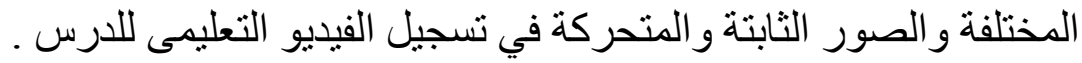

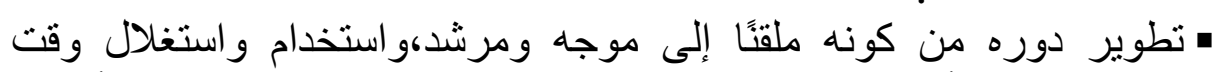

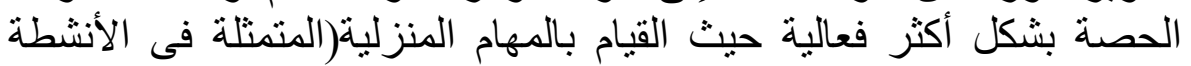

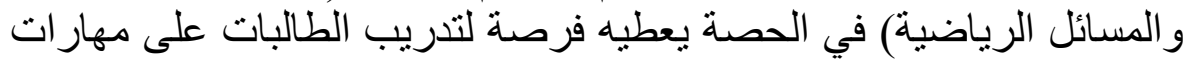

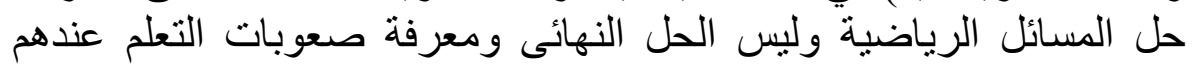

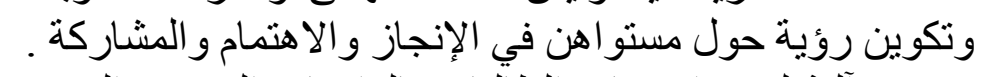

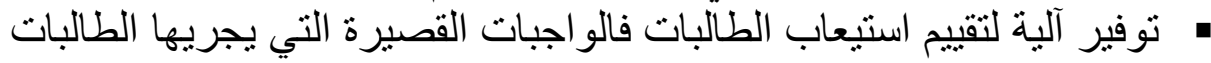

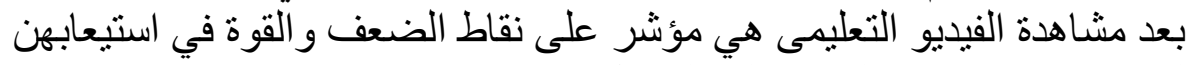

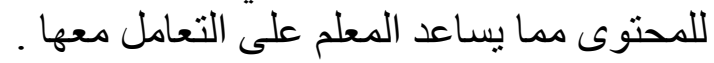


• تلقى استفسارات الطالبات حول الدرس المنضمن بالفيديو والردود عليها، وتوفير تغذية راجعة فورية الطالبات في الطي

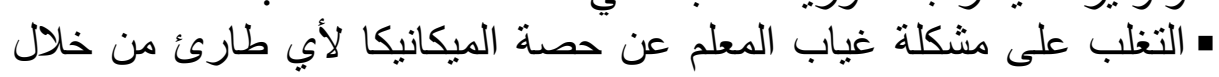
توفير الفيديو التعليمى المتضمن الدئل الدرس. • الاستخدام الأمثل للتقنية الحديثة في التعليم فهى تعتبر محاكاة للغة الئين اليوم حيث

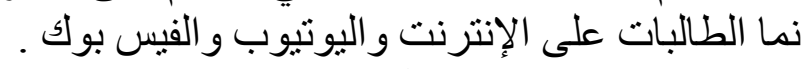

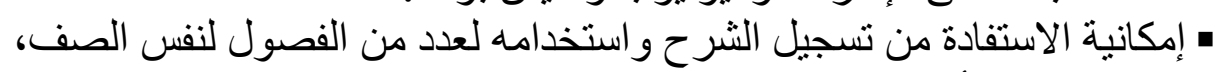
ما دام يحقق الأهداف المطلوبة منه بدقة

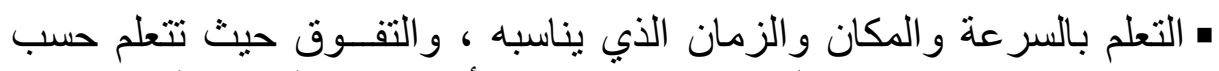

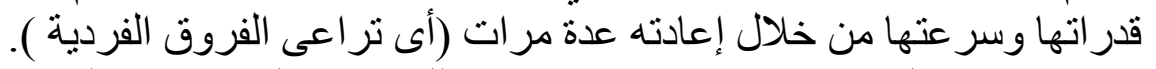

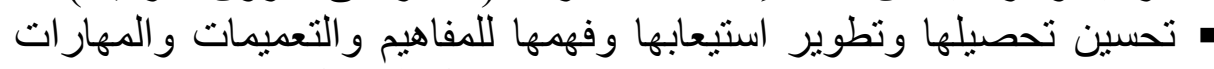

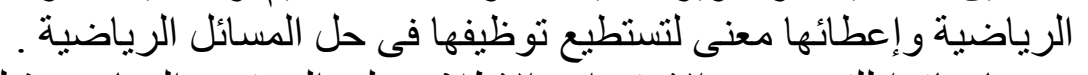

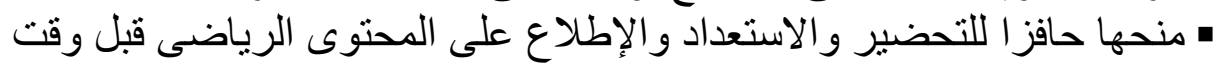

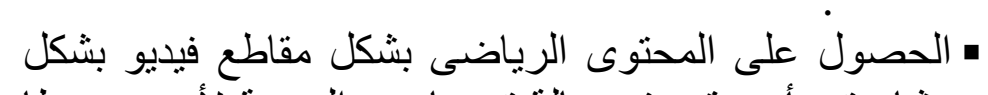

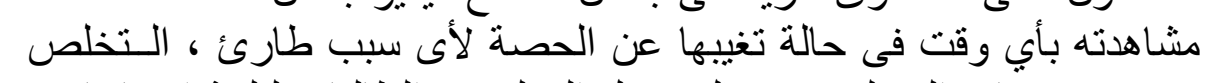

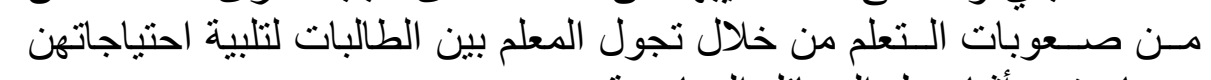

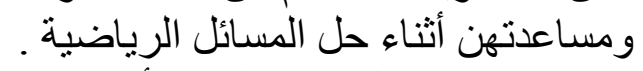

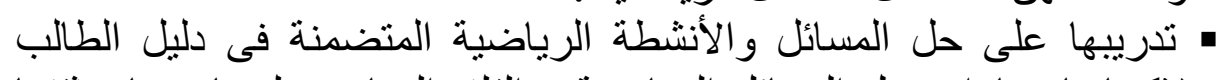

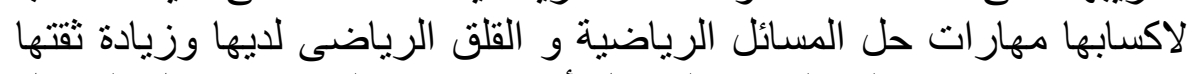

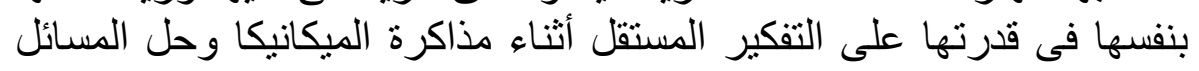

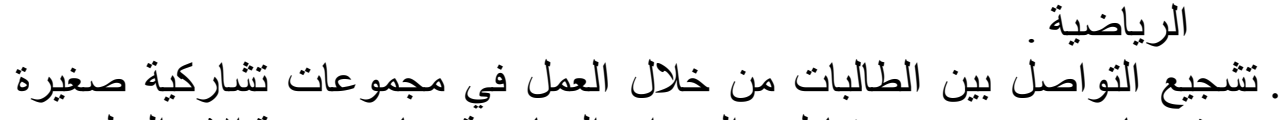

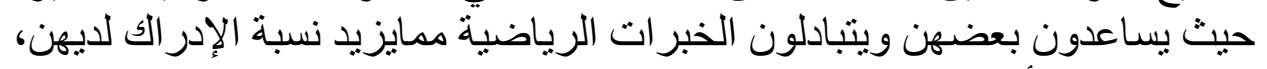
وتزد داد ثقتهن بأنفسهن و بغير هم. توصيات البحث: يوصى البحث الحالى بـ: بأنفئ

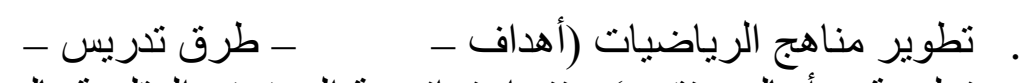
تعليمية ـ أساليب تقويم) وفق استر اتيجية الصفوف المقلوبة بالمريك احل التعليمية 


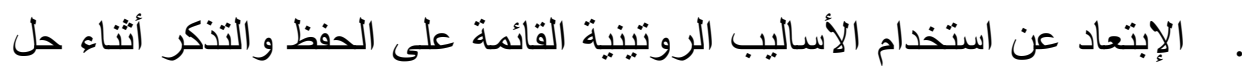

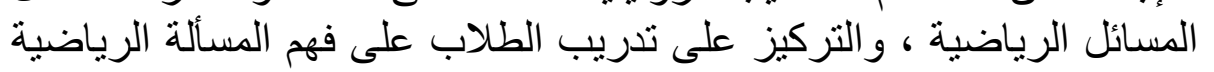

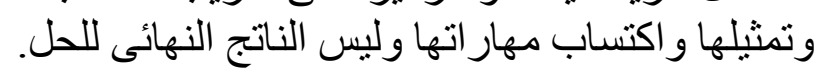

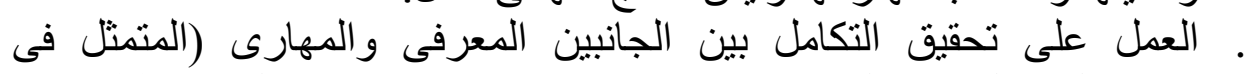

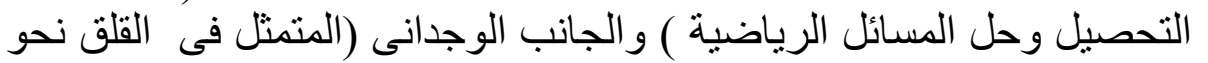

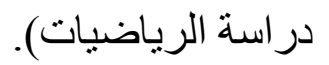

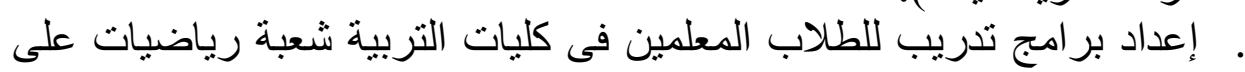

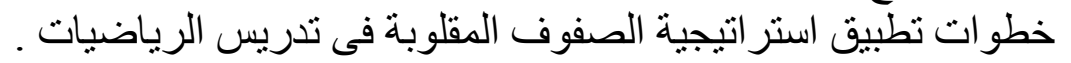

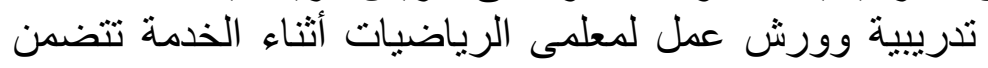

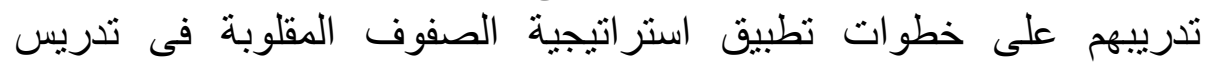

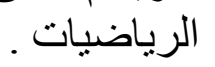
. تضمين" كتب الرياضيات بالمر احل التعليمية المختلفة على المسائل والأنشطة الرياضية ذات أفكار متنو عة و غير نمطية

\section{مقترحات البحث:}

التالية: ضوء ما توصل إليه البحث الحالى من نتائج تقترح الباحثة الاراسات المستقبلية

ـ إجر اء دراسات مماثلة تتناول استخدام الصفوف المقلوبة في تدريس الميكانيكا

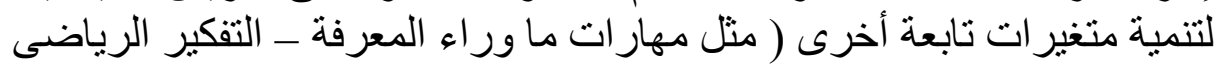

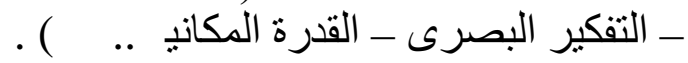

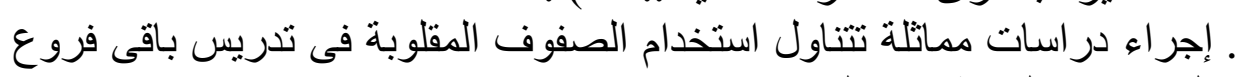

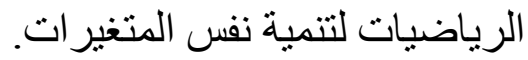

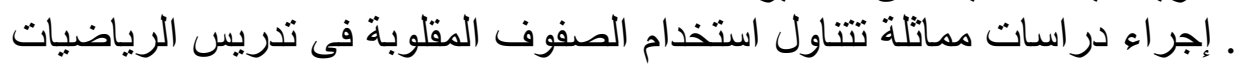

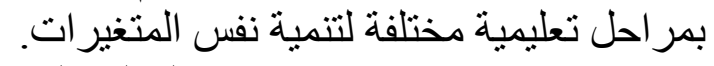

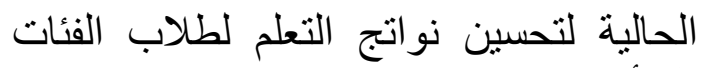

$$
\text { الخاصة (المتفوقين ، بطئ التعلم ، المتأخرين دراسيا ......الخ). }
$$

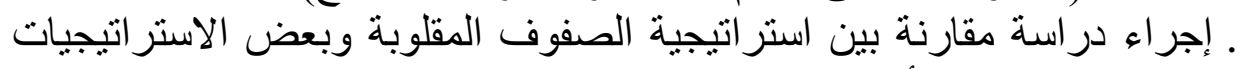

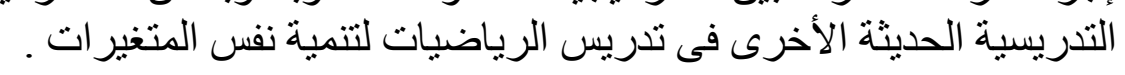




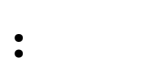

ـ ابتسام الكحيلى(:فاعلية الفصول المقلوبة فى التعليم ،مكتبة دار الزمان،المدينة

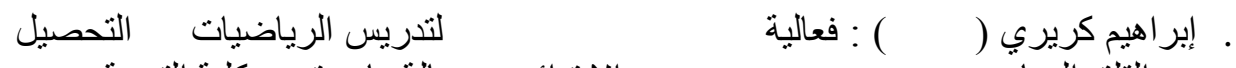

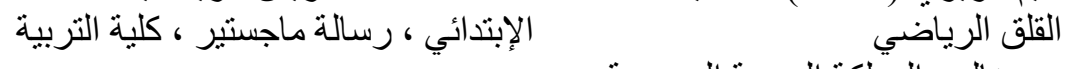

$$
\begin{aligned}
& \text { تنمية مهار ات مجنمات } \\
& \text {. إبر اهيم عطية( ) مارت ) : }
\end{aligned}
$$

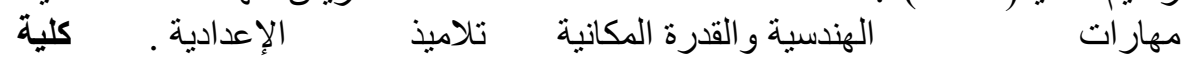

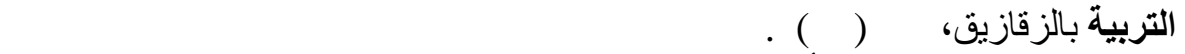

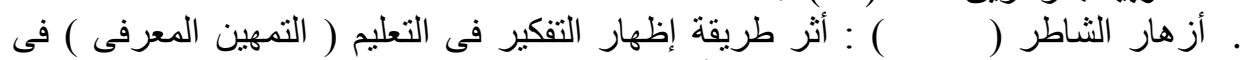

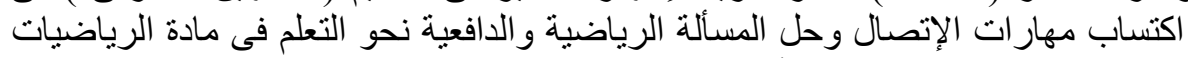

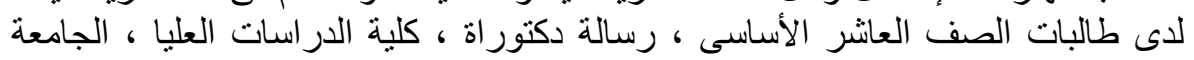
الأردنية.

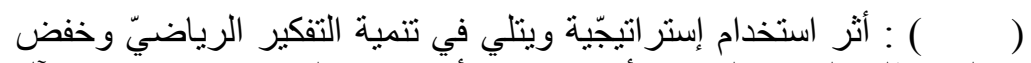

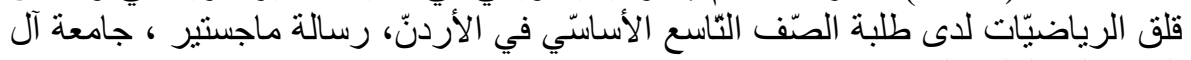

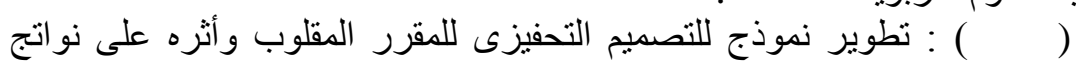

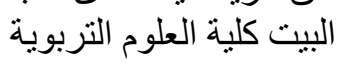

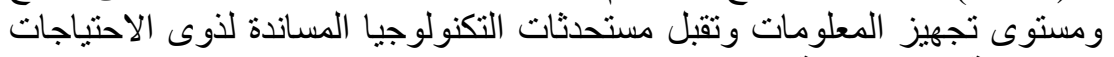

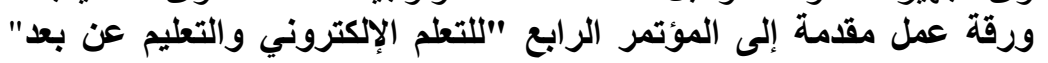

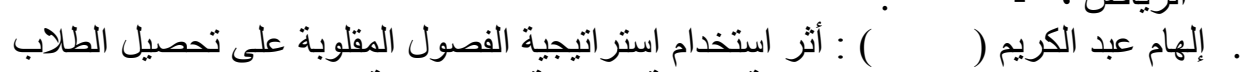

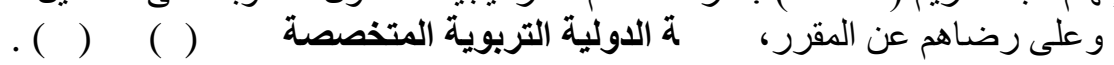

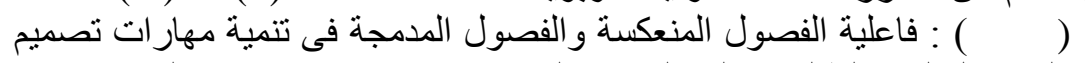

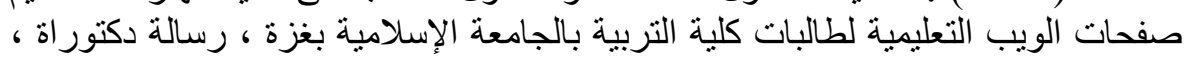

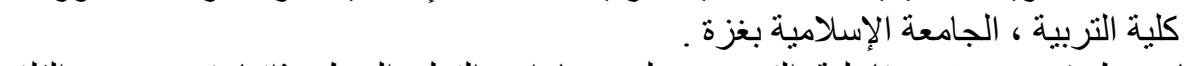

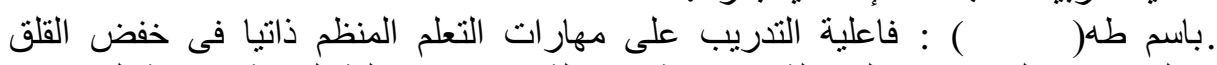

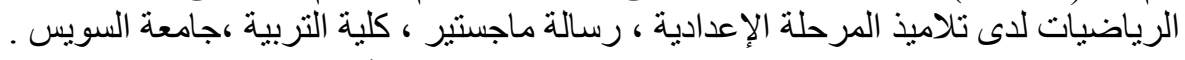

تنمية كالة

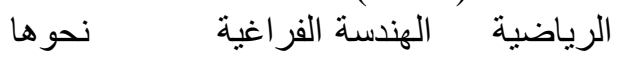

$$
\begin{aligned}
& \text { ماجستير، الجامعة الإسلامية الفية }
\end{aligned}
$$

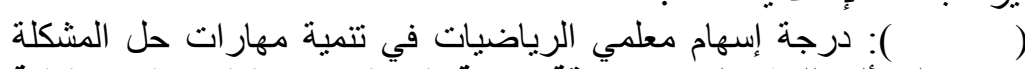

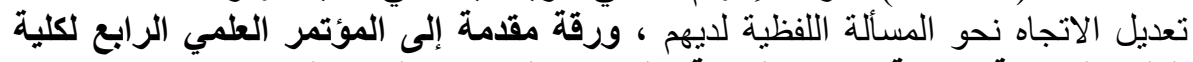
العلوم التربوية بجامعة جرش (التربية والمجتمع الحاضر والمستقبة المقيل), 
GeoGebral برمجية جيوجبر

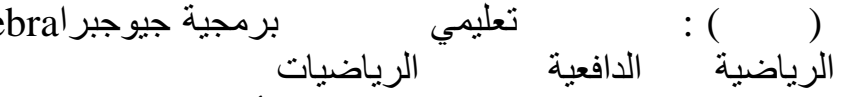

$$
\begin{aligned}
& \text { العربية السعودية، }
\end{aligned}
$$

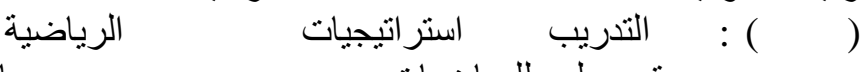

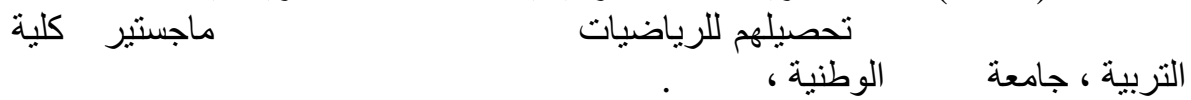

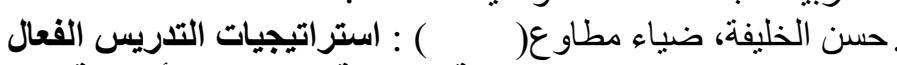

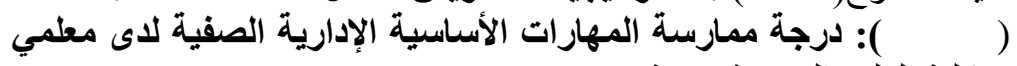

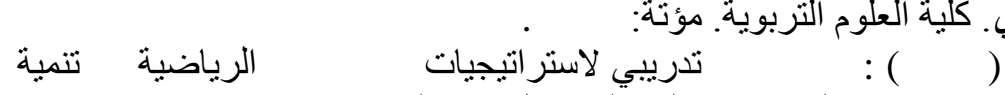

$$
\text { التعليم الثانوي. كلية العلوم التربوية. مؤتة: }
$$

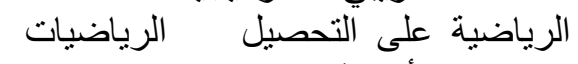

$$
\text { الأردنية التحلية }
$$

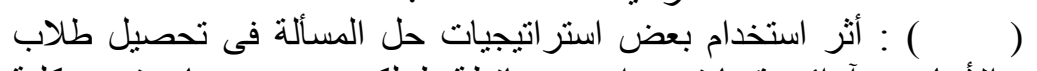

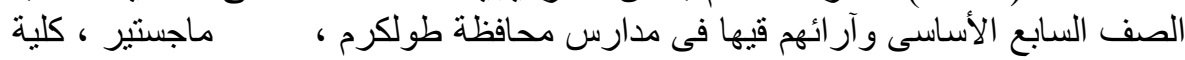

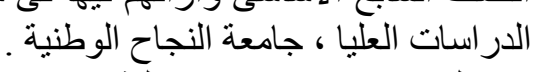

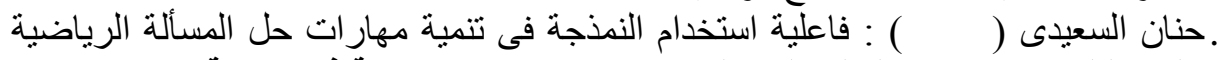

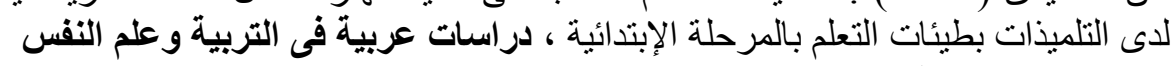

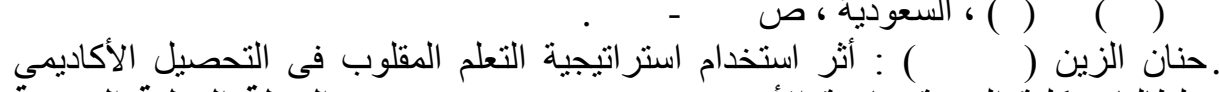
المجلة الدولية التربوية

لطالبات كلية التربية جامعة الأمير

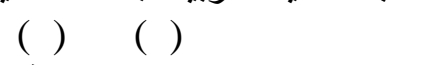

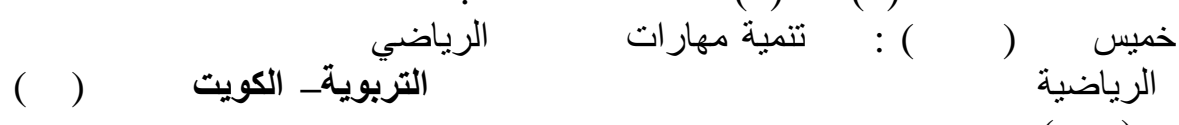

الريات

ماجستير، كلية

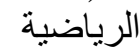

التربية جامعة الأز هر.

سليم حمام ، سبح عساف ( ) : الطريقة العلمية فى حل المسائل الرياضية ، المدرسة.

العربية ، Www.schoolarabia.net

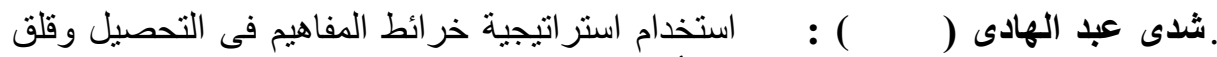

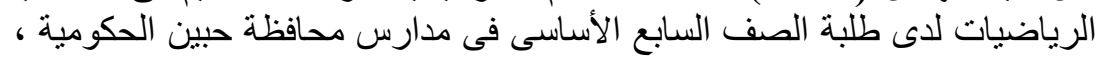

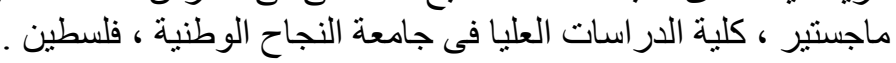

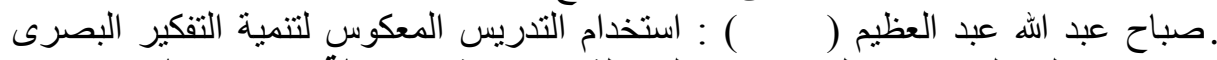

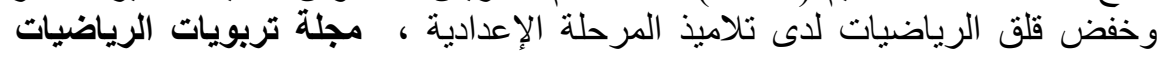

الرياضيات لديهر تدريس

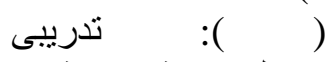

الرياضية وتنمية مهار ات التفكير

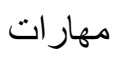




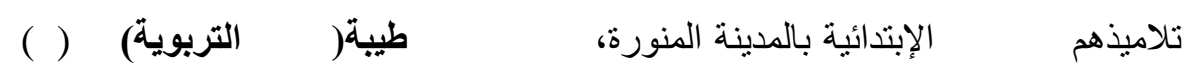

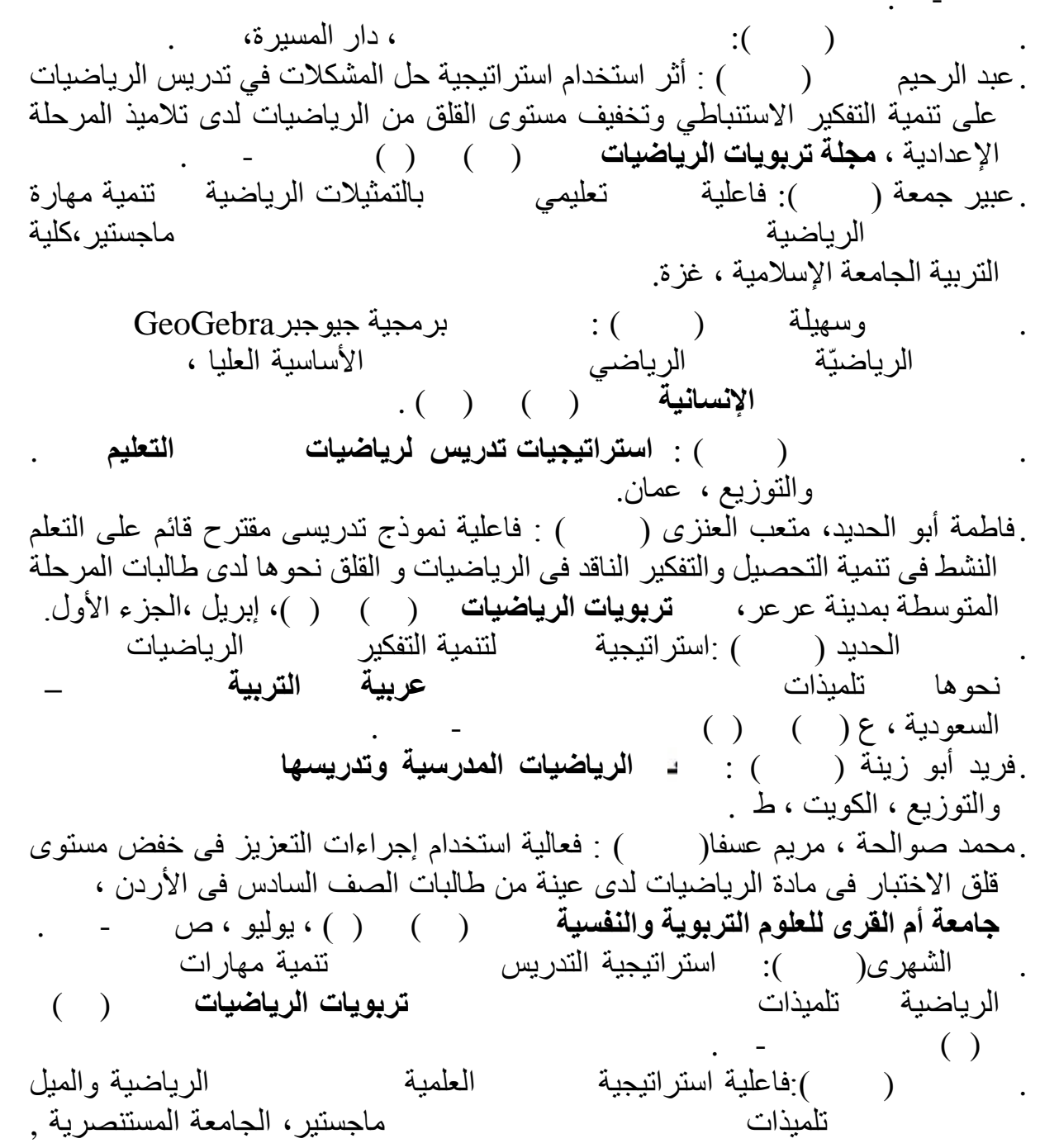

38. Arturo G \& etal (2016): Anxiety toward Mathematics, EURASIA J ournal of M athematics, Science and Technology E ducation , V(12), $\mathrm{N}(2)$.

39. Bergmann, J. \& Sams, A. (2012). Flip your classroom: Reach every student in every class every day. Washington, DC: International Society for Technology in Education. 
40. Berinder, Jeet \& Yeao, Ban ( 2010) : Mathematics anxiety across third, fourth and fifth grade, Master of Science in Middle School M athematics, Central Connecticut state university.

41. Bhagat Kaushal \& etal (2016) : The Impact of the Flipped Classroom on Mathematics Concept Learning in High School, J ournal of E ducational Technology \& Society ,V(19), No(3), (July),p 134-142

42. Bishop.J\&Verleger,M(2013) :The flipped classroom :A survey of the research, paper presented at the 120 th ASEE conference \& Exposition .

43. Brian , F \& David , P (2003) : Mathematics Anxiety and Mathematics Achievement, Mathematics Education Research J ournal , V(15), $\mathrm{N}(2), \mathrm{P} 138-150$.

44. Clark, K. (2013). Examining The Effects Of The Flipped Model Of Instruction On Student Engagement And Performance In The Secondary Mathematics Classroom: An Action Research Study.(Ph.D). Dissertation , Capella University.

45. Davies, R \& etal(2013): Flipping the classroom and instructional technology integration in a college-level information systems spreadsheet course. E ducation Tech R esearch , V(61), P563-580 .

46. Debra Ingram \& etal (2014) : A Study of the Flipped Math Classroom in the Elementary Grades,Center for Applied R esearch and E ducational Improvement University of M innesota - March.

47. Effandi , Zakaria \& Norazah ,Nordin(2008):The effects of Mathematics Anxiety on matriculation student as related to motivation and achievement , E urasia J ournal of M athematics, science \& technology education, $\mathrm{V}(4), \mathrm{N}(1), \mathrm{p} 27-30$.

48. Finlayson, Moureen (2014) : Addressing Math Anxiety in the classroom, Improving Schools, V(117), N(1), p99-115, Mar.

49. Homdan \&etal (2013) : Areview of flipped learning :George mason university.

50. Honeycutt, B\& Garrett .J (2014): Expanding the Definition of a Flipped Learning Environment Faculty Focus blog. available at : $\mathbf{h t t p : / / w w w . ~}$ facultyfocus.com/articles/instructional-design/expandingdefinition flipped-learning-environment/

51. Katsa, M \& etal (2016): Envestigating the Potential of the Flipped Classroom Model in(K-12)Mathematics Teaching and Learning, International Association for Development of the Information Society, 
Paper presented at the International Association for Development of the Information Society(IADIS)International Conference on Cognition and Exploratory Learning in the Digital Age(CELDA) (13 ${ }^{\text {th }}$, M annheim, Germany, Oct 28-30.

52. Kimber . C (2009) : The effect of training in self- regulated Learning on Math anxiety and achievement among preservice elementary teachers in a freshman course in mathematics Concepts . PhD. Dissertation Temple University, United States-Pennsylvania .

53. Klara , P (2012) : On teaching mathematical problem posing, $\mathrm{PhD}$ Dissertation, Bolyai In statue, University of Szeyed.

54. Maloney, E \& Beilock, S(2012) : Math Anxiety : Who has it, Why it Develops , and how to guard against it , Trends in Cognitive Sciences , $\mathrm{V}(16), \mathrm{N}(8), \mathrm{p} 404-406$.

55. Marco, Ronchetti. (2010). Using video lectures to make teaching more interactive. International J ournal of Emerging Technologies in Learning (IJ ET),V (5), N(2), p. 45-48.

56. Maria,D\&etal(2014):Achievement goals, Motivation to learn , and mathematics anxiety among pre-service teachers, J ournal of research in education, $\mathrm{V}(24), \mathrm{N}(1)$.

57. Morin, Lisa \&etal(2017): e Use of a Bar Model Drawing to Teach Word Problem Solving to Students with Mathematics Difficulties, Learning Disability Quarterly, v(40), N(2), p91-104, May .

58. Nahil,Aljaberi1\&Eman Gheith (2016): Pre-Service Class Teacher' Ability in Solving Mathematical Problems and Skills in Solving Daily Problems ,C anadian Center of Science and E ducation, $\operatorname{Vol}(6), \mathrm{No}(3)$, p32-48.

59. Rubinsten, O \& Tannock, R (2010) : Mathematics Anxiety in Children With Developmental Dyscalculia, Behavioral and Brain Functions, $\mathrm{V}(6), \mathrm{N}(1), \mathrm{P} 46-58$.

60. Schwankl, E.(2013).B Bended Learning: Achievement And Perception Flipped Classroom: E ffects on Achievement and Student Perception. (Ph.D). Dissertation, Southwest Minnesota State University.

61. Smith ,C \& ,.McDonald ,K(2013) : The Flipped Classroom for Professional Development :Part II .Making Podcasts and Videos. J ournal of Continuing E ducation in Nursing, $\mathrm{V}(44), \mathrm{N}(11)$. 
62. Snowden, K. (2012). Teacher perceptions of the flipped classroom: Using video lectures online to replace traditional in-class lectures. Master of Arts, University Of North Texas.

63. Strayer, J. (2012). How learning in an inverted classroom influences cooperation, innovation and task orientation. Learning Environments R esearch, V(15), p171-193.

64. Torkelson, V(2012) :The flipped classroom putting learning back into the hands of students .(Ph.D).Dissertation ,Saint Mary's College of California.

65. Wiginton, B. (2013). Flipped instruction: An investigation into the effect of learning environment on student self-efficacy, learning style, and academic achievement in Algebra I classroom. (Ph.D). Dissertation, The University of Alabama 